\title{
Modeling the climate impact of road transport, maritime shipping and aviation over the period 1860-2100 with an AOGCM
}

\author{
D. J. L. Olivié ${ }^{1, *}$, D. Cariolle ${ }^{1,2}$, H. Teyssèdre ${ }^{1}$, D. Salas ${ }^{1}$, A. Voldoire ${ }^{1}$, H. Clark ${ }^{1,{ }^{* *}}$, D. Saint-Martin ${ }^{1}$, M. Michou ${ }^{1}$,

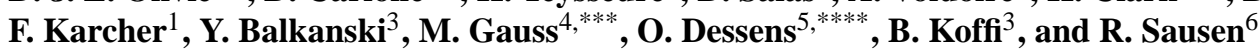 \\ ${ }^{1}$ GAME/CNRM, Météo-France, UMR1357, CNRS - Centre National de Recherches Météorologiques, Toulouse, France \\ ${ }^{2}$ Sciences de l'Univers au CERFACS, CERFACS/CNRS, URA1875, Toulouse, France \\ ${ }^{3}$ Laboratoire des Sciences du Climat et de l'Environnement, UMR8212, CEA-CNRS-UVSQ, Cedex, France \\ ${ }^{4}$ Department of Geosciences, University of Oslo, Oslo, Norway \\ ${ }^{5}$ Centre for Atmospheric Science, Department of Chemistry, University of Cambridge, Cambridge, UK \\ ${ }^{6}$ Deutches Zentrum für Luft- und Raumfahrt (DLR), Oberpfaffenhofen, Germany \\ *now at: Department of Geosciences, University of Oslo, Oslo, Norway \\ ** now at: CNRS, Laboratoire d'Aérologie, UMR5560, Toulouse, France \\ *** now at: Norwegian Meteorological Institute, Oslo, Norway \\ **** now at: Energy Institute, University College London, London, UK
}

Correspondence to: D. J. L. Olivié (dirk.olivie@geo.uio.no)

Received: 10 May 2011 - Published in Atmos. Chem. Phys. Discuss.: 12 July 2011

Revised: 15 December 2011 - Accepted: 18 January 2012 - Published: 7 February 2012

\begin{abstract}
For the period 1860-2100 (SRES scenario A1B for 2000-2100), the impact of road transport, maritime shipping and aviation on climate is studied using an Atmosphere Ocean General Circulation Model (AOGCM). In addition to carbon dioxide $\left(\mathrm{CO}_{2}\right)$ emissions from these transport sectors, most of their non- $\mathrm{CO}_{2}$ emissions are also taken into account, i.e. the forcing from ozone, methane, black carbon, organic carbon, sulfate, CFC-12 and HFC-134a from air conditioning systems in cars, and contrails. For the year 2000 , the $\mathrm{CO}_{2}$ emissions from all sectors together induce a global annual-mean surface air temperature increase of around $0.1 \mathrm{~K}$. In 2100 , the $\mathrm{CO}_{2}$ emissions from road transport induce a global mean warming of $0.3 \mathrm{~K}$, while shipping and aviation each contribute $0.1 \mathrm{~K}$. For road transport, the non- $\mathrm{CO}_{2}$ impact is largest between 2000 and 2050 (of the order of $0.1 \mathrm{~K}$ ) becoming smaller at the end of the 21 st century. The non- $\mathrm{CO}_{2}$ impact from shipping is negative, reaching $-0.1 \mathrm{~K}$ between 2050 and 2100 , while for aviation it is positive and its estimate varies between 0 and $0.15 \mathrm{~K}$ in 2100 . The largest changes in sea-level from thermal expansion in 2000 are $1.6 \mathrm{~mm}$ for the $\mathrm{CO}_{2}$ emissions from road transport, and around $-3 \mathrm{~mm}$ from the non- $\mathrm{CO}_{2}$ effects of shipping. In 2100 , sea-level rises by $18 \mathrm{~mm}$ due to the $\mathrm{CO}_{2}$ emissions from road transport and by $4.6 \mathrm{~mm}$ due to shipping or avia-
\end{abstract}

tion $\mathrm{CO}_{2}$ emissions. Non- $\mathrm{CO}_{2}$ changes are of the order of $1 \mathrm{~mm}$ for road transport, $-6.6 \mathrm{~mm}$ for shipping, and the estimate for aviation varies between -1.2 and $4.3 \mathrm{~mm}$. When focusing on the geographical distribution, the non- $\mathrm{CO}_{2} \mathrm{im}-$ pact from road transport and shipping on the surface air temperature is only slightly stronger in northern than in southern mid-latitudes, while the impact from aviation can be a factor of 5 stronger in the northern than in the southern hemisphere. Further it is observed that most of the impacts are more pronounced at high latitudes, and that the non- $\mathrm{CO}_{2}$ emissions from aviation strongly impact the NAO index. The impacts on the oceanic meridional overturning circulation and the Niño3.4 index are also quantified.

\section{Introduction}

In recent years, the evidence for anthropogenic impacts on climate (IPCC, 1996, 2001, 2007) has increased. Where observational studies have shown that the global mean surface air temperature has risen by around $0.8 \mathrm{~K}$ over the 20 th century, modeling studies have demonstrated that this increase, in particular since the mid-20th century, can be attributed mainly to anthropogenic influences. Each activity which 
alters the radiative properties of the atmosphere (by emission or formation of greenhouse gases (GHGs) and aerosols) or modifies the properties of the Earth's surface (a change in land-use can affect the local hydrological cycle or the albedo) may have an impact on climate. A wide range of anthropogenic activities such as industrial production processes, agriculture, transport, power generation, or domestic heating therefore possibly contributes to climate change.

It is important to quantify the contribution from individual sectors such as road transport, shipping, or aviation to climate change, because this allows more informed assessments of the potential effects of mitigation of emissions from these sectors, given the high growth rate of transport emissions in comparison to other anthropogenic sources. Over the last two decades, many studies have been performed which addressed this question - three recent reviews presented current assessments of the radiative forcing due to road (and rail) transport (Uherek et al., 2010), shipping (Eyring et al., 2010), and aviation (Lee et al., 2010) - see also Fuglestvedt et al. (2008). From the transport sector, an important contribution to climate change is from carbon dioxide $\left(\mathrm{CO}_{2}\right)$ emissions, but the emissions of other species, including short lived ones, are also important. Several studies have assessed the impact of the emission of reactive gases (nitrogen oxides $-\mathrm{NO}_{\mathrm{x}}$, carbon monoxide - $\mathrm{CO}$ or volatile organic compounds - VOCs) on tropospheric ozone $\left(\mathrm{O}_{3}\right)$ and the hydroxyl radical $(\mathrm{OH})$ from road transport (Granier and Brasseur, 2003; Niemeier et al., 2006; Matthes et al., 2007), shipping (Granier et al., 2006; Eyring et al., 2007) and aviation (Brasseur et al., 1996; Kentarchos and Roelofs, 2002; Gauss et al., 2006), or from all three sectors (Hoor et al., 2009; Koffi et al., 2010; Dahlmann et al., 2011; Myhre et al., 2011). The present-day tropospheric $\mathrm{O}_{3}$ changes lead to a radiative forcing between 10 and $30 \mathrm{~mW} \mathrm{~m}^{-2}$ for the different transport sectors individually. These $\mathrm{O}_{3}$ perturbations have a typical lifetime of a few weeks (Stevenson et al., 2004). Through the impact of $\mathrm{NO}_{\mathrm{x}}$ emissions on the $\mathrm{OH}$ concentration, transport also affects the concentration of methane $\left(\mathrm{CH}_{4}\right)$. Generally, this is a reduction in the concentration of $\mathrm{CH}_{4}$, and therefore a negative radiative forcing; the $\mathrm{CH}_{4}$ reduction also leads to an associated reduction in $\mathrm{O}_{3}$. Due to the long lifetime of $\mathrm{CH}_{4}$, these perturbations have a lifetime in the order of 1 to 2 decades (Stevenson et al., 2004). For the current emissions from the transport sectors the net combined effect (from $\mathrm{O}_{3}$ and $\mathrm{CH}_{4}$ ) for road transport and aviation is a positive radiative forcing while it is negative for maritime shipping (Myhre et al., 2011).

The emissions from the transport sectors also lead to increased concentrations of aerosols such as black carbon (BC), organic carbon (OC) and sulfate. Aerosols have a direct impact through their scattering and absorption of radiation. This impact has been assessed for the three transport sectors in Balkanski et al. (2010) and in Eyring et al. (2007) for shipping only. Aerosols also have an indirect effect by changing the albedo (first indirect effect) and lifetime (sec- ond indirect effect) of clouds as well as a semi-direct forcing due to $\mathrm{BC}$ - these forcings are much more uncertain (see Lee et al., 2010; Eyring et al., 2010; Uherek et al., 2010).

Several modeling and observational studies have tried to assess the global impact of contrails and aviation-induced cirrus (e.g. Bakan et al., 1994; Minnis et al., 2004; Marquart et al., 2003; Stordal et al., 2005; Burkhardt and Kärcher, 2009, 2011; Kärcher et al., 2010). Best estimates for the current radiative forcing due to contrail and aviation-induced cirrus impacts vary between 10 and $80 \mathrm{~mW} \mathrm{~m}^{-2}$ (Lee et al., 2009). The most recent best estimates with the most detailed models of contrails and aviation-induced cirrus are at the lower end of this range, around $31 \mathrm{~mW} \mathrm{~m}^{-2}$ (Burkhardt and Kärcher, 2011). Detailed process studies show an increased understanding of the formation and properties of contrails (Paugam et al., 2010).

In addition to detailed studies focussing on one or a few aspects of the impact of transport, some studies have tried to calculate its total radiative forcing (Fuglestvedt et al., 2008; Penner et al., 1999). For aviation, multiple assessments have been made to assess its total impact (Brasseur et al., 1998; Penner et al., 1999; Sausen et al., 2005; Lee et al., 2009). As mentioned earlier, impacts on climate of all three modes of transport have recently been assessed (EU projects QUANTIFY and ATTICA) (Lee et al., 2010; Eyring et al., 2010; Uherek et al., 2010).

The impacts on climate in terms of changes in temperature and precipitation, are also of interest. Therefore, some studies use Atmosphere General Circulation Models (AGCMs) coupled to slab ocean models. Slab ocean models represent the ocean mixed layer but not the deep ocean, and they use prescribed local tendencies to represent large-scale ocean transport. These tendencies are assumed not to be affected by climate change, which might influence the quality of the climate predictions of this type of models. AGCMs coupled to a slab ocean model are used to study the climate change which would occur when the perturbation or anthropogenic influence is constant for a long period (e.g. Stuber et al., 2001, 2005; Joshi et al., 2003; Ponater et al., 2006), but are not able to describe so well the transient phase of climate change.

When the climate system is subject to a variable forcing, its thermal inertia will cause a delay in its response. Initially, there is a fast response of the atmosphere, the land surface and the ocean mixed layer with a characteristic time scale of 1 to $5 \mathrm{yr}$ (e.g. Hasselmann et al., 1993; Boucher and Reddy, 2008; Olivié and Stuber, 2010). This fast response contributes around $60-80 \%$ to the total long term response. In addition, the deep ocean is responsible for a slow response (which contributes 20-40\%) with an estimated time scale in the order of 100 to $500 \mathrm{yr}$. For the study of the impact of the transport sectors, this inertia has been taken into account mainly in studies on aviation (Sausen and Schumann, 2000; Ponater et al., 2005, 2006; Lim et al., 2007; Lee et al., 2009). Also slightly more complicated Simple Climate Models (SCMs) which contain a simple representation 
of ocean and sea-ice thermodynamics (Harvey et al., 1997; Skeie et al., 2009), have been used. They all simulate reasonably well the transient phase of climate change (Meinshausen et al., 2011a,b), but do not give information on the geographical distribution or seasonal variation of impacts.

A more complete but computationally more expensive approach is to use an Atmosphere Ocean General Circulation Model (AOGCM) which contains a detailed description of the atmosphere, ocean and sea-ice. Within the perspective of climate change, oceans play an important role in redistributing heat, in mitigating atmospheric heating in the transient phase due to their large thermal inertia, and in the radiative balance due to the possible presence of sea-ice at high latitudes (impact on albedo). Over the last decade, AOGCMs have been used frequently to model the total climate impact from anthropogenic forcing (IPCC, 2001). These models are currently able to reproduce the temperature change observed in the 20th century, and confidence exists in the quality of their projections of future climate change (IPCC, 2007, Chap. 8). This confidence is stronger at continental than regional scales, and higher for variables as temperature than for precipitation. However, although the AOGCMs are the most advanced tools, there remain important uncertainties in the representation of some processes, for example those defining the strength of cloud-climate feedbacks (IPCC, 2007). In addition, AOGCMs, when used to make global climate studies over multiple decennia or centuries, cannot be expected to describe all physico-chemical processes in the atmosphere in great detail, e.g. emissions, formation and transformation of aerosols and chemical species, and possible removal mechanisms. Therefore, distributions of long-lived GHGs are often assumed to be homogeneously distributed in the atmosphere $\left(\mathrm{CO}_{2}, \mathrm{CH}_{4}\right.$, nitrous oxide $-\mathrm{N}_{2} \mathrm{O}$, and chlorofluorocarbons - CFCs), but their global concentration might evolve with time (according to a prescribed scenario). For aerosols and $\mathrm{O}_{3}$ (or its precursors) which, due to their shorter lifetimes, are inhomogeneously distributed in the atmosphere, threedimensional (3-D) prescribed climatologies are often used based on calculations from more detailed models. Here we present one of the first studies where an AOGCM is used to assess the impact of the transport sectors on climate. Using an AOGCM allows the study of geographical distributions of changes in surface air temperature, precipitation and cloud cover, and to quantify impacts on typical ocean parameters such as ocean 3-D temperature, sea-level rise, and the meridional overturning circulation (MOC). We study the period 1860-2100 and perform full 240-yr long integrations. We focus on the impact of road transport, maritime shipping and aviation, and distinguish between the impact from $\mathrm{CO}_{2}$ emissions and the impact from all other emissions (which we call, collectively, non- $\mathrm{CO}_{2}$ ).

In Sect. 2 we describe the AOGCM which is used, the emissions from the transport sectors that are taken into account, and the simulations which are performed. In Sect. 3 we analyze the impacts of the transport sectors on the atmo- sphere, and in Sect. 4 their impacts on the ocean. In Sect. 5 we present our conclusions.

\section{Description of the model, forcings and experiments}

\subsection{The CNRM-CM3.3 AOGCM}

The Centre National de Recherches Météorologiques (CNRM) Coupled Model version 3.3 (CNRM-CM3.3) (Johns et al., 2011) consists of the atmosphere component ARPEGE-Climat4.6, the ocean component OPA8.0 and the sea-ice component GELATO2. CNRM-CM3.3 is an updated but very similar version of the CNRM-CM3.1 coupled model used for simulations described in Salas-Mélia et al. (2005), IPCC (2007) and Olivié and Stuber (2010).

The atmosphere component ARPEGE-Climat 4.6 is a spectral model with a T42 horizontal resolution (equivalent to about $2.8^{\circ} \times 2.8^{\circ}$ ) and 31 hybrid sigma levels (model top at $10 \mathrm{hPa}$ ). Turbulent vertical fluxes and dry convection are described by Ricard and Royer (1993), and deep convection (Bougeault, 1985) is modeled using a mass-flux scheme with Kuo-type closure. The cloud microphysics is also described in Ricard and Royer (1993), and the model does not take into account ice supersaturation. The model uses the FMR15 radiation scheme (Morcrette, 1990, 1991), which considers two shortwave and six longwave spectral bands. The model takes into account the radiative impact of water vapour $\left(\mathrm{H}_{2} \mathrm{O}\right)$, of the well-mixed GHGs $\mathrm{CO}_{2}, \mathrm{CH}_{4}, \mathrm{~N}_{2} \mathrm{O}$, CFC-11, CFC-12, and of the $\mathrm{O}_{3}$ and aerosol distributions, as well as clouds. Six types of aerosols (prescribed as monthly mean 3-D climatologies) are considered: continental (including BC and OC), marine, desert, volcanic, stratospheric, and sulfate aerosols. The model takes into account their direct effect, and the indirect effect of sulfate aerosols based on a parametrisation of Boucher and Rodhe (1994) and Boucher and Lohmann (1995) with a calibration from POLDER satellite data (Quaas and Boucher, 2005). The $\mathrm{O}_{3}$ distribution is determined by a parametrisation of its homogeneous and heterogeneous chemistry (Cariolle and Déqué, 1986; Cariolle et al., 1990; Cariolle and Teyssèdre, 2007) (see further in Sect. 2.2.4). The model contains a description for river routing from Tokyo University (Oki and Sud, 1998; Oki et al., 1999). Changes in land use are introduced through a modification of the fractions of crop and pasture types in the land-surface classification, and the resulting surface properties have been computed with an updated version (ECOCLIMAP-2) of the ECOCLIMAP vegetation map (Champeaux et al., 2005). Both the ocean model OPA8.0 and the sea-ice model GELATO2 (Salas-Mélia, 2002) are grid point models and share the same mesh of $182 \times 152$ points. OPA8.0 has 31 levels, including 10 levels in the upper $100 \mathrm{~m}$ of the ocean.

The principal changes w.r.t. CNRM-CM3.1 are a revision of the atmosphere-ocean coupling through OASIS2.2 
to achieve a better conservation of the energy fluxes during interpolations between the atmosphere and the ocean grids. Moreover, in the ocean and sea-ice models minor corrections have been implemented to improve energy conservation. These improvements have led to reduced drift in the ocean temperature fields and in surface air temperature. Finally, the atmospheric component of the model was updated from version 3 to 4.6 .

The model (version CNRM-CM3.1 and CNRM-CM3.3) has been used to simulate both past and future climate change (Salas-Mélia et al., 2005; IPCC, 2007; Johns et al., 2011). In the historical simulation of the period 1860-2000 with CNRM-CM3.3, the heating (global mean surface air temperature) over the $1901-2000$ period was $0.7 \mathrm{~K}$, being slightly smaller than the observed trend over the 20th century $(0.8 \mathrm{~K}$, Brohan et al., 2006). Sea-ice distributions were reasonably well modeled (Salas-Mélia et al., 2005), and the deep convection sites simulated by OPA8.0 within CNRM-CM3.1 were found to be realistic (Guémas and Salas-Mélia, 2008).

\subsection{Forcing agents}

To model the climate change over the period 1860-2100, CNRM-CM3.3 takes into account changes in well-mixed GHGs, aerosols, total inorganic chlorine, and surface properties. Changes in the total solar irradiance and aerosols resulting from volcanic eruptions are not taken into account. For the period 2000-2100 we consider the SRES scenario A1B (Nakicenovic et al., 2000). The A1B scenario is based on the assumptions, for the 21st century, of rapid economic growth, further population increase until 2050 and a decline thereafter, global adoption of efficient technologies, and a balanced reliance on fossil- and non-fossil-fuel energy sources. In comparison to other SRES scenarios, this scenario results in a middle-of-the road increase in anthropogenic forcing. As the original SRES scenarios are not disaggregated enough, this general storyline was translated into specific emission scenarios for each transport sector individually (cf. Eyring et al., 2010; Lee et al., 2010; Uherek et al., 2010). The transport emission estimates for the 21 st century are based on traffic demand estimates (which are assumed to be mainly driven by the gross domestic product (GDP) and population development), fuel efficiency estimates, and emission factor estimates (emission factors indicate how much $\mathrm{NO}_{\mathrm{x}} / \mathrm{SO}_{2} / \mathrm{BC} / \ldots$ is emitted per unit fuel burnt). A distinction is made between different world regions, different vehicle, ship and aircraft types, different engine types and different fuel types. In scenario A1B, fuel consumption is assumed to grow for all three sectors, with some stabilization for road transport in the second half of the 21 st century. For road transport (Uherek et al., 2010) it is assumed that emission standards will be taken over in the next decades on a global scale such that it will ultimately lead to a net decrease in $\mathrm{NO}_{\mathrm{x}}$ emissions from 2030 on, despite the sustained increase in fuel consumption. For aviation (Lee et al., 2009, 2010; Owen et al., 2010), a sustained fuel efficiency improvement is projected over the whole period 2020-2100 $\left(1 \% \mathrm{yr}^{-1}\right)$, and the emission factor for $\mathrm{NO}_{\mathrm{x}}$ is assumed to decrease up to 2050 and remain constant thereafter. For shipping (Eyring et al., 2005, 2010; Eide et al., 2007), it is assumed that gas usage will increase rapidly and strongly, and legislation for reduced emission factors will be implemented at a moderate pace. One assumes that around 2050 maritime shipping will have fulfilled the full potential for emission reduction for the given engine types and fuel types (Eide et al., 2007). The estimated use of biofuels is moderate for shipping and low for aviation.

From the transport sectors, we take into account 6 different forcings. This includes for all sectors, the forcing from $\mathrm{CO}_{2}, \mathrm{CH}_{4}, \mathrm{O}_{3}$, and aerosols. In addition we take into account the emissions of CFC-12 and HFC-134a from road transport (from air conditioning systems in cars), and contrails and aviation-induced cirrus. The perturbations from $\mathrm{CO}_{2}, \mathrm{CH}_{4}$, CFC-12 and HFC-134a are assumed to be homogeneous perturbations (both horizontally and vertically), while the other perturbations have a geographical and vertical distribution. In Sect. 2.2.1 to 2.2.6, we describe the forcings in more detail.

Most of the emission data we use were developed during the QUANTIFY project, and can be found on http://www. ip-quantify.eu/ (Borken et al., 2007). These data are spatially disaggregated with a $1^{\circ} \times 1^{\circ}$ horizontal resolution for each transport sector for the years 2000, 2025, 2050, 2100, and also include time series of decadal global emission estimates for the complete period 1860-2100. In this study we have taken the point of view that we limit the transport activity to the tailpipe emission plus the direct energy consumption to generate the fuel. An overview of the emissions by road transport, maritime shipping and aviation can be found in Tables 1,2 , and 3 .

\subsubsection{Carbon dioxide}

Of all the $\mathrm{CO}_{2}$ emitted in the atmosphere, about $10 \%$ disappears from the atmosphere on relatively short time scales of around 1 to $2 \mathrm{yr}$. A large proportion of the emitted $\mathrm{CO}_{2}$ stays much longer in the atmosphere as it is taken-up only slowly by oceans during the centuries following its emission. A significant fraction (between 20 and $30 \%$ ) of the $\mathrm{CO}_{2}$ remains in the atmosphere on time scales longer than $1000 \mathrm{yr} . \mathrm{CO}_{2}$ has thus a long residence time and is rather well mixed in the troposphere and the stratosphere (IPCC, 2007).

Figure 1a shows the evolution of the $\mathrm{CO}_{2}$ concentration from 1860 until 2100 assuming the A1B emission scenario as developed in QUANTIFY for the transport sectors (http://www.ip-quantify.eu/) and the remaining $\mathrm{CO}_{2}$ emissions from the respective marker scenario (Jiang et al., 2000). The $\mathrm{CO}_{2}$ concentration has risen from $286 \mathrm{ppmv}$ in 1860 up to $360 \mathrm{ppmv}$ in 2000 . One sees a further increase up to 700 ppmv in 2100 . Figure 2 shows the distribution of the $\mathrm{CO}_{2}$ emissions in 2000 from road transport, maritime 
Table 1. Time series of road transport emissions (Borken et al., 2007; Uherek et al., 2010, http://www.ip-quantify.eu/). NO $\mathrm{x}_{\mathrm{x}}$ emissions are given as equivalent $\mathrm{NO}_{2}$.

\begin{tabular}{rrrrrrrrr}
\hline & $\begin{array}{r}\mathrm{NO}_{\mathrm{x}} \\
\mathrm{Tg} \mathrm{yr}^{-1}\end{array}$ & $\begin{array}{r}\mathrm{CO} \\
\mathrm{Tg} \mathrm{yr}^{-1}\end{array}$ & $\begin{array}{r}\mathrm{CO}_{2} \\
\mathrm{Tg} \mathrm{yr}^{-1}\end{array}$ & $\begin{array}{r}\mathrm{BC} \\
\mathrm{Tg} \mathrm{yr}^{-1}\end{array}$ & $\begin{array}{r}\mathrm{OC} \\
\mathrm{Tg} \mathrm{yr}^{-1}\end{array}$ & $\begin{array}{r}\mathrm{SO}_{2} \\
\mathrm{Tg} \mathrm{yr}^{-1}\end{array}$ & $\begin{array}{r}\mathrm{CFC}-12 \\
\mathrm{Tg} \mathrm{yr}^{-1}\end{array}$ & $\begin{array}{r}\mathrm{HFC}-134 \mathrm{a} \\
\mathrm{Tg} \mathrm{yr}^{-1}\end{array}$ \\
\hline 1900 & 0.89 & 6.7 & 81 & 0.107 & 0.047 & 0.049 & - & - \\
1910 & 1.20 & 8.9 & 109 & 0.143 & 0.063 & 0.066 & - & - \\
1920 & 1.62 & 12.1 & 146 & 0.193 & 0.084 & 0.089 & - & - \\
1930 & 2.18 & 16.3 & 197 & 0.260 & 0.114 & 0.119 & - & - \\
1950 & 2.93 & 22.0 & 266 & 0.350 & 0.153 & 0.161 & - & - \\
1960 & 5.16 & 38.6 & 467 & 0.616 & 0.269 & 0.283 & - & - \\
1970 & 10.41 & 78.0 & 943 & 1.243 & 0.543 & 0.571 & - & - \\
1980 & 26.00 & 138.9 & 1806 & 1.400 & 0.440 & 1.094 & - & - \\
1990 & 32.78 & 158.5 & 2556 & 1.400 & 0.440 & 1.548 & 0.043 & - \\
2000 & 29.17 & 109.2 & 4302 & 0.587 & 0.187 & 2.000 & 0.087 & - \\
2010 & 30.37 & 100.8 & 5555 & 0.664 & 0.289 & 0.422 & - & 0.136 \\
2020 & 30.34 & 81.2 & 8230 & 0.350 & 0.149 & 0.153 & - & 0.152 \\
2030 & 12.04 & 48.2 & 9860 & 0.070 & 0.034 & 0.065 & - & 0.106 \\
2040 & 10.07 & 40.2 & 10768 & 0.057 & 0.027 & 0.036 & - & 0.060 \\
2050 & 5.61 & 26.3 & 11376 & 0.028 & 0.014 & 0.039 & - & 0.014 \\
2060 & 4.38 & 24.0 & 10850 & 0.022 & 0.011 & 0.038 & - & - \\
2070 & 2.70 & 18.7 & 9758 & 0.014 & 0.007 & 0.034 & - & - \\
2080 & 2.10 & 15.3 & 10331 & 0.010 & 0.005 & 0.036 & - & - \\
2090 & 1.33 & 10.4 & 10425 & 0.006 & 0.003 & 0.036 & - & - \\
2100 & 0.52 & 4.6 & 10450 & 0.001 & 0.001 & 0.036 & - & - \\
\hline
\end{tabular}

Table 2. Time series of maritime shipping emissions (Endresen et al., 2003; Eyring et al., 2010, http://www.ip-quantify.eu/).

\begin{tabular}{rrrrrr}
\hline & $\begin{array}{r}\mathrm{NO}_{\mathrm{x}} \\
\mathrm{Tg} \mathrm{yr}^{-1}\end{array}$ & $\begin{array}{r}\mathrm{CO}_{2} \\
\mathrm{Tg} \mathrm{yr}^{-1}\end{array}$ & $\begin{array}{r}\mathrm{BC} \\
\mathrm{Tg} \mathrm{yr}^{-1}\end{array}$ & $\begin{array}{r}\mathrm{OC} \\
\mathrm{Tg} \mathrm{yr}^{-1}\end{array}$ & $\begin{array}{r}\mathrm{SO}_{2} \\
\mathrm{Tg} \mathrm{yr}^{-1}\end{array}$ \\
\hline 1900 & 0.34 & 109 & 0.0062 & 0.0160 & 1.280 \\
1910 & 0.52 & 167 & 0.0095 & 0.0244 & 1.957 \\
1920 & 0.66 & 213 & 0.0121 & 0.0312 & 2.500 \\
1930 & 0.77 & 247 & 0.0140 & 0.0362 & 2.800 \\
1940 & 1.11 & 198 & 0.0112 & 0.0290 & 2.400 \\
1950 & 2.12 & 261 & 0.0148 & 0.0383 & 3.800 \\
1960 & 4.10 & 350 & 0.0199 & 0.0513 & 5.500 \\
1970 & 11.10 & 480 & 0.0273 & 0.0703 & 7.600 \\
1980 & 11.44 & 504 & 0.0286 & 0.0738 & 7.000 \\
1990 & 12.13 & 534 & 0.0303 & 0.0783 & 6.900 \\
2000 & 14.98 & 626 & 0.0355 & 0.1198 & 8.721 \\
2010 & 17.43 & 845 & 0.0457 & 0.1543 & 8.553 \\
2020 & 19.88 & 1065 & 0.0559 & 0.1888 & 8.384 \\
2030 & 22.56 & 1393 & 0.0700 & 0.2364 & 8.520 \\
2040 & 25.48 & 1832 & 0.0880 & 0.2972 & 8.960 \\
2050 & 28.40 & 2271 & 0.1060 & 0.3580 & 9.400 \\
2060 & 29.75 & 2811 & 0.1128 & 0.3808 & 7.705 \\
2070 & 31.11 & 3350 & 0.1196 & 0.4036 & 6.009 \\
2080 & 32.46 & 3890 & 0.1264 & 0.4264 & 4.314 \\
2090 & 33.82 & 4429 & 0.1332 & 0.4492 & 2.618 \\
2100 & 35.17 & 4969 & 0.1400 & 0.4720 & 0.923 \\
\hline & & & & & \\
\hline
\end{tabular}

Table 3. Time series of aviation emissions (Lee et al., 2010, http: //www.ip-quantify.eu/).

\begin{tabular}{rrrrrr}
\hline & $\begin{array}{r}\mathrm{NO}_{\mathrm{x}} \\
\mathrm{Tg} \mathrm{yr}^{-1}\end{array}$ & $\begin{array}{r}\mathrm{CO}_{2} \\
\mathrm{Tg} \mathrm{yr}^{-1}\end{array}$ & $\begin{array}{r}\mathrm{BC} \\
\mathrm{Tg} \mathrm{yr}^{-1}\end{array}$ & $\begin{array}{r}\mathrm{OC} \\
\mathrm{Tg} \mathrm{yr}^{-1}\end{array}$ & $\begin{array}{r}\mathrm{SO}_{2} \\
\mathrm{Tg} \mathrm{yr}^{-1}\end{array}$ \\
\hline 1940 & 0.09 & 28 & 0.0002 & - & 0.0036 \\
1950 & 0.19 & 61 & 0.0005 & - & 0.0078 \\
1960 & 0.41 & 132 & 0.0010 & - & 0.0168 \\
1970 & 0.89 & 286 & 0.0021 & - & 0.0363 \\
1980 & 1.34 & 407 & 0.0030 & - & 0.0516 \\
1990 & 2.04 & 549 & 0.0041 & - & 0.0645 \\
2000 & 2.80 & 677 & 0.0050 & - & 0.0873 \\
2010 & 3.29 & 832 & 0.0062 & - & 0.1029 \\
2020 & 4.00 & 1062 & 0.0078 & - & 0.1439 \\
2030 & 5.12 & 1449 & 0.0105 & - & 0.2252 \\
2040 & 6.54 & 1975 & 0.0140 & - & 0.3071 \\
2050 & 7.50 & 2418 & 0.0169 & - & 0.3760 \\
2060 & 9.51 & 3066 & 0.0214 & - & 0.3815 \\
2070 & 11.28 & 3634 & 0.0254 & - & 0.3392 \\
2080 & 12.91 & 4161 & 0.0290 & - & 0.2590 \\
2090 & 14.42 & 4647 & 0.0324 & - & 0.1446 \\
2100 & 15.72 & 5067 & 0.0354 & - & 0.0051 \\
\hline
\end{tabular}


shipping and aviation. Because the CNRM-CM3.3 model does not represent the carbon cycle, it does not use $\mathrm{CO}_{2}$ emissions as input data but needs prescribed $\mathrm{CO}_{2}$ concentrations. These are taken from simulations with a SCM (Skeie et al., 2009) including a description of the carbon cycle (M. Lund, personal communication, 2009). These SCM simulations allow the derivation of the contributions from the different transport sectors to the total $\mathrm{CO}_{2}$ concentration and it is this partitioning which is used in the CNRM-CM3.3 model. In our simulation, we use observed $\mathrm{CO}_{2}$ concentrations until 2000 and the SCM modeled $\mathrm{CO}_{2}$ concentrations from 2000 onwards. To avoid a discontinuity due to a small difference of around $3.5 \mathrm{ppmv}$ between the observed and modeled $\mathrm{CO}_{2}$ concentrations around 2000, we phase out this transition over the period 1990-2010.

Once the $\mathrm{CO}_{2}$ contribution from each sector is known, it is possible to estimate the corresponding radiative forcing $\Delta F$ from $\mathrm{CO}_{2}$ using the simple formula in IPCC (2001, Table 6.1),

$\Delta F=5.35 \mathrm{~W} \mathrm{~m}^{-2} \times \log \frac{r_{\mathrm{CO}_{2}}}{r_{\mathrm{CO}_{2}}^{0}}$,

where $r_{\mathrm{CO}_{2}}^{0}$ and $r_{\mathrm{CO}_{2}}$ refer to the reference and perturbed $\mathrm{CO}_{2}$ mixing ratios respectively. (Note that the radiative forcing in the AOGCM simulations are computed using the model's radiation scheme, rather than this simple formula.)

Figure 1c shows the radiative forcing from $\mathrm{CO}_{2}$ by the different transport sectors. It is clear that road transport has the largest contribution. The evolution of the radiative forcing from shipping and aviation are very similar (this is specific for the A1B scenario), although the significant contribution from shipping starts somewhat earlier (around 1900) than the contribution from aviation (around 1940). The radiative forcing estimates compare reasonably well with the values in Fuglestvedt et al. (2008) for the year 2000 who obtained $150 \mathrm{~mW} \mathrm{~m}^{-2}$ for road transport and 35 and $21 \mathrm{~mW} \mathrm{~m}^{-2}$ for shipping and aviation, respectively.

\subsubsection{CFC-12 and HFC-134a}

Air conditioning systems in cars currently contain CFC-12 and HFC-134a, and these GHGs can end up in the atmosphere due to leakage or at the end of the car's lifetime (Clodic et al., 2005). Their radiative impact can be as large as $20 \mathrm{~mW} \mathrm{~m}^{-2}$ and it is therefore taken into account here (G. Rädel, personal communication, 2009). CFC-12 and HFC-134a are also used in cooling and freezing systems for the transport of goods, but we do not take this into account. Figure 1e shows the radiative forcing by these two gases. For the radiative efficiency we use 0.32 and $0.16 \mathrm{~W} \mathrm{~m}^{-2} \mathrm{ppb}^{-1}$ for CFC-12 and HFC-134a, respectively (IPCC, 2001, Table 6.7). Due to the relatively long lifetimes (100 and $14 \mathrm{yr}$ for CFC-12 and HFC-134a, respectively), their effect goes on well beyond the emission periods (CFC-12 emissions from cars span the 1970 to 2010 period and peak around 19901995, HFC-134a emissions span the 1993-2053 period and peak around 2015). We do not take into account the impact from these extra CFC-12 and HFC-134a emissions on stratospheric $\mathrm{O}_{3}$ destruction. Uherek et al. (2010) estimated that this impact is smaller than $-10 \mathrm{~mW} \mathrm{~m}^{-2}$ in the period 1980 2000.

\subsubsection{Methane}

The evolution of the $\mathrm{CH}_{4}$ mixing ratio for the SRES scenario A1B is shown in Fig. 1b: the large increase during the 20th century continues in the first half of the 21 st century followed by a decrease. The transport sectors also have an impact on the $\mathrm{CH}_{4}$ concentration, not by direct $\mathrm{CH}_{4}$ emissions which are assumed small for the transport sectors, but by an enhanced destruction of $\mathrm{CH}_{4}$ by increased $\mathrm{OH}$ concentrations related to $\mathrm{NO}_{\mathrm{x}}$ emissions. This impact is often expressed as a reduction of the $\mathrm{CH}_{4}$ lifetime (Prather, 1994). For the transport volumes of the year 2000, Hoor et al. (2009) calculated for each sector, the impact on the $\mathrm{OH}$ distribution. As the reaction with $\mathrm{OH}$ is the principal sink of $\mathrm{CH}_{4}$, one can use these results to obtain the reduction in $\mathrm{CH}_{4}$ lifetime by each transport sector. For the year 2000, they found reductions of the $\mathrm{CH}_{4}$ lifetime of $1.61,4.12$ and $1.04 \%$ for road transport, shipping and aviation, respectively (including the feedback factor to include the long term equilibration to the new steady-state, Fuglestvedt et al., 1999). Their results were obtained using 6 different chemistry transport models (CTMs), driven by meteorological analyses for the year 2003 from the European Centre for Medium-range Weather Forecasts (ECMWF).

We use $\mathrm{OH}$ perturbation fields very similar to those of Hoor et al. (2009), derived from simulations by 3 CTMs (pTOMCAT, LMDZ-INCA and Oslo-CTM2) which used updated emissions for road transport and aviation (Koffi et al., 2010; Hodnebrog et al., 2011). In addition to transport volumes for 2000, the $\mathrm{OH}$ impact was also calculated for the assumed transport volumes in 2025 and 2050, with the same 2003 meteorological analyses.

Using the average of the $\mathrm{OH}$ distributions obtained with these $3 \mathrm{CTMs}, \mathrm{CH}_{4}$ lifetimes and lifetime changes for the years 2000,2025 and 2050 are calculated. For intermediate years over the period 1860-2100 where no CTM results are available, we linearly interpolate or extrapolate the $\mathrm{CH}_{4}$ lifetime, scaling the $\mathrm{CH}_{4}$ lifetime change caused by a specific sector with the total global $\mathrm{NO}_{\mathrm{x}}$ emission from that sector. The time series of the total $\mathrm{NO}_{\mathrm{x}}$ emission for the different sectors are shown in Fig. 1g. Using these $\mathrm{CH}_{4}$ lifetimes $\tau$ and lifetime changes $\Delta \tau$ and assuming that the transport sector does not contribute to the $\mathrm{CH}_{4}$ emissions, one can calculate the impact of the reduced $\mathrm{CH}_{4}$ lifetime on the $\mathrm{CH}_{4}$ concentration from the differential equation

$\frac{\mathrm{d} \Delta r_{\mathrm{CH}_{4}}}{\mathrm{~d} t}=-\frac{\Delta r_{\mathrm{CH}_{4}}}{\tau}+\frac{r_{\mathrm{CH}}^{0}}{\tau} \frac{\Delta \tau}{\tau}$, 
(a) $\mathrm{CO}_{2}$

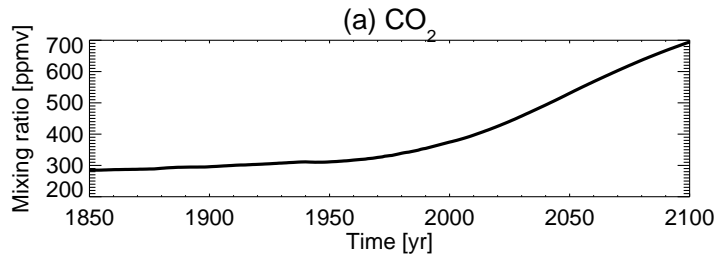

(c) $\mathrm{CO}_{2}$

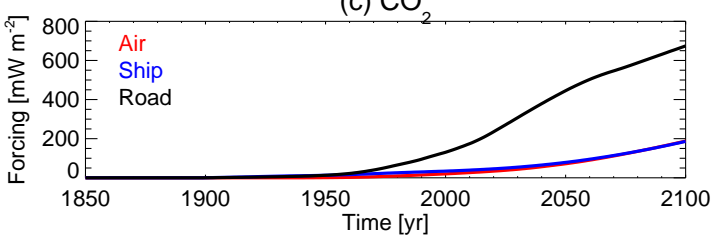

(e) CFC-12 and HFC-134a

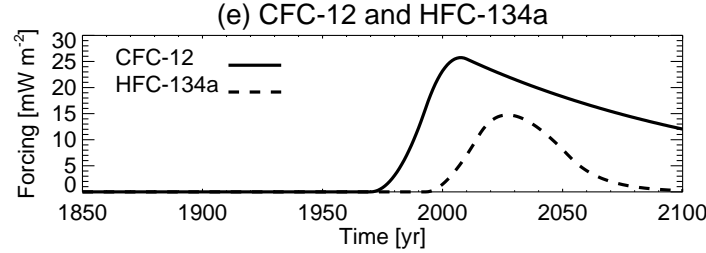

(g) NO

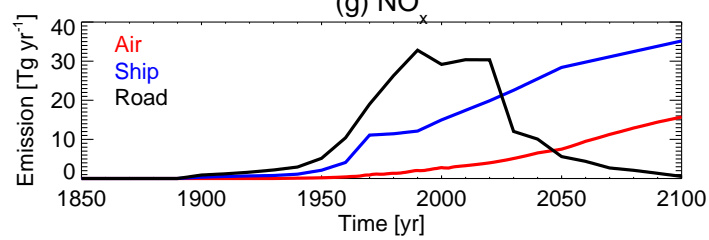

(i) OC

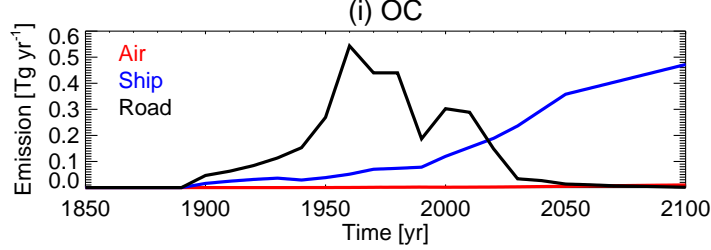

(b) $\mathrm{CH}_{4}$

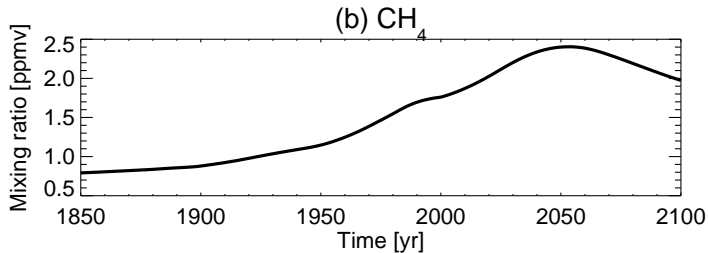

(d) $\mathrm{CH}_{4}$

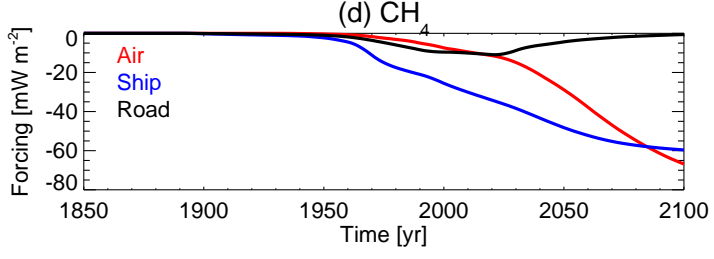

(f) Fuel

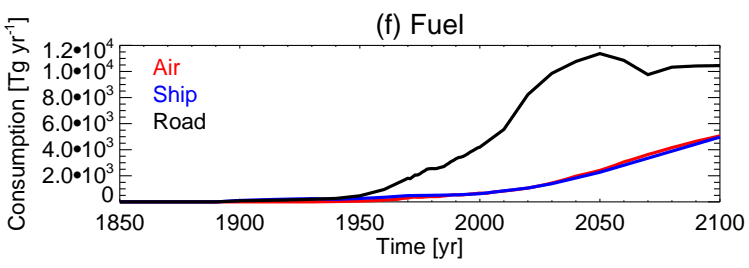

(h) BC

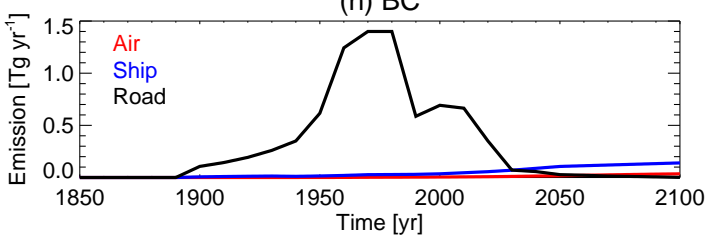

(j) $\mathrm{SO}_{2}$

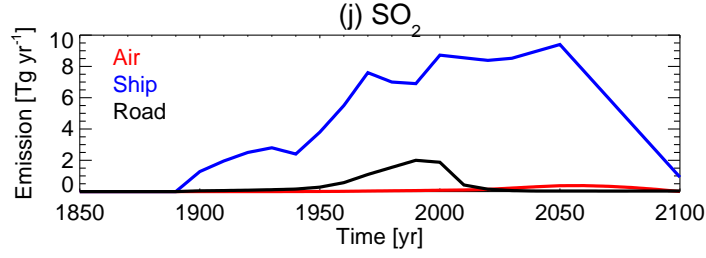

Fig. 1. Time series of the forcings taken into account in the model integrations over the period 1860-2100. The first row shows the evolution of (a) $\mathrm{CO}_{2}$ and (b) $\mathrm{CH}_{4}$ mixing ratios in the reference simulation. Row 2 until 5 show forcings and emissions from the transport sectors: (c) radiative forcing from $\mathrm{CO}_{2}$, (d) radiative forcing from $\mathrm{CH}_{4}$, (e) radiative forcing from CFC-12 and HFC-134a from road transport, (f) global annual fuel consumption, and emissions from (g) $\mathrm{NO}_{\mathrm{x}}$, (h) $\mathrm{BC}$, (i) $\mathrm{OC}$ and (j) $\mathrm{SO}_{2}$.

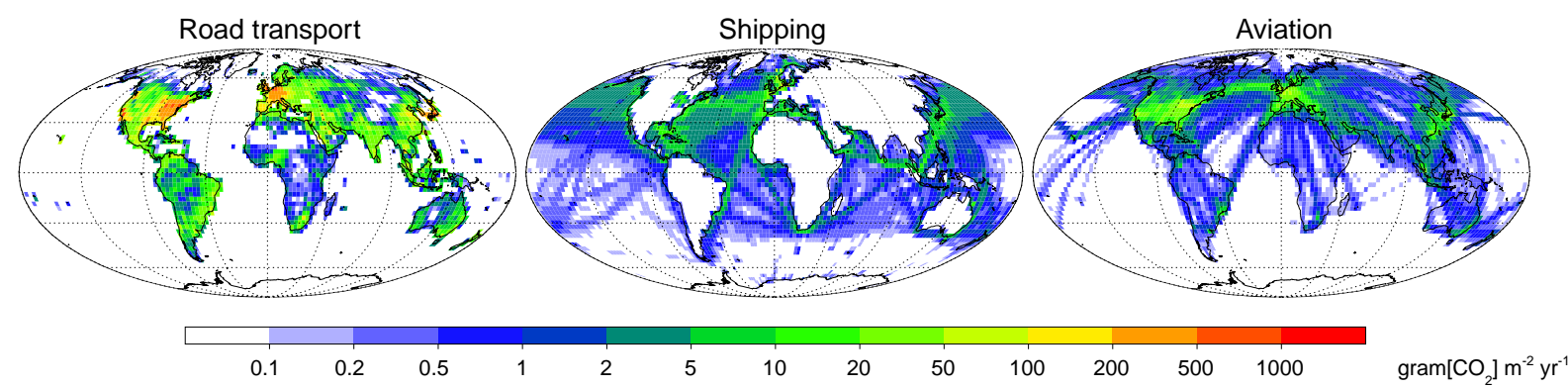

Fig. 2. Global maps of the annual $\mathrm{CO}_{2}$ emission estimates (in gram $\left[\mathrm{CO}_{2}\right] \mathrm{m}^{-2} \mathrm{yr}^{-1}$ ) for the year 2000 from road transport (left), maritime shipping (middle) and aviation (right). For more details, see Borken et al. (2007), Endresen et al. (2003), Lee et al. (2010), and http: //www.ip-quantify.eu/. 
where one takes the background evolution of methane $r_{\mathrm{CH}_{4}}^{0}$ from IPCC (2001, Appendix II). In this approach we disregard the stratospheric and soil sinks for $\mathrm{CH}_{4}$ with lifetimes of 120 and $160 \mathrm{yr}$, respectively (IPCC, 2001). Also, one must be aware that the reference $\mathrm{CH}_{4}$ lifetime is based on the mentioned CTM simulations and does not necessarily agree with the lifetime used in IPCC (2001), and therefore might hamper a coherent reconstruction. Figure $1 \mathrm{~d}$ shows the reduction of radiative forcing due to $\mathrm{CH}_{4}$ perturbations for the different sectors, calculated using IPCC (2001, Table 6.2). Shipping has the strongest impact on the $\mathrm{CH}_{4}$ lifetime (Hoor et al., 2009) and thus on its concentration and radiative forcing. Both shipping and aviation show an increasing impact of $\mathrm{CH}_{4}$ in the 21 st century due to increasing $\mathrm{NO}_{\mathrm{x}}$ emissions. At the end of the 21st century the impact from aviation on $\mathrm{CH}_{4}$ even equals the shipping impact. We do not take into account the impact from $\mathrm{CH}_{4}$-induced $\mathrm{O}_{3}$ changes, which might add an extra $42 \%$ negative radiative forcing (Hoor et al., 2009).

\subsubsection{Ozone}

CNRM-CM3. 3 contains a simplified $\mathrm{O}_{3}$ chemistry description which was specifically developed to simulate stratospheric $\mathrm{O}_{3}$ in AGCMs (Cariolle and Déqué, 1986; Cariolle et al., 1990; Cariolle and Teyssèdre, 2007). To be able to account for the tropospheric and lower stratospheric $\mathrm{O}_{3}$ changes induced by the transport sectors, we additionally use information from the CTM simulations mentioned earlier. From these simulations, the impacts of transport on $\mathrm{O}_{3}, \mathrm{NO}_{\mathrm{x}}$, $\mathrm{CO}$, and many other atmospheric components (e.g. $\mathrm{OH}$, see Sect. 2.2.3) were obtained for the years 2000, 2025 and 2050.

To take into account the $\mathrm{O}_{3}$ impact from transport, we use two different methods. In a first approach (dynamical $\mathrm{O}_{3}$ approach), we use an extended version of the linear $\mathrm{O}_{3}$ scheme. As the tropospheric $\mathrm{O}_{3}$ production is strongly dependent on the $\mathrm{NO}_{\mathrm{x}}$ and $\mathrm{CO}$ mixing ratio, the linear $\mathrm{O}_{3}$ parametrization of the AOGCM (Cariolle and Teyssèdre, 2007) has been extended to take into account the impact of $\mathrm{NO}_{\mathrm{x}}, \mathrm{CO}$ and $\mathrm{H}_{2} \mathrm{O}$ perturbations on the net $\mathrm{O}_{3}$ production. The net $\mathrm{O}_{3}$ production $P$ is approximated by

$$
\begin{aligned}
P & =c_{0}+c_{1}\left(T-c_{2}\right)+c_{3}\left(\Sigma_{\mathrm{O}_{3}}-c_{4}\right)+c_{5}\left(r_{\mathrm{O}_{3}}-c_{6}\right) \\
& +c_{7} r_{\mathrm{Cl}_{\mathrm{y}}}^{2} \theta\left(T_{c}-T\right) \theta\left(\phi_{c}-\phi\right) \\
& +c_{8}\left(r_{\mathrm{NO}_{\mathrm{x}}}-c_{9}\right)+c_{10}\left(r_{\mathrm{CO}}-c_{11}\right)+c_{12}\left(r_{\mathrm{H}_{2} \mathrm{O}}-c_{13}\right),
\end{aligned}
$$

with $T$ the temperature, $\Sigma_{\mathrm{O}_{3}}$ the local overhead total $\mathrm{O}_{3}$ column, $\phi$ the solar zenith angle, $\theta$ the unit step function, and $r_{\mathrm{O}_{3}}, r_{\mathrm{NO}_{\mathrm{x}}}, r_{\mathrm{CO}}$, and $r_{\mathrm{H}_{2} \mathrm{O}}$ the mixing ratios of the indexed species. The coefficients $c_{0}, c_{1}, \ldots, c_{13}$ are zonal monthly climatologies derived with the 2-D stratospheric chemistry transport model MOBIDIC (Cariolle and Teyssèdre, 2007). Coefficient $c_{7}(\leq 0)$ represents stratospheric heterogeneous destruction with $r_{\mathrm{Cl}_{\mathrm{y}}}$ the total inorganic chlorine mixing ratio. The factor $\theta\left(T_{s}-T\right) \theta\left(\phi_{c}-\phi\right)$ with $\theta$ the unit step function assures that the heterogeneous destruction is only ac- tive below a threshold temperature $T_{S}=195 \mathrm{~K}$ and for solar zenith angles smaller than $\phi_{c}=90^{\circ}$. The coefficients $c_{8}, \ldots, c_{13}$ describe the linearized impact of $\mathrm{NO}_{\mathrm{x}}, \mathrm{CO}$ and $\mathrm{H}_{2} \mathrm{O}$ on the net $\mathrm{O}_{3}$ production. In this setup the $\mathrm{NO}_{\mathrm{x}}, \mathrm{CO}$ and $\mathrm{H}_{2} \mathrm{O}$ fields can be seen as external forcings, in the same way AOGCMs often use prescribed aerosol climatologies. The zonal-mean distributions of the $\mathrm{NO}_{\mathrm{x}}$ perturbations can be seen in Fig. 3a, representative for June-July-August (JJA) around the year 2000. In the current study, we do not use the dependency on the $\mathrm{H}_{2} \mathrm{O}$ concentration, and for $\mathrm{CO}$ we only use it for the impact from road transport. To obtain the net $\mathrm{O}_{3}$ production for other years than 2000, 2025 or 2050, we scale the $\mathrm{NO}_{\mathrm{x}}$ and $\mathrm{CO}$ perturbation fields with the total global $\mathrm{NO}_{\mathrm{x}}$ and $\mathrm{CO}$ emissions (http://www.ip-quantify.eu/).

In a second approach (fixed $\mathrm{O}_{3}$ approach), we use the 3-D $\mathrm{O}_{3}$ perturbations originating from the CTMs directly in the AOGCM. These perturbations can be seen in Fig. $3 \mathrm{~b}$ and are added to the background $\mathrm{O}_{3}$ described by Eq. (3), but now with $c_{8}=c_{9}=c_{10}=c_{11}=c_{12}=c_{13}=0$. To obtain perturbation fields for years other than 2000, 2025 or 2050, we scale the $\mathrm{O}_{3}$ perturbations with the $\mathrm{NO}_{\mathrm{x}}$ emissions, assuming that $\mathrm{NO}_{\mathrm{x}}$ is the predominant factor for tropospheric and lower stratospheric $\mathrm{O}_{3}$ perturbations.

\subsubsection{Contrails and aviation-induced cirrus}

When describing the clouds generated by aircraft, one usually distinguishes between linear contrails (condensation trails) and aviation-induced cirrus. Contrails are line-shaped cirrus clouds produced in the wake of an aircraft when hot and moist air from the exhaust mixes with ambient air that is below a critical temperature (Schumann, 1996). Observational studies have been performed using satellite images to estimate the presence of contrails (Mannstein et al., 1998). Different modeling studies have estimated the cloud cover and radiative forcing associated with linear contrails (Marquart et al., 2003; Rädel and Shine, 2008; Rap et al., 2010), where the contrail coverage has been parameterized relying on observed values for the contrail formation frequency (Bakan et al., 1994). Lee et al. (2009) estimated the impact in 2005 of $12 \mathrm{~mW} \mathrm{~m}^{-2}$. When linear contrails persist, they can give rise to aviation-induced cirrus which due to the loss of the linear shape become indistinguishable from natural cirrus clouds. Therefore aviation-induced cirrus is much more difficult to estimate. Stordal et al. (2005) have used 16 yr of observational cloud data (1984-1999) to estimate the increase or decrease in the presence of cirrus, and derived a radiative forcing of $30 \mathrm{~mW} \mathrm{~m}^{-2}$ that includes both linear contrails and aviation-induced cirrus. Recently, modeling studies have been performed which model the evolution and aging of contrails: Burkhardt and Kärcher $(2009,2011)$ derived a radiative forcing of $31 \mathrm{~mW} \mathrm{~m}^{-2}$.

We use in CNRM-CM3.3 a simple description of the major forcing from linear contrails and aviation-induced cirrus. To model the possible presence of linear contrails and 
Road transport

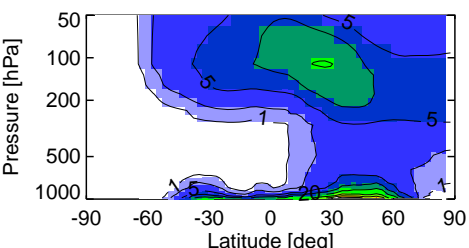

Shipping

(a) $\mathrm{NO}_{\mathrm{x}}$

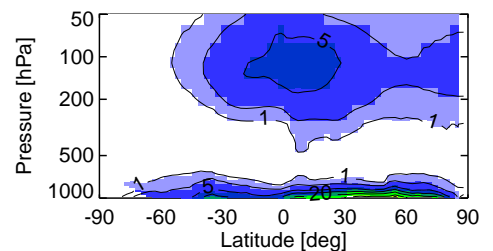

Aviation

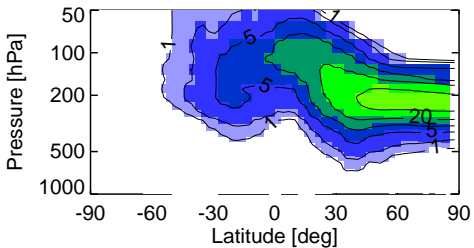

(b) $\mathrm{O}_{3}$
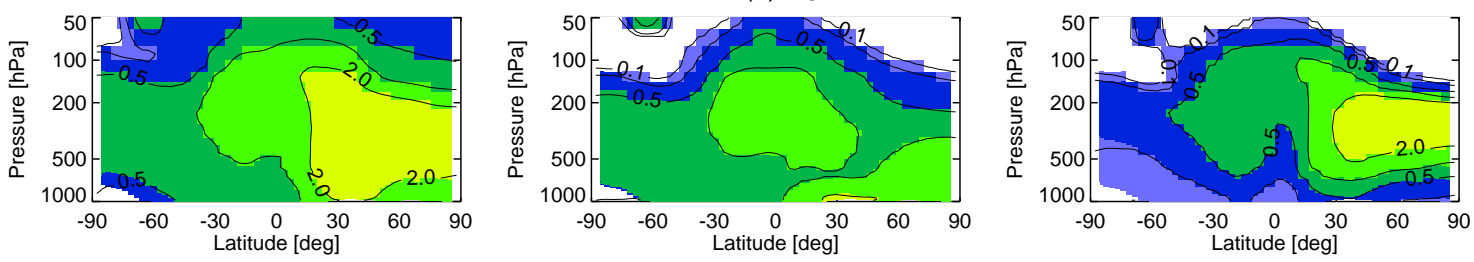

pptv

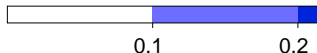

0.5

(c) $\mathrm{SO}_{4}$
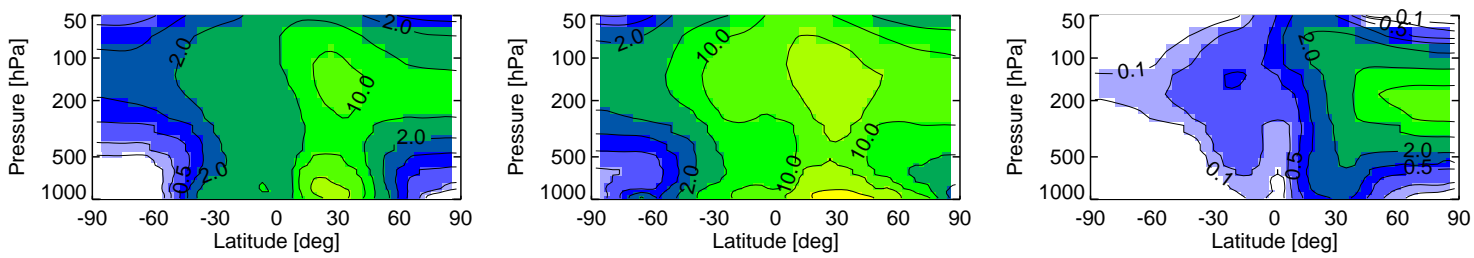

(d) BC
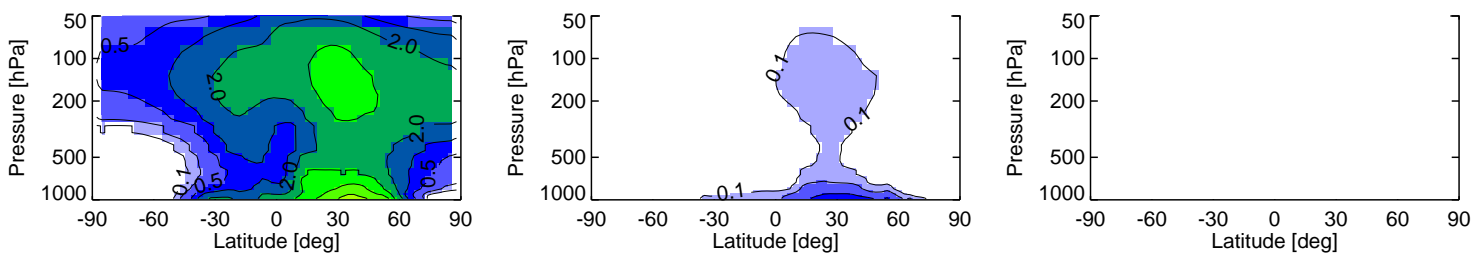

(e) OC
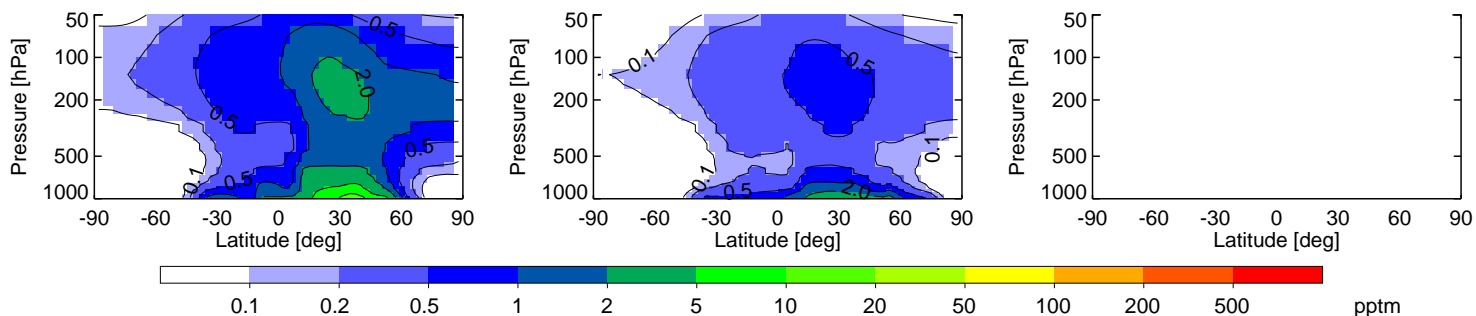

Fig. 3. Contribution by road transport (left), shipping (middle) and aviation (right) to the distribution of (a) $\mathrm{NO}_{\mathrm{x}}(\mathrm{pptv})$, (b) $\mathrm{O}_{3}$ (ppbv), (c) sulfate (ppt), (d) BC (ppt), and (e) OC (ppt) in JJA 2000. These contributions are obtained by off-line $\mathrm{CTM}$ simulations: $\mathrm{O}_{3}$ and $\mathrm{NO}_{\mathrm{x}}$ are averages over the p-Tomcat, LMDZ-INCA and Oslo-CTM2 models, while the aerosol fields are those of the LMDZ-AER model.

aviation-induced cirrus in the regions with dense air traffic, we use a "recent exhaust" distribution obtained with a CTM (Teyssèdre et al., 2007). We model the distribution of this tracer for the years $2000,2025,2050$ and 2100 , taking as its source the fuel consumption, assuming a lifetime varying with height (i.e. $15 \mathrm{~h}$ at $250 \mathrm{hPa}$ and $2 \mathrm{~h}$ at $850 \mathrm{hPa}$ ), and integrating the large scale transport with ECMWF meteoro- logical analyses for 2003. For aviation, monthly 3-D fuel consumption data are available for the years 2000, 2025, 2050, and 2100 (http://www.ip-quantify.eu/). The monthly mean distribution of the "recent exhaust" tracer is used in CNRM-CM3.3 to indicate air masses affected by recent air traffic. We assume that high concentrations of this tracer can induce a cirrus cloud if the temperature is below $-40^{\circ} \mathrm{C}$ 
Table 4. Time series of mixing ratios of GHGs and total inorganic chlorine as used in the reference simulation.

\begin{tabular}{rrrrrrr}
\hline & $\begin{array}{r}\mathrm{CO}_{2} \\
\text { ppmv }\end{array}$ & $\begin{array}{r}\mathrm{CH}_{4} \\
\text { ppbv }\end{array}$ & $\begin{array}{r}\mathrm{N}_{2} \mathrm{O} \\
\text { ppbv }\end{array}$ & $\begin{array}{r}\text { CFC-11 } \\
\text { pptv }\end{array}$ & $\begin{array}{r}\text { CFC-12 } \\
\text { pptv }\end{array}$ & $\begin{array}{r}\text { Chlorine } \\
\text { pptv }\end{array}$ \\
\hline 1850 & 285 & 792 & 276 & 12.5 & 0.0 & 484 \\
1860 & 286 & 806 & 277 & 12.5 & 0.0 & 484 \\
1870 & 288 & 821 & 277 & 12.5 & 0.0 & 484 \\
1880 & 291 & 837 & 278 & 12.5 & 0.0 & 484 \\
1890 & 294 & 857 & 279 & 12.5 & 0.0 & 484 \\
1900 & 296 & 879 & 280 & 12.5 & 0.0 & 484 \\
1910 & 300 & 924 & 281 & 12.5 & 0.0 & 485 \\
1920 & 303 & 978 & 283 & 13.1 & 0.0 & 490 \\
1930 & 308 & 1036 & 286 & 14.6 & 0.0 & 503 \\
1940 & 311 & 1089 & 288 & 19.8 & 0.3 & 547 \\
1950 & 311 & 1148 & 290 & 32.8 & 6.8 & 661 \\
1960 & 317 & 1248 & 293 & 50.6 & 32.6 & 805 \\
1970 & 326 & 1386 & 296 & 134.0 & 123.3 & 1321 \\
1980 & 339 & 1547 & 302 & 329.8 & 307.7 & 2424 \\
1990 & 354 & 1694 & 308 & 563.3 & 485.2 & 3471 \\
2000 & 375 & 1760 & 316 & 653.5 & 535.0 & 3453 \\
2010 & 397 & 1871 & 324 & 778.3 & 527.3 & 3336 \\
2020 & 425 & 2026 & 331 & 785.8 & 485.7 & 3009 \\
2030 & 458 & 2202 & 338 & 769.1 & 440.8 & 2622 \\
2040 & 493 & 2337 & 344 & 834.0 & 399.6 & 2321 \\
2050 & 531 & 2400 & 350 & 948.8 & 362.3 & 2061 \\
2060 & 568 & 2386 & 356 & 1083.3 & 328.5 & 1850 \\
2070 & 603 & 2301 & 360 & 1199.1 & 297.8 & 1683 \\
2080 & 636 & 2191 & 365 & 1264.6 & 270.0 & 1546 \\
2090 & 667 & 2078 & 368 & 1303.4 & 244.8 & 1431 \\
2100 & 694 & 1974 & 372 & 1315.9 & 222.0 & 1331 \\
\hline & & & & & &
\end{tabular}

and if the relative humidity is above $80 \%$ (Rädel and Shine, 2008). We impose this $80 \%$ limit as the current version of the atmospheric model does not consider ice supersaturation. The relationship between the recent exhaust tracer and the presence of linear contrails or aviation-induced cirrus is calibrated to have a top of the atmosphere (TOA) radiative forcing of $0.024 \mathrm{~W} \mathrm{~m}^{-2}$ for the year 2000 (slightly lower than the $31 \mathrm{~mW} \mathrm{~m}^{-2}$ in Burkhardt and Kärcher, 2011). This value of $0.024 \mathrm{~W} \mathrm{~m}^{-2}$ is based on the assumptions that the impact from linear contrails alone is $0.006 \mathrm{~W} \mathrm{~m}^{-2}$ in the year 2000 (Rädel and Shine, 2008) and that the impact of aviation-induced cirrus is 3 times larger than from linear contrails (Fuglestvedt et al., 2010). Using these distributions in CNRM-CM3.3, we find TOA net radiative forcings in 1980, 2000, 2025, 2050 and 2100 of 14.9, 24.1, 44.2, 101 and $211 \mathrm{~mW} \mathrm{~m}^{-2}$, respectively. In tests where we impose a global uniform contrail coverage of $0.01,0.1$ and 1 with a contrail optical depth of 0.3 , we find net TOA radiative forcings of $0.16,1.63$ and $15.1 \mathrm{~W} \mathrm{~m}^{-2}$. This value of $0.16 \mathrm{~W} \mathrm{~m}^{-2}$ corresponds well with the values mentioned in Myhre et al. (2009) which is a comparative study among different line-by-line radiative transfer codes and codes used in AGCMs, including the one used in CNRM-CM3.3. For an experiment with a 0.01 global contrail cover at 0.3 opti- cal depth, where the grey body emissivity formulation had been replaced by a two-stream approximation in order to accommodate the prescribed optical properties of the contrail, a value of $0.19 \mathrm{~W} \mathrm{~m}^{-2}$ was reported for CNRM-CM3.3, close to the best estimate of $0.163 \mathrm{~W} \mathrm{~m}^{-2}$. Myhre et al. (2009) further mention that for this experiment they found a strong similarity in the spatial pattern of the radiative forcing among the models, with rather low values at high latitudes. For years other than 2000, 2025, 2050 and 2100, we interpolate the 3D recent exhaust tracer distributions scaling them with the global annual fuel consumption by aviation, which can be found in Fig. 1f.

\subsubsection{Aerosols}

The CNRM-CM3.3 model accounts for both direct and indirect effects of aerosols. The indirect effect is however limited to the sulfate component, which leads to an underestimation of the total indirect effect. As the transport sectors are a source of aerosols in the atmosphere, we take into account the BC, OC and sulfate aerosols from the different transport sectors, and use monthly mean 3-D distributions which are available from simulations with the INCA-AER model (Balkanski et al., 2010), using the emissions from http://www.ip-quantify.eu/. Figure 3c-e shows the zonal mean distribution of the perturbation in $\mathrm{BC}$, OC and sulfate aerosols induced by the different transport sectors in JJA 2000. We use these 3-D aerosol distributions in the AOGCM in addition to the standard aerosol distributions in the model. For the year 2000, we find optical depths at $550 \mathrm{~nm}$ similar to those of Balkanski et al. (2010, Table 2). However, changes in net incoming radiation at the TOA are quite different. BC induces changes at the TOA of 1.15, 0.027 and $0.00014 \mathrm{~mW} \mathrm{~m}^{-2}$ for road transport, shipping and aviation respectively, which is at least a factor 40 lower than mentioned in Balkanski et al. (2010). This will mainly have an impact on the road transport sector (see Fig. 1h). With correct forcings one would probably see a slight increase in the warming from the road sector, although this would depend on the poorly understood semi-direct effect of BC on clouds. For OC we find equally small values. For sulfate we find changes at the TOA of $-32.2,-95$ and $-4.5 \mathrm{~mW} \mathrm{~m}^{-2}$ for road transport, shipping and aviation, respectively. This is considerably more than the values in Balkanski et al. (2010), which only included the direct aerosol effect. As we also include the first indirect aerosol effect, part of the differences can be attributed to that.

To obtain the aerosol distribution for years other than 2000, we scale the 3-D distribution with the annual global $\mathrm{BC}, \mathrm{OC}$, and $\mathrm{SO}_{2}$ emissions (see Fig. 1h-j). Road transport is the main contributor to $\mathrm{BC}$ and $\mathrm{OC}$ emissions, while the $\mathrm{SO}_{2}$ emissions are strongest for shipping however showing a large reduction at the end of the 21 st century. The $\mathrm{SO}_{2}$ emissions from aviation, that peak around 2050, are much lower than from shipping. 

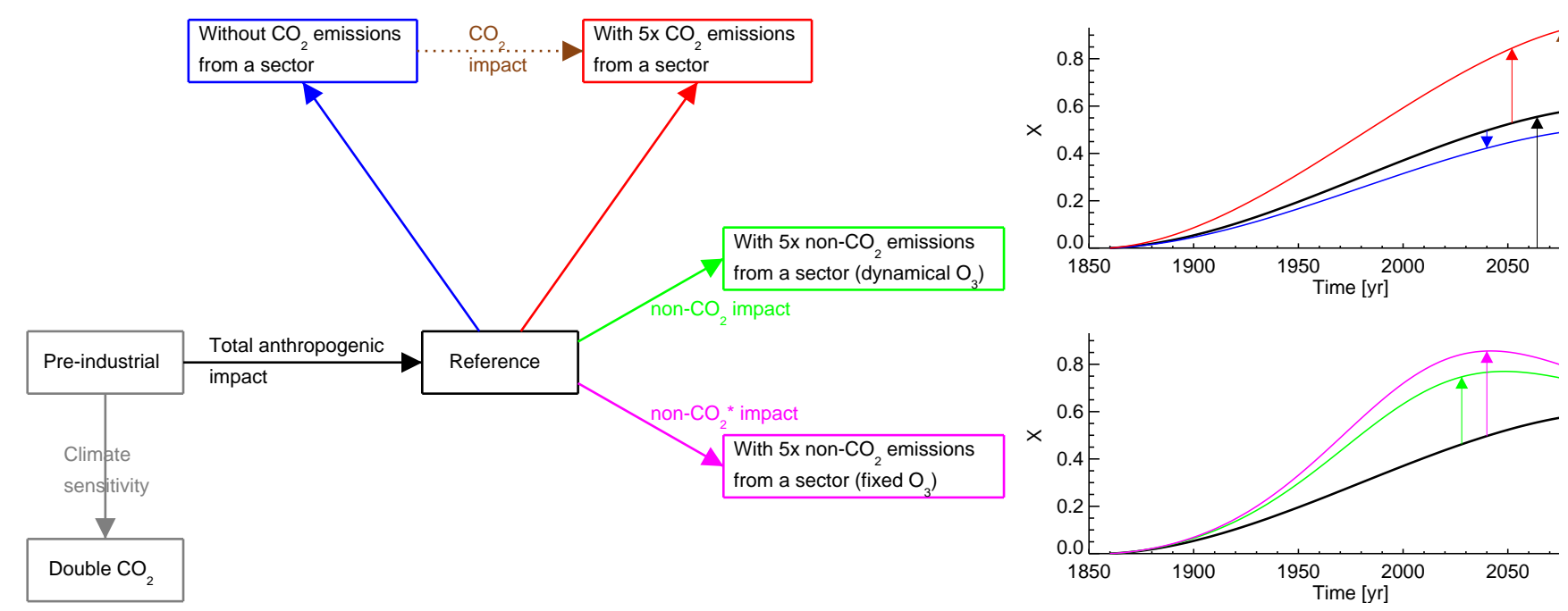

Fig. 4. Schematic representation of the different simulations and impacts (a general impact is represented by $\mathrm{X}$ in the ordinate). The black curve (box) denotes the simulation which takes into account all the anthropogenic forcings. The other coloured curves (boxes) represent simulations where the $\mathrm{CO}_{2}$ or non- $\mathrm{CO}_{2}$ emissions of one of the transport sectors are modified. The blue curve (box) denotes a simulation without $\mathrm{CO}_{2}$ emissions of one of the transport sectors, and the red curve (box) denotes a simulation with 5 times the $\mathrm{CO}_{2}$ emissions of the same sector. The green curve (box) indicates a simulation with 5 times the non- $\mathrm{CO}_{2}$ emissions from one transport sector, using the dynamical $\mathrm{O}_{3}$ approach. The purple curve (box) indicates a simulation with the same emissions but using the fixed $\mathrm{O}_{3}$ approach (see Sect. 2.2.4). A simulation with doubled $\mathrm{CO}_{2}$ concentration (grey box) is used to derive the climate sensitivity.

\subsection{Experiments}

We perform several simulations with the CNRM-CM3.3 model over the period 1860-2100. A schematic picture of the different simulations can be found in Fig. 4. The reference simulation (see black curve and black box in Fig. 4) uses the standard forcings to model the evolution of the Earth's climate over the period 1860-2100 (scenario A1B from 2000 onwards). The $\mathrm{CO}_{2}$ and $\mathrm{CH}_{4}$ evolutions used are shown in Fig. 1a-b, but also $\mathrm{N}_{2} \mathrm{O}, \mathrm{CFC}-11$, CFC-12, the surface properties and the sulfate aerosol evolve with time. An overview of the time series of prescribed GHGs as used in the reference simulation can be found in Table 4. Comparing this simulation with a simulation under pre-industrial conditions (grey box in Fig. 4) allows the derivation of the "total anthropogenic impact".

To study the impact of the different transport sectors, we perform a number of sensitivity simulations (also indicated in Fig. 4), making separate simulations to quantify the $\mathrm{CO}_{2}$ and non- $\mathrm{CO}_{2}$ impact. The non- $\mathrm{CO}_{2}$ impact includes the effects from $\mathrm{O}_{3}, \mathrm{CH}_{4}, \mathrm{CFC}-12$ and HFC-134a, aerosols, and contrails. To study the $\mathrm{CO}_{2}$ impact, we do two types of simulations, represented in the upper right panel of Fig. 4: a first one without the $\mathrm{CO}_{2}$ contribution from a certain sector (blue curve), and a second one with five times the $\mathrm{CO}_{2}$ contribution from that sector (red curve). To study the non- $\mathrm{CO}_{2} \mathrm{im}-$ pact (see lower right panel in Fig. 4), we perform simulations where we add 5 times the non- $\mathrm{CO}_{2}$ forcing from a certain sector w.r.t. the reference simulation. We perform simula- tions using the dynamical $\mathrm{O}_{3}$ approach (which we will call non- $\mathrm{CO}_{2}$, green line or box in Fig. 4), and simulations using the fixed $\mathrm{O}_{3}$ approach (which we call non- $\mathrm{CO}_{2} *$, purple line or box in Fig. 4). Each simulation is repeated 3 times, using different initial conditions for the ocean, sea-ice and atmosphere, resulting in small ensembles of 3 members. The initial conditions for the members of the ensembles are taken from a pre-industrial simulation with a $10 \mathrm{yr}$ time interval. Figure 5 indicates how the use of ensembles and amplification of the forcings reduces the overlap between the uncertainty interval of the reference experiment and a perturbation experiment: using more members in an ensemble reduces the size of the uncertainty interval, and amplifying the forcing increases the spacing between these intervals. Note that due to non-linearity, the best estimate based on an amplification of the forcing (red dot, Fig. 5) might be different from the actual impact (grey S1 dot).

As the emissions of the transport sectors are assumed negligible before 1890 , our perturbation simulations do not show any impact before 1890. Because shipping and aviation have almost the same temporal evolution for their $\mathrm{CO}_{2}$ contribution in scenario A1B (see Fig. 1c), we perform only one simulation that represents the $\mathrm{CO}_{2}$ impact for both sectors. We also make a 100-yr long simulation where we double the $\mathrm{CO}_{2}$ mixing ratio (grey box in Fig. 4) w.r.t. the pre-industrial value to estimate the climate sensitivity according to Gregory et al. (2004).

Finally, we want to mention that we do not consider certain forcings from the transport sectors such as the impact of BC 


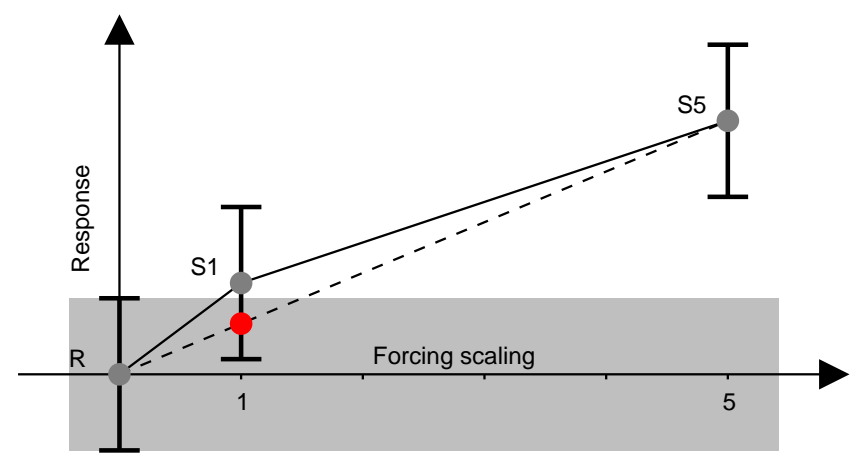

Fig. 5. Schematic representation of the impact of ensemble size and amplification of the forcing on the signal-to-noise ratio. The response (y-axis) is represented as a function of the size of the forcing (x-axis) in (R) a reference simulation, (S1) a simulation including once the forcing from a transport sector, and (S5) a simulation including 5 times the forcing from that transport sector. The black vertical bars indicate the uncertainty on the experiments best estimates. Increasing the ensemble size reduces these uncertainties. Note that due to non-linearity, the best estimate based on an amplification of the forcing (red dot) might be different from the actual impact (grey S1 dot).

on the formation of ice clouds (Penner et al., 2009; Liu et al., 2009), the impact of $\mathrm{N}_{2} \mathrm{O}$ emissions (conversion of $\mathrm{NO}_{\mathrm{x}}$ into $\mathrm{N}_{2} \mathrm{O}$ in catalytic converters in cars), the impact of water vapour emissions from aircraft in the upper troposphere or lower stratosphere, the direct impact of $\mathrm{CH}_{4}$ emissions, the impact of $\mathrm{CH}_{4}$ changes on stratospheric water vapour, or the impact of $\mathrm{CH}_{4}$ changes on $\mathrm{O}_{3}$. We also do not take into account the indirect impact of increased $\mathrm{O}_{3}$ concentrations (from $\mathrm{NO}_{\mathrm{x}}$ emissions) on the $\mathrm{CO}_{2}$ uptake by vegetation (Sitch et al., 2007; Collins et al., 2010). Furthermore, in our approach resultant climate impacts do not feed back or affect the forcing mechanisms. E.g. $\mathrm{OH}, \mathrm{NO}_{\mathrm{x}}$, and $\mathrm{O}_{3}$ distributions for the year 2050 have been calculated using 2050 emissions but using year 2000 (or 2003) meteorology, such that impacts of possibly warmer and wetter conditions on the presence of these species are not taken into account. Expected impacts of changes in precipitation on aerosol distributions are not taken into account either. Several studies (Brasseur et al., 2006; Wu et al., 2008; Hedegaard et al., 2008; Koffi et al., 2010) investigated the impact of climate change on tropospheric chemistry and aerosols. Over the period 20002050, Wu et al. (2008) found that $\mathrm{OH}$ changes from climate change prevail on changes from emissions, while $\mathrm{O}_{3}$ changes are mainly driven by emission changes (Brasseur et al., 2006; Wu et al., 2008; Koffi et al., 2010). Hedegaard et al. (2008) found both regions with increasing and decreasing wet deposition of aerosols, but none of these changes were significant in their simulations.

\section{Atmosphere}

In this section, we describe the impact of the 3 transport sectors on some key aspects of the atmosphere over the period 1860-2100: $\mathrm{O}_{3}$, TOA forcing, surface air temperature, atmospheric temperature profiles, precipitation, cloud cover, and the NAO index. We show the separate impact of the transport sectors and distinguish between the $\mathrm{CO}_{2}$ and non$\mathrm{CO}_{2}$ impacts, and, as a reference, we also show the total anthropogenic impact. We show time averages over 4 different periods, i.e. 1980-1999, 2011-2030, 2046-2065 and 20802099, which also have been studied in IPCC (2007).

\subsection{Ozone}

We use two different methods to take into account the $\mathrm{O}_{3}$ perturbations. In the first method (dynamical $\mathrm{O}_{3}$ approach) we impose 3- $\mathrm{D} \mathrm{NO}_{\mathrm{x}}$ and $\mathrm{CO}$ perturbations which are used by the extended linear $\mathrm{O}_{3}$ scheme to calculate the net $\mathrm{O}_{3}$ production. The actual resulting $\mathrm{O}_{3}$ mixing ratio might differ considerably from the prescribed $\mathrm{O}_{3}$ perturbations of the second (fixed $\mathrm{O}_{3}$ ) approach, where we impose 3-D $\mathrm{O}_{3}$ perturbations directly. Figure $6 \mathrm{a}-\mathrm{d}$ shows the impact from the transport sectors on the evolution of the $\mathrm{O}_{3}$ mixing ratio at 850 and $250 \mathrm{hPa}$ in the $\mathrm{SH}$ and $\mathrm{NH}$. At $850 \mathrm{hPa}$, there is a reasonable agreement between the dynamical and fixed $\mathrm{O}_{3}$ approaches. The correspondence is rather strong in the $\mathrm{SH}$ and for shipping in the $\mathrm{NH}$, but the impacts from road transport and aviation in the $\mathrm{NH}$ differ by a factor of 2 . In general, the dynamical approach leads to larger $\mathrm{O}_{3}$ perturbations. For both approaches, we see stronger impacts in the NH than in the SH. Shipping has the smallest hemispheric difference, with an impact in 2100 of slightly more than 3 ppbv in the $\mathrm{NH}$ and slightly less than $2 \mathrm{ppbv}$ in the SH. The impact of road transport is strongest between 1990 and 2020, and decreases rapidly after 2020 . Finally one can see that at the end of the 21st century the impact of aviation and shipping are of similar magnitude. At $250 \mathrm{hPa}$, the differences between the dynamical and fixed $\mathrm{O}_{3}$ approach become especially large for aviation. The impact at $250 \mathrm{hPa}$ is generally dominated by aviation, whereas before 2020 the impact in the SH from road is dominant. The impact from aviation in the $\mathrm{SH}$ is almost a factor of 5 smaller than in the $\mathrm{NH}$, a consequence of the much stronger emissions in the $\mathrm{NH}$, the short tropospheric $\mathrm{O}_{3}$ lifetime and the slow inter-hemispheric mixing.

Figure $6 \mathrm{e}-\mathrm{f}$ shows the evolution of the total $\mathrm{O}_{3}$ column in Dobson Units (DU), due to the total anthropogenic impact (left, absolute columns), and due to transport impacts (right, changes in $\mathrm{O}_{3}$ columns). The $\mathrm{O}_{3}$ column is around $315 \mathrm{DU}$ in the first part of the 20th century, but at the end of the 21st century it reaches $325 \mathrm{DU}$. This increase is related to the impact of a colder stratosphere in a changing climate on $\mathrm{O}_{3}$ concentrations. The Antarctic $\mathrm{O}_{3}$ hole is manifest in the second half of the 20th and first half of the 21st century. To better see the evolution of the Antarctic $\mathrm{O}_{3}$ hole, we show the mean $\mathrm{O}_{3}$ 
(a) Ozone at $850 \mathrm{hPa}(\mathrm{SH})$

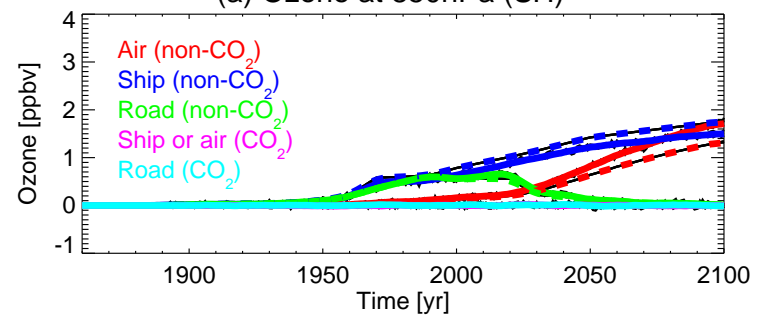

(c) Ozone at $250 \mathrm{hPa}(\mathrm{SH})$

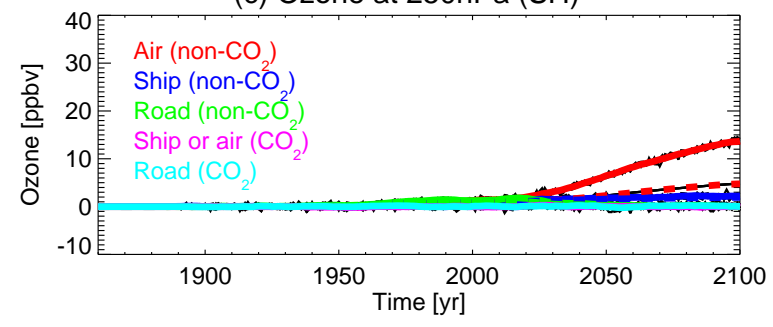

(e) Total ozone column (global)

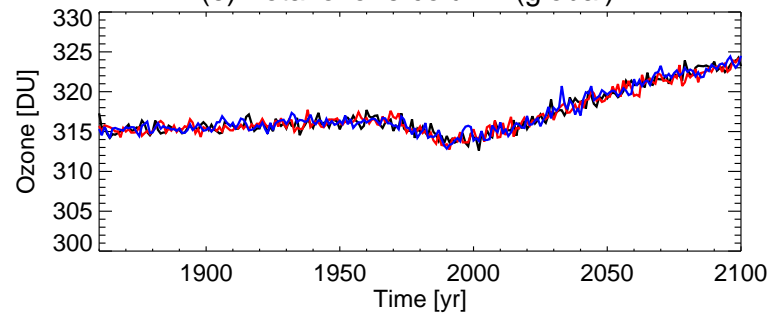

(g) Ozone at $50 \mathrm{hPa}(60 \mathrm{~S}-90 \mathrm{~S})$

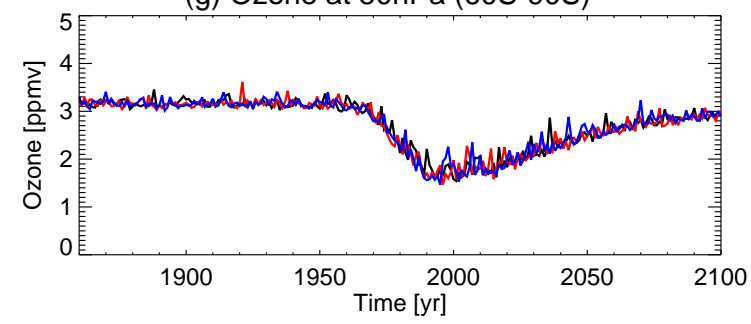

(b) Ozone at $850 \mathrm{hPa}(\mathrm{NH})$

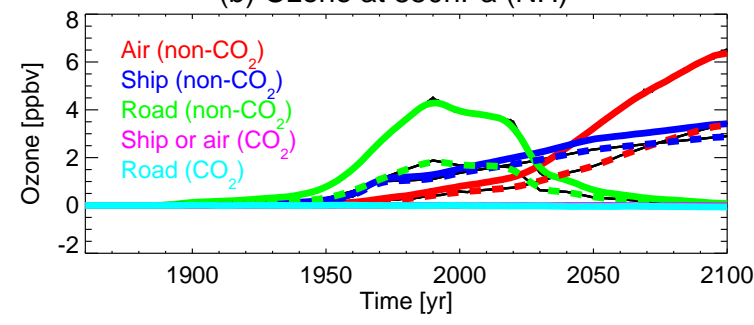

(d) Ozone at $250 \mathrm{hPa}(\mathrm{NH})$

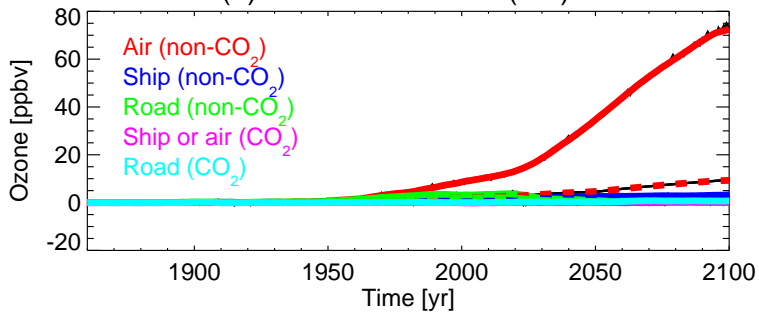

(f) Total ozone column (global)

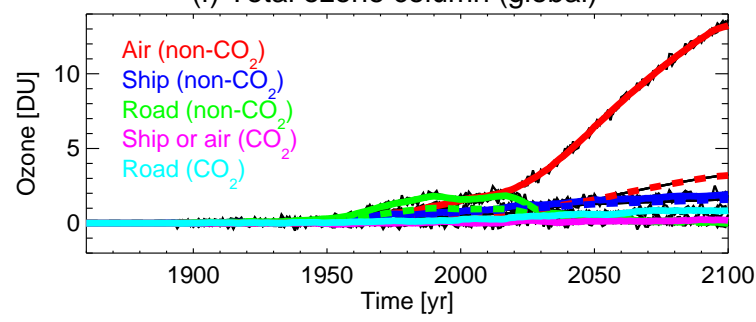

(h) Ozone at $50 \mathrm{hPa}(60 \mathrm{~N}-90 \mathrm{~N})$

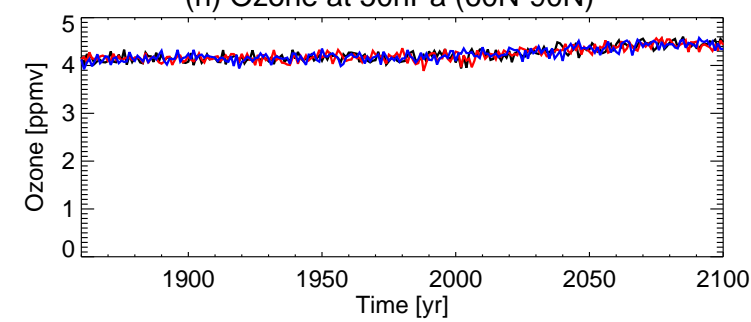

Fig. 6. Time series of the $\mathrm{O}_{3}$ evolution: impact from the transport sectors on the $\mathrm{O}_{3}$ mixing ratio at $850 \mathrm{hPa}$ in the (a) $\mathrm{SH}$ and (b) $\mathrm{NH}$, and at $250 \mathrm{hPa}$ in the (c) $\mathrm{SH}$ and (d) $\mathrm{NH}$; total $\mathrm{O}_{3}$ column (e) in the reference simulation and (f) impact from the transport sectors; (g) $\mathrm{O}_{3}$ mixing ratio in the reference simulation at $50 \mathrm{hPa}$ averaged over the $60-90^{\circ} \mathrm{S}$ region in September and (h) over the $60-90^{\circ} \mathrm{N}$ region in March. In (a), (b), (c), (d) and (f), full lines indicate the dynamical $\mathrm{O}_{3}$ approach and dashed lines the fixed $\mathrm{O}_{3}$ approach. In (e), (g) and (h), the three different lines (black, red and blue) represent the three different members of the ensemble.

concentration at $50 \mathrm{hPa}$ averaged over $60-90^{\circ} \mathrm{S}$ in September in Fig. $6 \mathrm{~g}$ and over $60-90^{\circ} \mathrm{N}$ in March in Fig. 6h for the 3 members of the reference simulations. One sees an important decrease in the $60-90^{\circ} \mathrm{S} \mathrm{O}_{3}$ concentration in 1990 2010 , with an almost complete recovery up to pre-1960 values in 2070-2080. This agrees rather well with results from AGCMs with full stratospheric chemistry (WMO, 2010).

$\mathrm{CO}_{2}$ emissions from transport also have some effect on the total $\mathrm{O}_{3}$ column (Fig. 6f), probably due to a cooler stratosphere: there is a small increase at the end of the 21 st century of around $1 \mathrm{DU}$ due to road transport (light blue line), and less than $0.5 \mathrm{DU}$ due to shipping or aviation (purple line).
These changes are in agreement with the total anthropogenic impact. For the non- $\mathrm{CO}_{2}$ impact from aviation, the evolution of the $\mathrm{O}_{3}$ column clearly shows again the strong difference between the perturbations due to the non- $\mathrm{CO}_{2}$ (full line) and the non- $\mathrm{CO}_{2} *$ (dashed line) approaches.

\subsection{TOA forcing}

For $\mathrm{CO}_{2}, \mathrm{CH}_{4}, \mathrm{CFC}-12$ and HFC-134a, the radiative forcings from the transport sectors were presented in Fig. 1c-e. Here we present the TOA radiative forcing caused by $\mathrm{O}_{3}$ (fixed $\mathrm{O}_{3}$ approach), contrails and aerosols. To obtain these values 
(a) TOA net SW radiative forcing

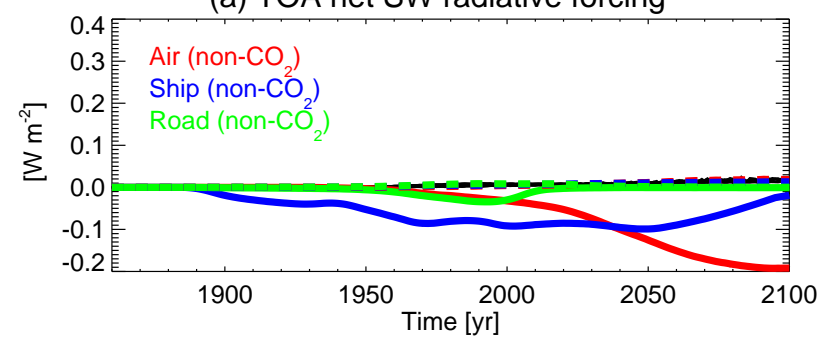

(b) TOA net LW radiative forcing

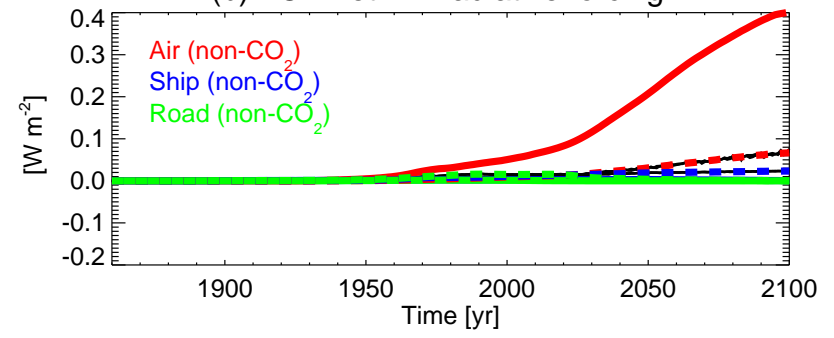

(c) TOA net radiative forcing

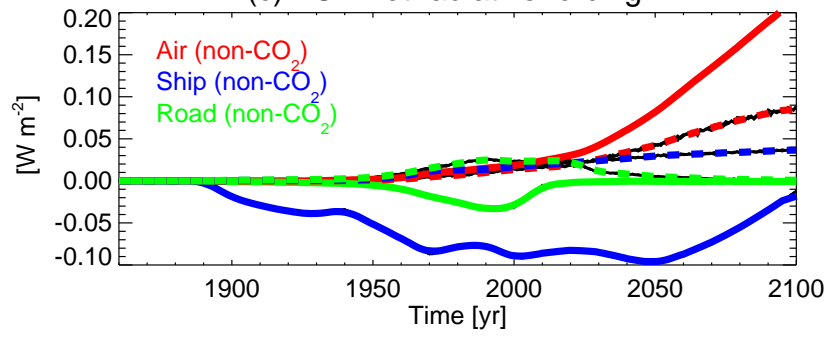

Fig. 7. Time series of annual global mean impact of $\mathrm{O}_{3}$, aerosols and contrails on TOA (a) shortwave, (b) longwave and (c) net radiative fluxes from road transport (green), maritime shipping (blue) and aviation (red). The impact from $\mathrm{O}_{3}$ (from the fixed $\mathrm{O}_{3}$ approach) is indicated by the dashed lines, while the impact from aerosols and contrails together is indicated by the full lines.

for the period 1860-2100, we perform the radiative transfer calculation twice, once with the transport induced perturbation agents, and once without them (for the dynamical $\mathrm{O}_{3}$ approach this is not possible). The difference gives the radiative imbalance induced by the forcing agent. With this method we obtain from the non- $\mathrm{CO}_{2}$ simulations the summed impact from contrails and aerosols, and from the non- $\mathrm{CO}_{2} *$ simulations the summed impact from $\mathrm{O}_{3}$, contrails and aerosols. By taking the difference between these approaches one can also derive the fixed $\mathrm{O}_{3}$ impact.

Figure 7 shows the net TOA radiation impact from the $\mathrm{O}_{3}$ forcing (dashed line) and from the combined aerosol and contrail forcing (full line). The $\mathrm{O}_{3}$ impact in 2000 is 23.5 , 16.8 and $13.5 \mathrm{~mW} \mathrm{~m}^{-2}$ for road transport, shipping and aviation, respectively, and evolves in 2100 to $0.7,36.5$ and $85.3 \mathrm{~mW} \mathrm{~m}^{-2}$. Although the $\mathrm{NO}_{\mathrm{x}}$ emissions in 2100 are still considerably lower for aviation than for shipping, their radiative impact is considerably stronger - the radiative impact of both sectors is of similar size around 2020-2030. Surpris- ingly the values for the year 2000 are lower than the values from Hoor et al. (2009, their Table 8), especially when one takes into consideration their lower road transport and aviation emissions: they found $27.9,27.3$ and $16.3 \mathrm{~mW} \mathrm{~m}^{-2}$ for road transport, shipping and aviation, respectively. Our values are also smaller than the ones in Myhre et al. (2011) who found 31,24 and $17 \mathrm{~mW} \mathrm{~m}^{-2}$. The discrepancy can be partially caused by differences in the radiation scheme. For road transport, shipping and aviation, the impact from aerosols and contrails is found to be $-28.4,-89.0$ and $18.3 \mathrm{~mW} \mathrm{~m}^{-2}$ respectively in the year 2000 . These values correspond reasonably well with the results for aerosols and contrails in Sects. 2.2.5 and 2.2.6. As the forcing from BC is very small in our model, we find the total impact from road transport aerosols to be negative (this contrasts with Fuglestvedt et al., 2008; Balkanski et al., 2010; Uherek et al., 2010). The value for aviation is the sum of the positive impact from contrails and the negative impact from sulfate. In 2100 we find forcings of $-0.7,-18.1$ and $209 \mathrm{~mW} \mathrm{~m}^{-2}$ for road transport, shipping and aviation, respectively. The strong decrease in the $\mathrm{SO}_{2}$ emissions of shipping in the last $50 \mathrm{yr}$ of the $21 \mathrm{st}$ century leads to this strongly reduced forcing in 2100 .

In Fig. 8 we show global maps of the net TOA radiative impact from $\mathrm{O}_{3}$ perturbations (rows $\mathrm{a}, \mathrm{b}$ and $\mathrm{c}$ ) and from aerosol and contrail perturbations (rows $\mathrm{d}$, e and $\mathrm{f}$ ). The $\mathrm{O}_{3}$ perturbations are more zonally homogeneous than the summed aerosol and contrail perturbations, and for aviation we see the strongest impact between 10 and $40^{\circ} \mathrm{N}$. When focussing on the aerosol and contrail impacts, we also see for road a negative impact caused by sulfate (due to underestimation of the $\mathrm{BC}$ impact). The impact is clearly stronger in the northern hemisphere (NH). For shipping, the strongest impact is over the $\mathrm{NH}$ oceans, and this perturbation is clearly greatest in the periods 1980-1999, 2011-2030 and 20462065 , in agreement with the time series of $\mathrm{SO}_{2}$ emissions. For aviation, the strongest positive impact is seen over the most frequently used aircraft routes in the NH. In regions of low air traffic however, we see some areas where the impact on TOA radiation is negative. This is clearest in the period 2046-2065 in the NH over the Arctic, and over the subtropical Atlantic and Pacific. As we do not find any of these signatures in simulations that included contrails only (not shown), we attribute the local negative forcing to sulfate. Sulfate has a clear signature in the Arctic (see the aviation sulfate distribution in Fig. 3c), is mainly confined to the $\mathrm{NH}$ and peaks around the year 2050. As the lifetime of contrails and $\mathrm{SO}_{2}$ /sulfate are different, one can have different distributions for their radiative forcing. Moreover the contrail and sulfate distributions result from two distinct CTMs, driven by different ECMWF analyses.

\subsection{Surface air temperature}

Figure 9a shows time series of the global annual mean of the surface air temperature for the three members of the 


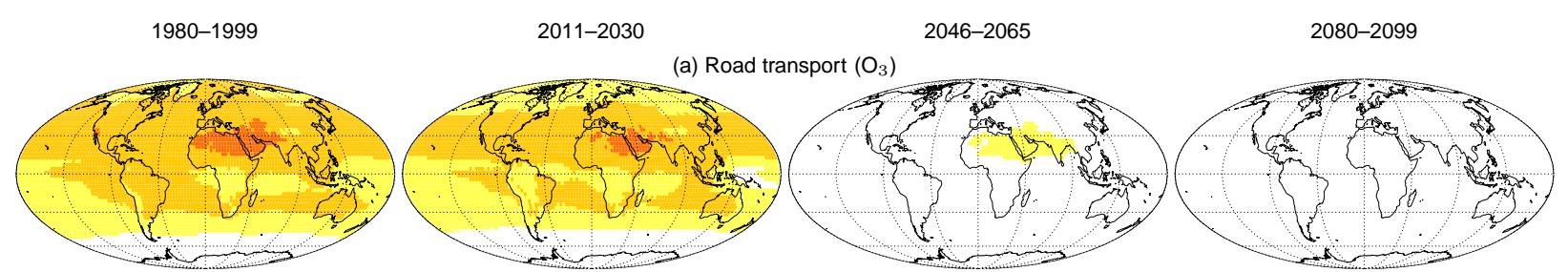

(b) Shipping $\left(\mathrm{O}_{3}\right)$
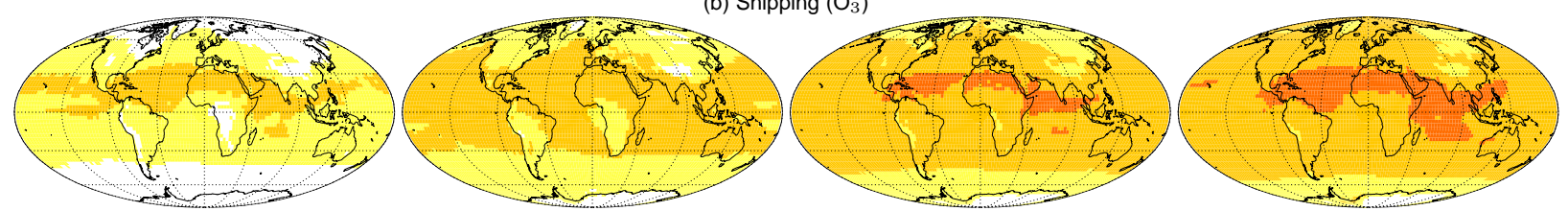

(c) Aviation $\left(\mathrm{O}_{3}\right)$
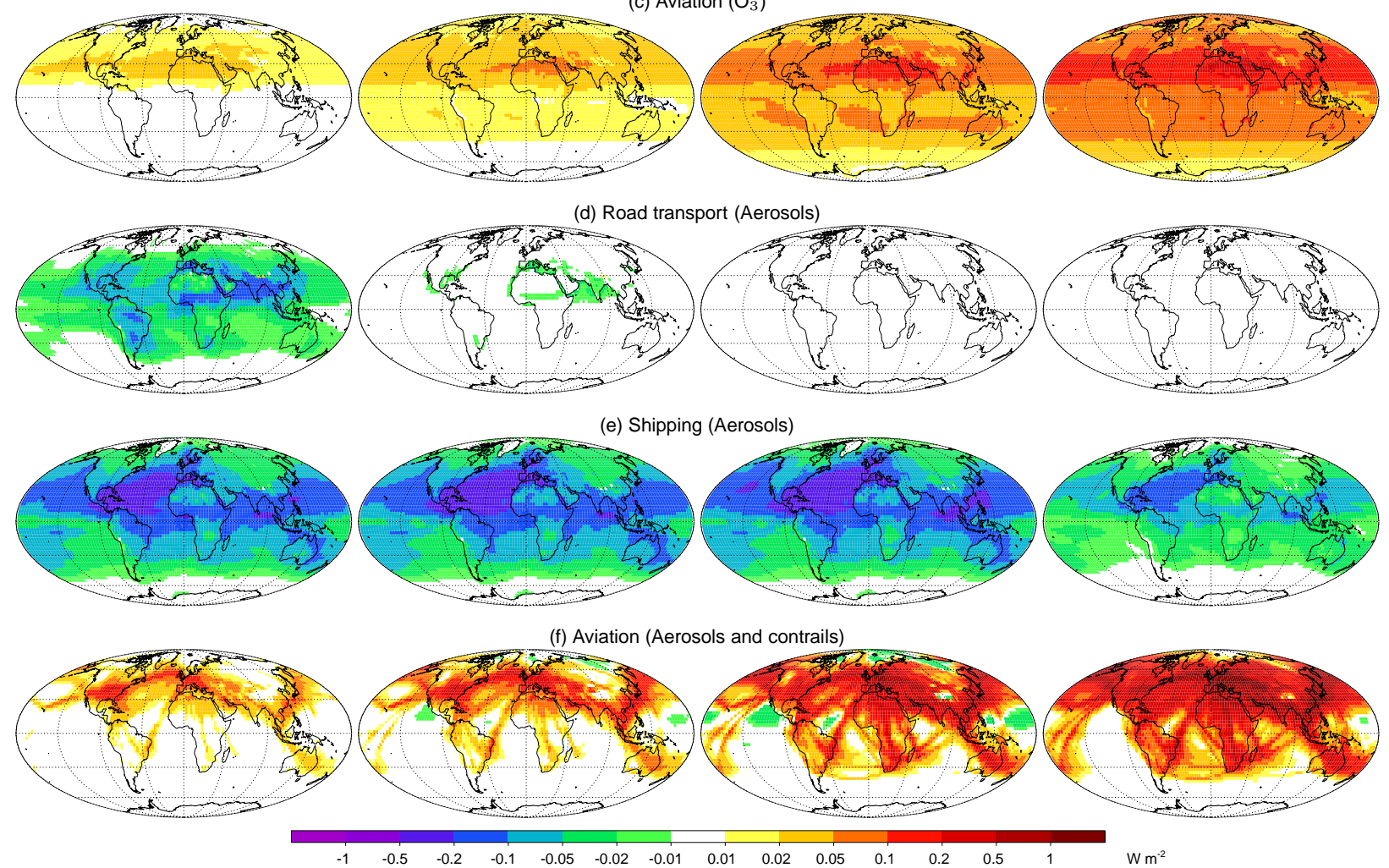

Fig. 8. Global maps of the annual mean impact on the net TOA forcing in the periods 1980-1999, 2011-2030, 2046-2065 and 2080-2099 by $\mathrm{O}_{3}$ perturbations from (a) road transport, (b) maritime shipping and (c) aviation, by aerosols from (d) road transport and (e) maritime shipping, and (f) by aerosols and contrails from aviation.

reference simulation. Around the year 2000, the temperature increase is around $0.8 \mathrm{~K}$ w.r.t. 1860 , increasing by almost $3.0 \mathrm{~K}$ in 2100 . One notices that the three members of the ensemble show a very similar behavior. Using the results from the pre-industrial and doubled $\mathrm{CO}_{2}$ simulation, we can determine the climate sensitivity using the method of Gregory et al. (2004) and find a value of around $0.8 \mathrm{~K}\left(\mathrm{~W} \mathrm{~m}^{-2}\right)^{-1}$, which corresponds with a $2.97 \mathrm{~K}$ temperature increase for a doubling of the $\mathrm{CO}_{2}$ concentration. This is well within the interval mentioned in IPCC (2007) of 2.1 to $4.4 \mathrm{~K}$ with a mean value of $3.2 \mathrm{~K}$.
Figure $9 \mathrm{~b}$ shows time series of the impact of the transport sectors on the evolution of the global annual mean of the surface air temperature. The thin black lines show the annual global mean impact for the individual members of the ensemble, and the thick colored lines show the 11-yr running mean, averaged over the 3 ensemble members. For $\mathrm{CO}_{2}$ the impact of road transport is strongest, showing a temperature increase of around $0.05 \mathrm{~K}$ in 2000 , reaching $0.3 \mathrm{~K}$ in 2100. For aviation and shipping, the temperature impact until 2050 is small, reaching $0.1 \mathrm{~K}$ in 2100 . The non- $\mathrm{CO}_{2} \mathrm{im}-$ pact from road is strongest between 2000 and 2050 (around 
(a) Temperature

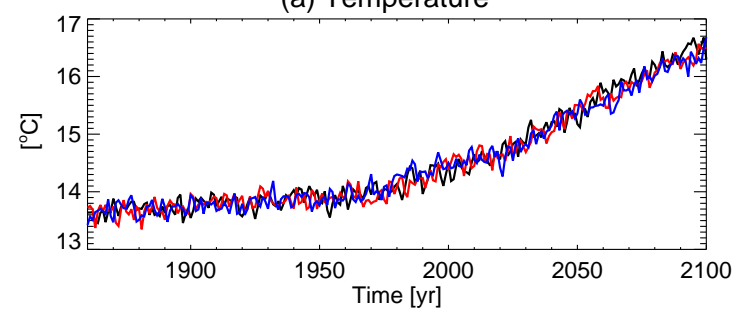

(c) Precipitation

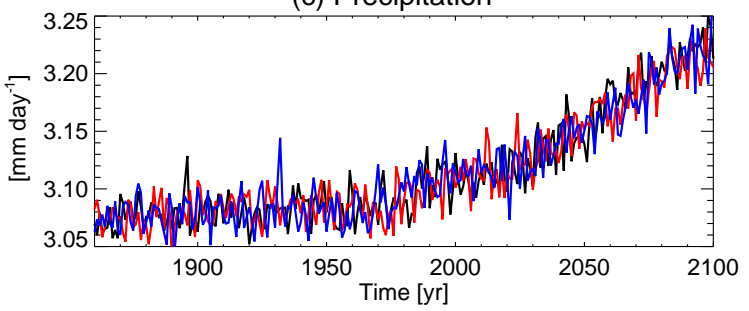

(e) Cloud cover

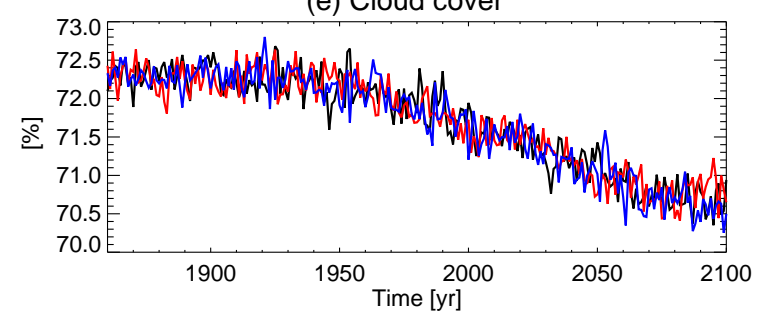

(b) Temperature

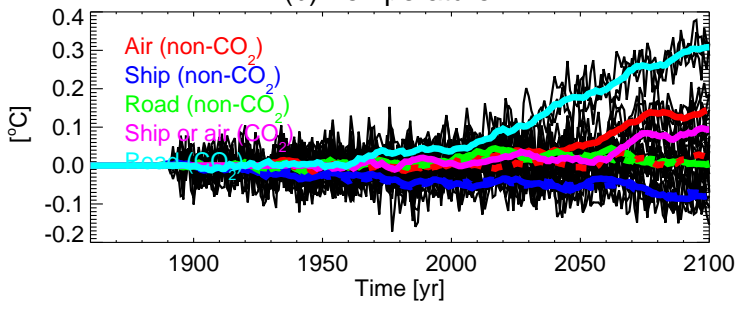

(d) Precipitation

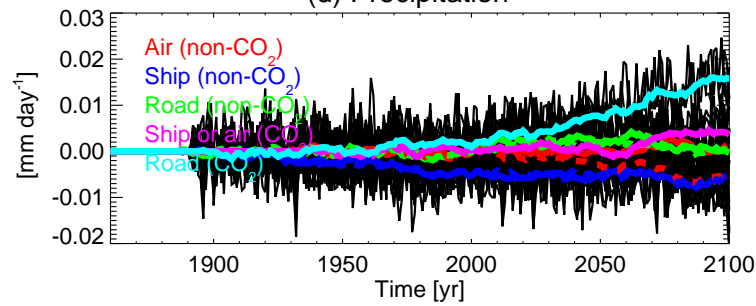

(f) Cloud cover

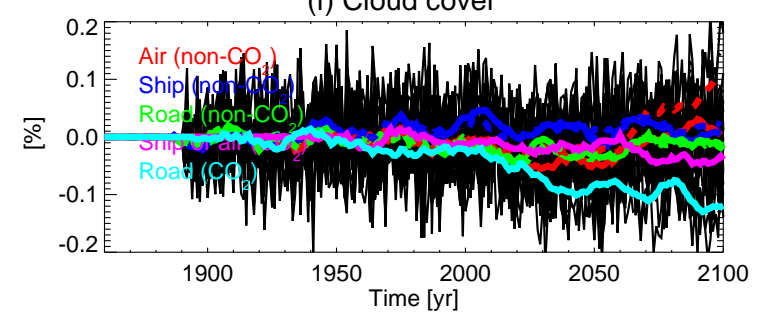

Fig. 9. Left: time series of annual global mean (a) surface air temperature, (c) precipitation, and (e) cloud cover over the period 1860-2100 taking into account the total anthropogenic forcing. The three different lines (black, red and blue) represent the three different members of the ensemble. Right: time series of impact on (b) surface air temperature, (d) precipitation, and (f) cloud cover by road transport, shipping and aviation, separately for their $\mathrm{CO}_{2}$, non- $\mathrm{CO}_{2}$ and non- $\mathrm{CO}_{2} *$ impact (the non- $\mathrm{CO}_{2} *$ impact is indicated by the dashed lines). The thin black lines indicate the individual impact from each of the three members of the simulation, and the thick lines indicate the 11-year running average of the ensemble mean.

$0.05 \mathrm{~K}$ ), and reduces thereafter. This is mainly caused by a strong reduction in the road transport emissions of $\mathrm{NO}_{\mathrm{x}}$ in the second half of the 21 st century and of the earlier reductions in the emission of CFC-12 and HFC-134a. Taking into account a stronger impact of $\mathrm{BC}$ would probably strengthen this behaviour. The non- $\mathrm{CO}_{2}$ emissions from shipping show a negative impact on the temperature of around -0.05 to $-0.1 \mathrm{~K}$ over the period $2000-2100$. This is caused by significant $\mathrm{SO}_{2}$ emissions leading to the formation of sulfate aerosols, together with a strong impact of $\mathrm{OH}$ on $\mathrm{CH}_{4}$ by, on the one hand, significant $\mathrm{NO}_{\mathrm{x}}$ emissions, and on the other hand, a characteristic strong impact of $\mathrm{NO}_{\mathrm{x}}$ shipping emissions on the $\mathrm{CH}_{4}$ lifetime (Hoor et al., 2009). For the non$\mathrm{CO}_{2}$ impact from aviation we see a strong difference between the non- $\mathrm{CO}_{2}$ and non- $\mathrm{CO}_{2} *$ approaches, caused by the rather different $\mathrm{O}_{3}$ perturbations (see Fig. 6). The non$\mathrm{CO}_{2}$ approach shows a positive impact reaching $0.15 \mathrm{~K}$ in 2100. This is caused by the strong increase in the $\mathrm{NO}_{\mathrm{x}}$ aviation emissions that are more than 2.5 times more efficient than the other transport emissions at producing $\mathrm{O}_{3}$ (see Hoor et al., 2009), and by the impact from the linear contrails and aviation-induced cirrus. However, in the extended linear $\mathrm{O}_{3}$ scheme the $\mathrm{O}_{3}$ production in the upper troposphere seems to be overestimated (see Sect. 3.1). Using the non- $\mathrm{CO}_{2} *$ approach leads to almost no temperature signal, except for a very small increase in the last part of the 21 st century. Both approaches probably are affected by the too strong negative forcing from sulfate aerosols (see Sect. 2.2.6). Taking this into consideration together with the fact that the model is not very sensitive to $\mathrm{O}_{3}$ perturbations (see Sect. 2.2.4), we assume that the actual impact from aviation will be somewhere in between the results for both approaches.

Sausen and Schumann (2000) made projections of the impact of aviation on the global mean surface air temperature. They included the impact from $\mathrm{CO}_{2}$ and $\mathrm{O}_{3}$ changes due to $\mathrm{NO}_{\mathrm{x}}$ emissions but not the impact from the reduction in the $\mathrm{CH}_{4}$ lifetime or the impact from contrails or aviationinduced cirrus. One should also note that the climate sensitivity of their SCM was rather low, i.e. $0.61 \mathrm{~K}\left(\mathrm{~W} \mathrm{~m}^{-2}\right)^{-1}$. They found a temperature increase of $0.006 \mathrm{~K}$ in 2000 , and for their scenarios Fa1, Eab and Eah, respectively 0.025, 0.033 and $0.050 \mathrm{~K}$ in 2050 and $0.047,0.086$ and $0.146 \mathrm{~K}$ in 
2100. We find in 2100 a total impact from aviation of around $0.25 \mathrm{~K}$ for the non- $\mathrm{CO}_{2}$ approach and around $0.15 \mathrm{~K}$ using the non- $\mathrm{CO}_{2} *$ approach. Skeie et al. (2009) performed simulations with a more evolved SCM, using the SRES scenarios $\mathrm{A} 1 \mathrm{~B}, \mathrm{~A} 2, \mathrm{~B} 1$ and $\mathrm{B} 2$, and calculated the combined $\mathrm{CO}_{2}$ and non- $\mathrm{CO}_{2}$ impact on surface air temperature for the different sectors. With a climate sensitivity of $0.8 \mathrm{~K}\left(\mathrm{~W} \mathrm{~m}^{-2}\right)^{-1}$, they found for the A1B scenario, an annual global mean surface air temperature impact in 2100 of $0.38 \mathrm{~K}$ for road, $0.02 \mathrm{~K}$ for shipping, and $0.28 \mathrm{~K}$ for aviation, which is in rather good agreement with our results. They used similar emission scenarios, however they took into account more forcings (stratospheric water vapour feedback, methane ozone feedback, ...). Berntsen and Fuglestvedt (2008) did a similar study but only looked at the present-day impact.

We now focus on the geographical distribution of the surface air temperature impact. In Fig. 10 we present the annual mean changes averaged over the periods 1980-1999, 2011-2030, 2046-2065 and 2080-2099 from the total anthropogenic impact (row a) and from the separate transport impacts (rows b-g). Note the difference in the contour intervals between the first row and the other rows. For the total anthropogenic impact, a clear signal can already be seen in 1980-1999, which increases gradually until 20802099. Continents show a considerably stronger impact than oceans, and the temperature over the Labrador Sea shows an even stronger negative temperature response in 2046-2065 and 2080-2099. In the Southern Ocean, we also find a weak warming. A strong impact is also noticeable poleward of $65^{\circ} \mathrm{N}$. These results compare well with results shown in IPCC (2007, Fig. 10.8).

For the road sector, we find a significant $\mathrm{CO}_{2}$ impact of $0.2 \mathrm{~K}$ over continents for 2011-2030, with some regions showing increases of more than $0.4 \mathrm{~K}$ in 2080-2099. Large similarities with the total anthropogenic impact exist, e.g. the stronger impact at high northern latitudes and the stronger impact over continents. For the $\mathrm{CO}_{2}$ impact from shipping and aviation, increases of $0.2 \mathrm{~K}$ over continents are seen in 2080-2099. The non- $\mathrm{CO}_{2}$ impact for road transport is slightly positive in 2011-2030 and 2046-2065, whereas that from shipping is clearly negative and rather constant over the 21st century, with some extremes over the continents and over the northern high latitude regions. Using the non$\mathrm{CO}_{2}$ approach, the impact from aviation is clearly positive by 2011-2030, and a steady increase is seen for the periods 2046-2065 and 2080-2099 especially in the NH. However, using the non- $\mathrm{CO}_{2} *$ approach, we observe a clearly positive signal over the NH mid-latitudes only in 2080-2099.

In order to investigate the latitudinal dependence of the impacts, we show the annual zonal-mean surface air temperature in Fig. 11a. Results are shown for the periods 19801999, 2011-2030, 2046-2065 and 2080-2099, and are the mean of the 3 members over the 20 -year periods. We also indicate the $95 \%$ confidence intervals with thin lines. The zonal mean temperature response to the total anthropogenic forcings shows a smaller impact at mid-latitudes $\left(50-60^{\circ} \mathrm{S}\right.$, $40-50^{\circ} \mathrm{N}$ ), but an amplification at the poles which is most pronounced in the Arctic. The confidence intervals are larger closer to the poles and smaller in the extra-tropics to midlatitudes. Figure $11 \mathrm{~b}-\mathrm{i}$ shows the $\mathrm{CO}_{2}$ and non- $\mathrm{CO}_{2}$ impacts of the transport sectors on the annual zonal mean surface air temperature. The $\mathrm{CO}_{2}$ impact from shipping and aviation only becomes clearly distinguishable in 2080-2099 (around $0.1 \mathrm{~K}$ in low and mid-latitudes), with a large amplification in the Arctic. The impact from road transport is stronger: at low latitudes, it is significant as from 2011-2030 (0.1 K), going up to $0.3 \mathrm{~K}$ in $2080-2099$, and shows also a strong amplification in the Arctic. In contrast, the non- $\mathrm{CO}_{2}$ impact from road in the tropics and at mid-latitudes is strongest in the periods 2011-2030 and 2046-2065 and has large confidence intervals in the Arctic and Antarctic. From shipping, the non- $\mathrm{CO}_{2}$ impact is negative everywhere (except at southern high latitudes for the period 2011-2030 when it is weakly positive), with similar values in 2011-2030 and 2046-2065 in the tropics and extra tropics, and larger ones at northern high latitudes. The strongest non- $\mathrm{CO}_{2}$ signal is from aviation with a very asymmetric response of up to $0.3 \mathrm{~K}$ in the region $20-60^{\circ} \mathrm{N}$ in 2100 . The non- $\mathrm{CO}_{2} *$ approach however shows a much weaker signal, clearly positive between 20 and $50^{\circ} \mathrm{N}$, but negative between 60 and $90^{\circ} \mathrm{N}$. This local negative impact is possibly a consequence of the over-estimated sulfate (see the aviation sulfate distribution in Fig. 3c) and underestimated $\mathrm{O}_{3}$ impacts.

To estimate the difference in geographical distribution of the impacts, we quantify the correlation between the patterns of climate change in the different periods shown in Fig. 10. For each impact in each period we calculate the correlation with the distribution that shows the strongest signal, i.e. the total anthropogenic impact in 2080-2099. Similar comparisons have been performed in IPCC (2007, Table 10.5), but using different measures (Watterson, 1996). Figure 12a shows these correlations for the surface air temperature distribution. One sees a strong correlation for the first 3 periods of the total anthropogenic impact, and for the $\mathrm{CO}_{2}$ impact from road transport. Further, we see a negative correlation with the non- $\mathrm{CO}_{2}$ impact from shipping. For the non- $\mathrm{CO}_{2}$ impact from road, we see a positive correlation, which, however, disappears in 2080-2099.

In the sensitivity simulations, we amplified the forcings by a factor of five to derive the impacts from the different transport sectors. Whether such an amplification of the forcing is justified is determined by whether the perturbations are still small enough for the system to be in a linear regime (see Fig. 4). For the strongest perturbation (i.e. where we model the $\mathrm{CO}_{2}$ impact from road) we can expect the strongest nonlinearity. In the year 2100, we find an increase in global mean surface air temperature of $0.3 \mathrm{~K}$ due to the $\mathrm{CO}_{2}$ emissions from road transport. This means that the actual temperature difference between the simulations is around $1.5 \mathrm{~K}$, which is large w.r.t. a total climate change of around $3 \mathrm{~K}$. To 


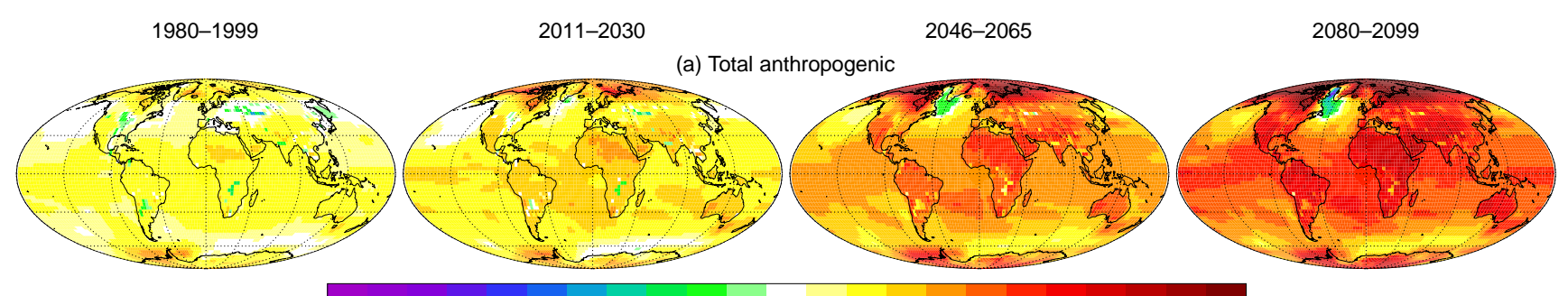

$\begin{array}{lllllllllllllllllllllll}-5 & -4.5 & -4 & -3.5 & -3 & -2.5 & -2 & -1.5 & -1 & -0.5 & -0.25 & 0.25 & 0.5 & 1 & 1.5 & 2 & 2.5 & 3 & 3.5 & 4 & 4.5 & 5 & \mathrm{k}\end{array}$

(b) Road transport $\left(\mathrm{CO}_{2}\right)$
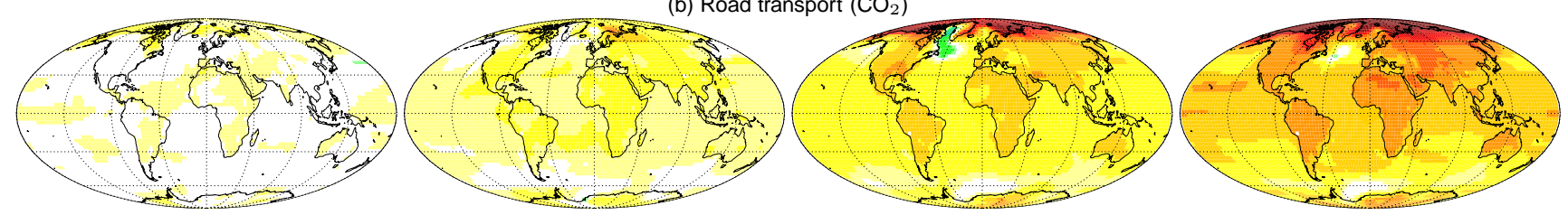

(c) Shipping or aviation $\left(\mathrm{CO}_{2}\right)$
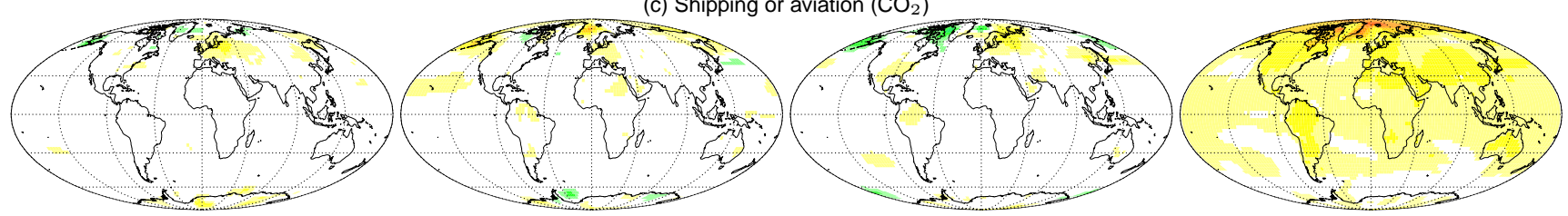

(d) Road transport (non- $\mathrm{CO}_{2}$ )
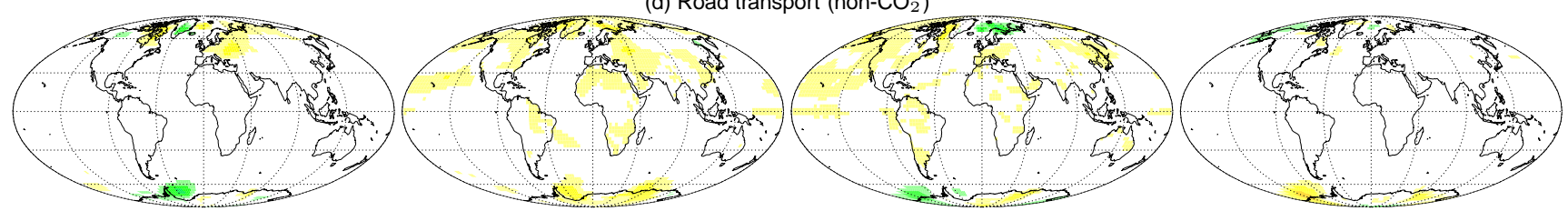

(e) Shipping (non- $\mathrm{CO}_{2}$ )
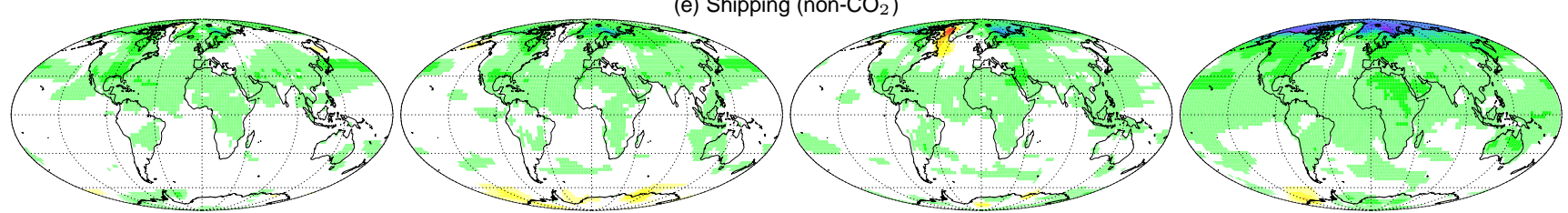

(f) Aviation (non- $\mathrm{CO}_{2}$ )
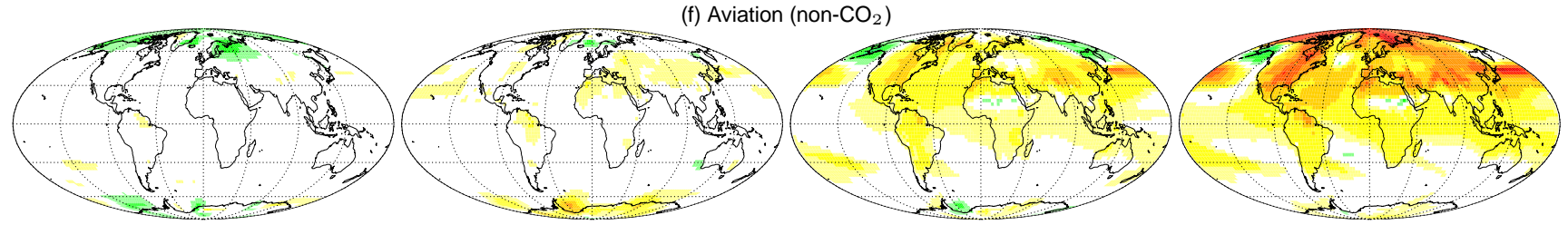

(g) Aviation (non- $\left.\mathrm{CO}_{2}{ }^{*}\right)$
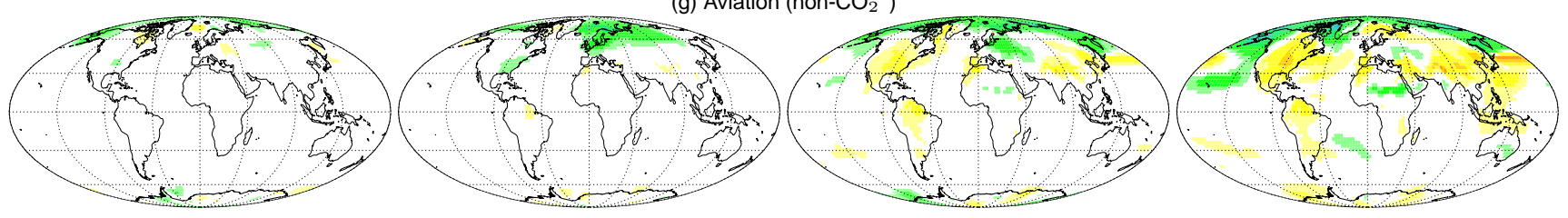

$\begin{array}{lllllllllllllllllllllll}-1 & -0.9 & -0.8 & -0.7 & -0.6 & -0.5 & -0.4 & -0.3 & -0.2 & -0.1 & -0.05 & 0.05 & 0.1 & 0.2 & 0.3 & 0.4 & 0.5 & 0.6 & 0.7 & 0.8 & 0.9 & 1\end{array}$

Fig. 10. Global maps of the annual mean surface air temperature impact in the periods 1980-1999, 2011-2030, 2046-2065 and 2080-2099 caused by (a) the total anthropogenic forcing, the $\mathrm{CO}_{2}$ forcing from (b) road transport and (c) shipping or aviation, by the non- $\mathrm{CO}_{2}$ forcing from (d) road transport, (e) shipping and (f) aviation where we use the dynamical $\mathrm{O}_{3}$ approach to take into account the effect of $\mathrm{O}_{3}$, and (g) by the non- $\mathrm{CO}_{2} *$ impact from aviation (using the fixed $\mathrm{O}_{3}$ approach). Notice that the contour intervals are 5 times larger for the total anthropogenic perturbation (a). 
(a) Total anthropogenic

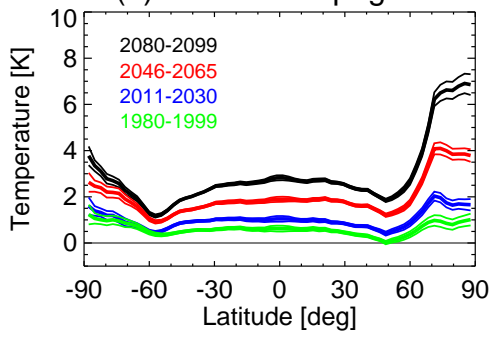

(b) Road $\left(\mathrm{CO}_{2}\right)$

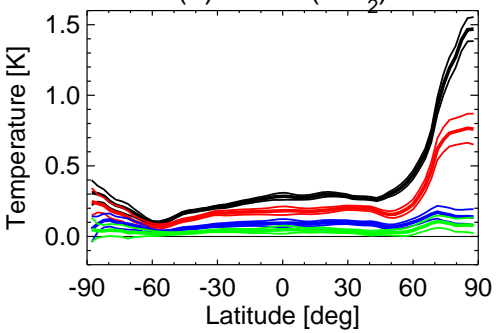

(c) Shipping or aviation $\left(\mathrm{CO}_{2}\right)$

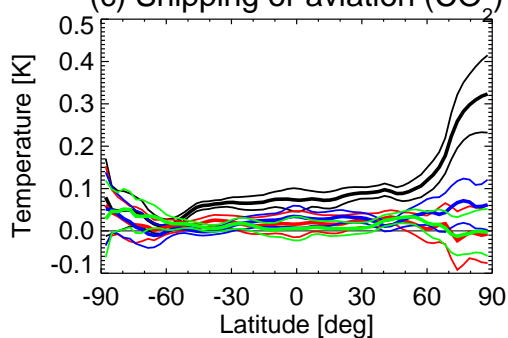

(d) Road (non- $\mathrm{CO}_{2}$ )

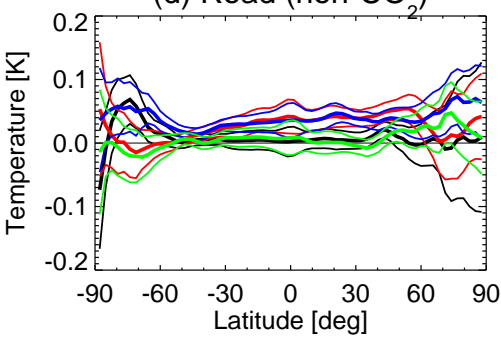

(e) Shipping (non- $\mathrm{CO}_{2}$ )

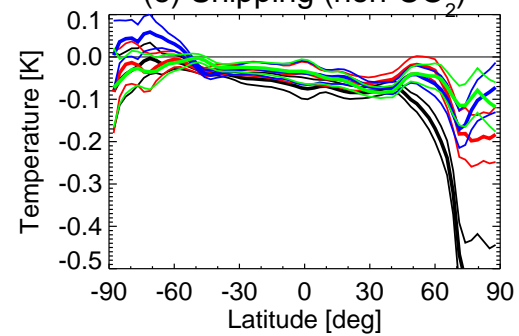

(f) Aviation (non- $\mathrm{CO}_{2}$ )

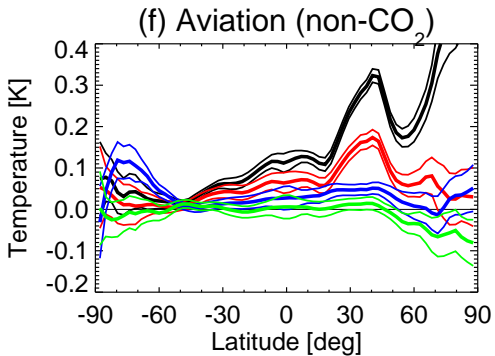

(g) Road (non- $\left.\mathrm{CO}_{2}{ }^{*}\right)$

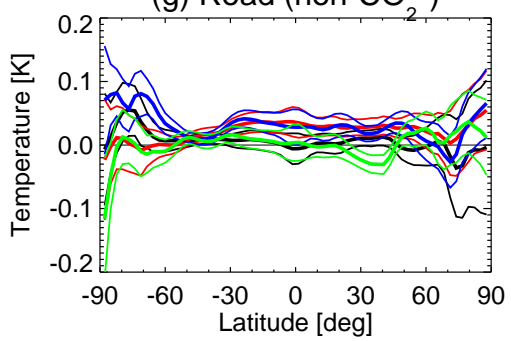

(h) Shipping (non- $\mathrm{CO}_{2}{ }^{*}$ )

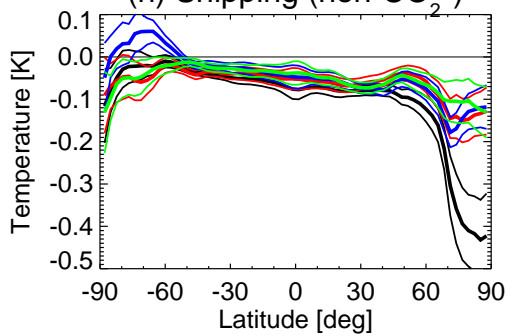

(i) Aviation (non- $\left.\mathrm{CO}_{2}^{*}\right)$

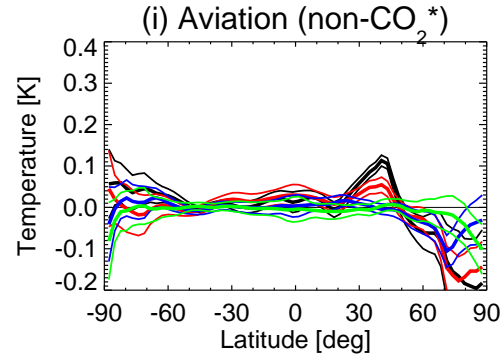

Fig. 11. Annual zonal mean surface air temperature impact in 1980-1999 (green), 2011-2030 (blue), 2046-2065 (red) and 2080-2099 (black): (a) total anthropogenic impact, $\mathrm{CO}_{2}$ impact from (b) road transport and (c) shipping or aviation, non- $\mathrm{CO}_{2}$ impact using the dynamical $\mathrm{O}_{3}$ approach for (d) road transport, (e) shipping and (f) aviation, and non- $\mathrm{CO}_{2} *$ impact using fixed $\mathrm{O}_{3}$ approach for (g) road transport, (h) shipping and (i) aviation. Thick lines are the mean over the 3 members and thin lines indicate the $95 \%$ confidence interval.

(a) Temperature

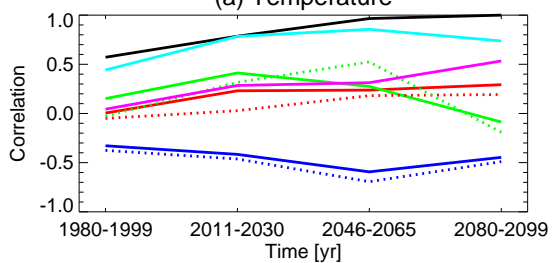

(d) Temperature

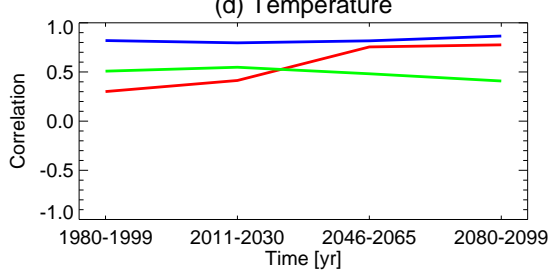

(b) Cloud cover

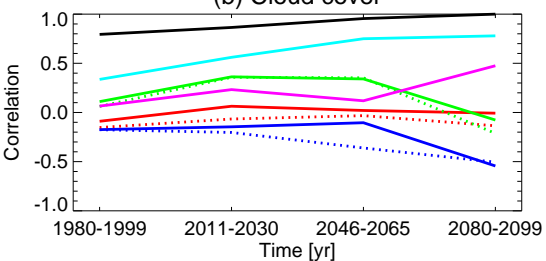

(e) Cloud cover

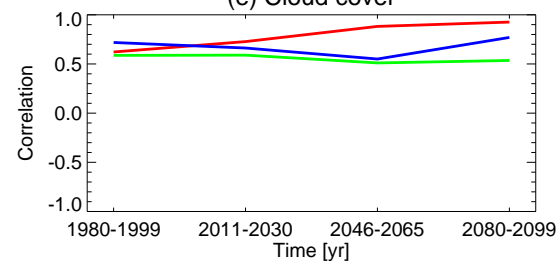

(c) Precipitation

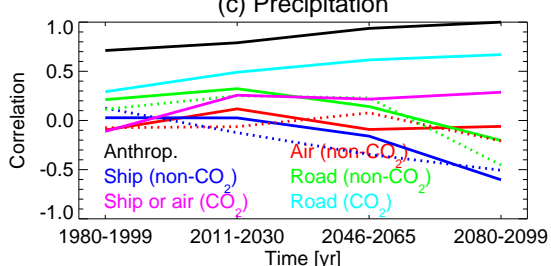

(f) Precipitation

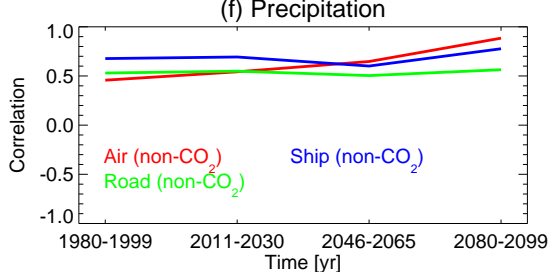

Fig. 12. First row: correlation between the impact on the geographical distributions of annual mean (a) surface air temperature, (b) cloud cover and (c) precipitation from a perturbation in a certain period with the total anthropogenic impact of the period 2080-2099. The dotted lines show the result for the fixed $\mathrm{O}_{3}$ approach. Second row: correlation between the two different non- $\mathrm{CO}_{2}$ approaches (fixed $\mathrm{O}_{3}$ versus dynamical $\mathrm{O}_{3}$ approach) for (d) surface air temperature, (e) cloud cover and (f) precipitation. 


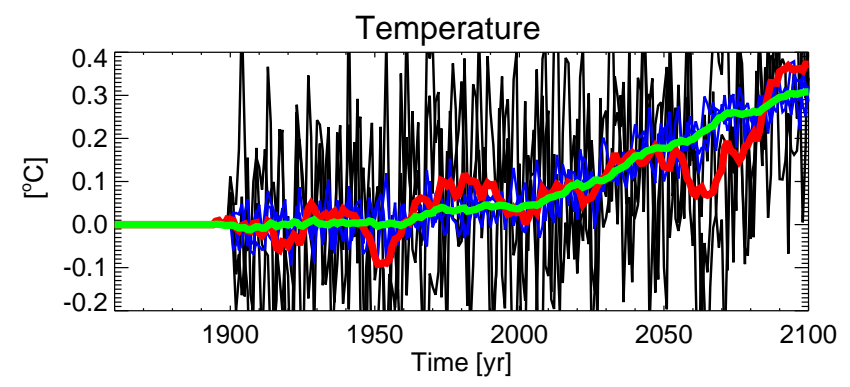

Fig. 13. Time series of the annual global mean surface air temperature over the period 1860-2100: black (scaling 1), red (scaling 1, 11-yr running average), blue (scaling 5), and green (scaling 5, 11-yr running average).

obtain the $\mathrm{CO}_{2}$ impact from road transport, we thus compare a simulation containing 5 times the $\mathrm{CO}_{2}$ emissions from road transport (red line in Fig. 4) with a simulation with no $\mathrm{CO}_{2}$ emissions from road transport (blue line). The $\mathrm{CO}_{2}$ impact from road transport can also be analyzed using the difference between the reference simulation (black line) and the simulation with no $\mathrm{CO}_{2}$ emissions from road (blue line). Figure 13 shows the evolution of the annual global mean surface air temperature for both approaches. The approach without amplification of the forcing gives a much noisier result, with a high inter-annual variability, while the approach with a 5 times stronger forcing shows a much more stable signal and a suppressed variability, but on average both approaches coincide. Figure 14 shows the impact on the zonal mean surface air temperature from both approaches for the periods 1980-1999, 2011-2030, 2046-2065 and 2080-2099. There, one sees that both approaches agree in the tropics up to the mid-latitudes rather well, but that at high latitudes the differences are larger. The $95 \%$ confidence interval is considerably smaller for the simulations where we apply 5 times the actual forcing.

\subsection{Atmospheric temperature profile}

Figure 15a shows the total anthropogenic impact on the annual zonal mean temperature profile for the periods 1980 1999, 2011-2030, 2046-2065 and 2080-2099 w.r.t. the preindustrial simulation. Strongest values appear in the lowlatitude mid- and upper-troposphere, up to $1,1.5,3.5$ and $5 \mathrm{~K}$ for the respective 4 periods, which correspond well with those in IPCC (2007, Fig. 10.7). The impact at the surface is smaller and shows more variability. Figure $15 \mathrm{~b}-\mathrm{c}$ shows the impact on the annual zonal mean temperature profile by $\mathrm{CO}_{2}$ from road transport and maritime shipping or aviation. The $\mathrm{CO}_{2}$ impact from road transport is much stronger than that from shipping or aviation. In the mid- to upper-troposphere it varies around $0.05,0.15,0.35$ and $0.5 \mathrm{~K}$ in $1980-1999$, 2011-2030, 2046-2065 and 2080-2099, respectively. For shipping and aviation, there is no clear signal in 1980-1999,
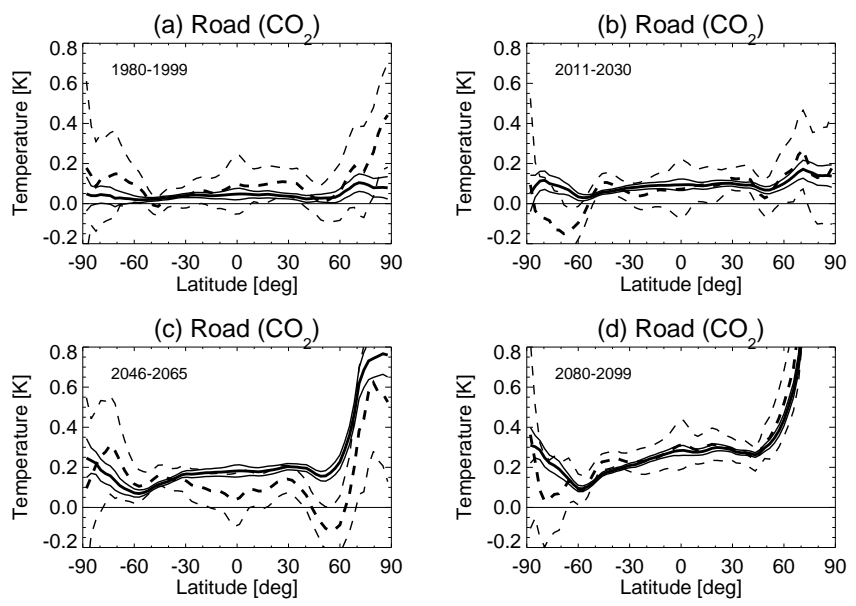

Fig. 14. Annual zonal mean surface air temperature impact from road transport for the periods (a) 1980-1999, (b) 2011-2030, (c) 2046-2065 and (d) 2080-2099 using scaling 1 (dashed lines) and scaling 5 (full lines). The thin lines indicate the $95 \%$ confidence interval.

2011-2030 and 2046-2065 (although an indication of a lowlatitude mid- to upper-troposphere temperature increase appears). In 2080-2099 this impact goes up to $0.15 \mathrm{~K}$ in the tropical upper troposphere.

The non- $\mathrm{CO}_{2}$ impacts for the transport sectors are shown in Fig. $15 \mathrm{~d}-\mathrm{g}$, with both non- $\mathrm{CO}_{2}$ and non- $\mathrm{CO}_{2} *$ approaches shown for aviation. We observe a positive signal in 20112030 and 2045-2065 for road transport, and a smaller impact at the end of the 21 st century. For maritime shipping, there is a distinctive negative impact over the whole depth of the troposphere which is strongest in 2080-2099. The non- $\mathrm{CO}_{2}$ impact from aviation is clearly positive in the troposphere, and in contrast with that from road transport and maritime shipping, it is very asymmetric being much stronger in the $\mathrm{NH}$ with a maximum around $300 \mathrm{hPa}$ at $30-60^{\circ} \mathrm{N}$. Here, the temperature increases by more than $0.5 \mathrm{~K}$ in 2100 . Using the non- $\mathrm{CO}_{2} *$ approach the general pattern is similar, although the heating is weaker and one observes a strengthened cooling around $200 \mathrm{hPa}$ between 50 and $80^{\circ} \mathrm{N}$. Moreover, a negative signal appears at the surface between 60 and $90^{\circ} \mathrm{N}$. Using an AGCM coupled to a slab ocean model and the emission scenario $\mathrm{Fa}$, Ponater et al. (2005) found a maximum zonal mean temperature impact from aviation for the year 2050 of $0.35 \mathrm{~K}$ around $40-50^{\circ} \mathrm{N}$ at $300-400 \mathrm{hPa}$.

\subsection{Precipitation and cloud cover}

Time series of cloud cover and precipitation can be found in Fig. 9c-f. Taking into account the total anthropogenic impact, the precipitation rises by $0.2 \mathrm{~mm} \mathrm{day}^{-1}$ in 2100 , while the cloud cover decreases by $1.8 \%$, coinciding with the increase in global mean surface air temperature. A similar relationship is seen for individual transport sectors, although 

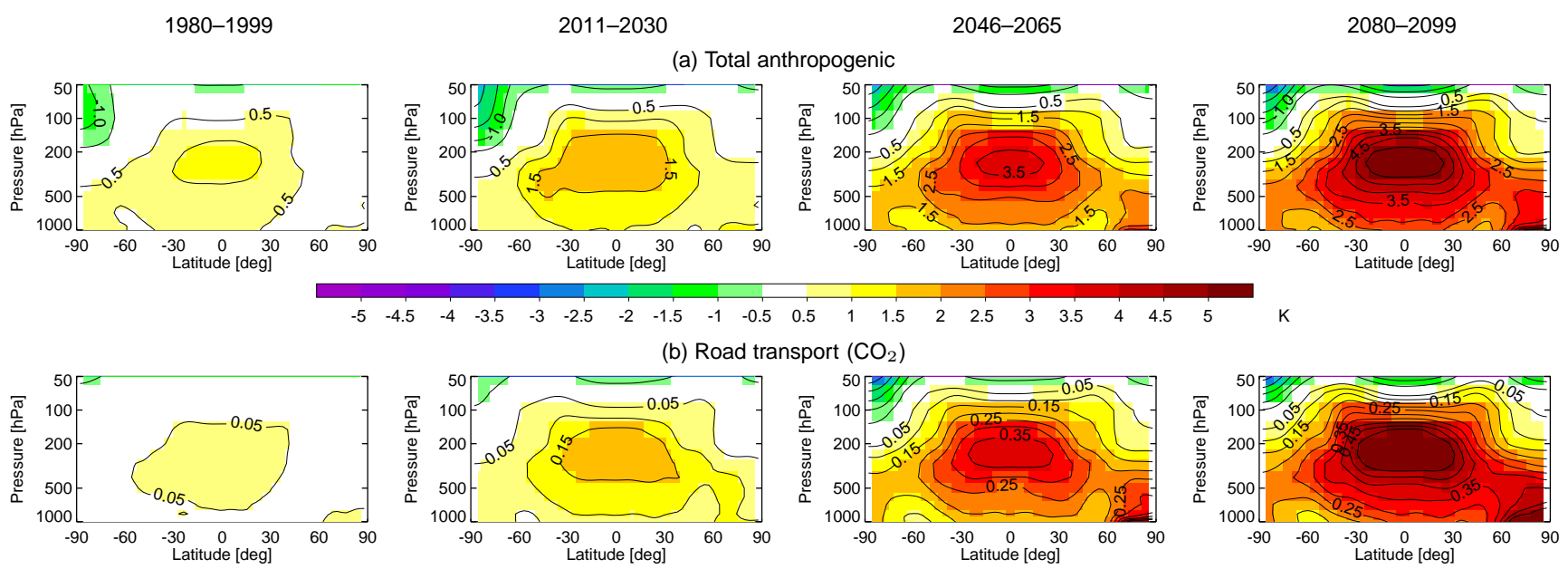

(c) Shipping or aviation $\left(\mathrm{CO}_{2}\right)$
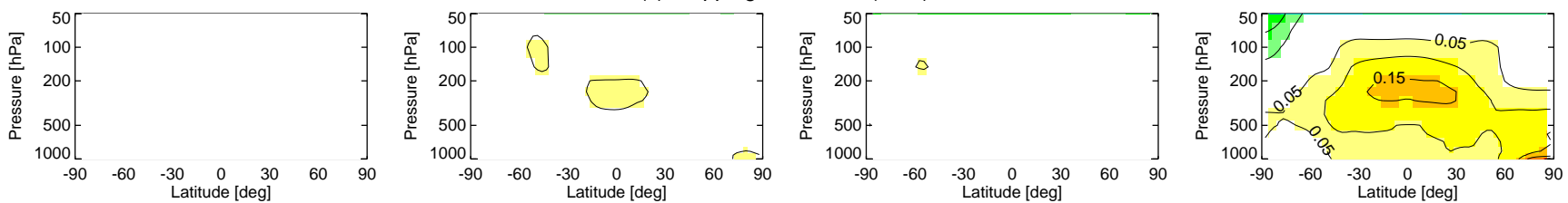

(d) Road transport (non- $\left.\mathrm{CO}_{2}\right)$
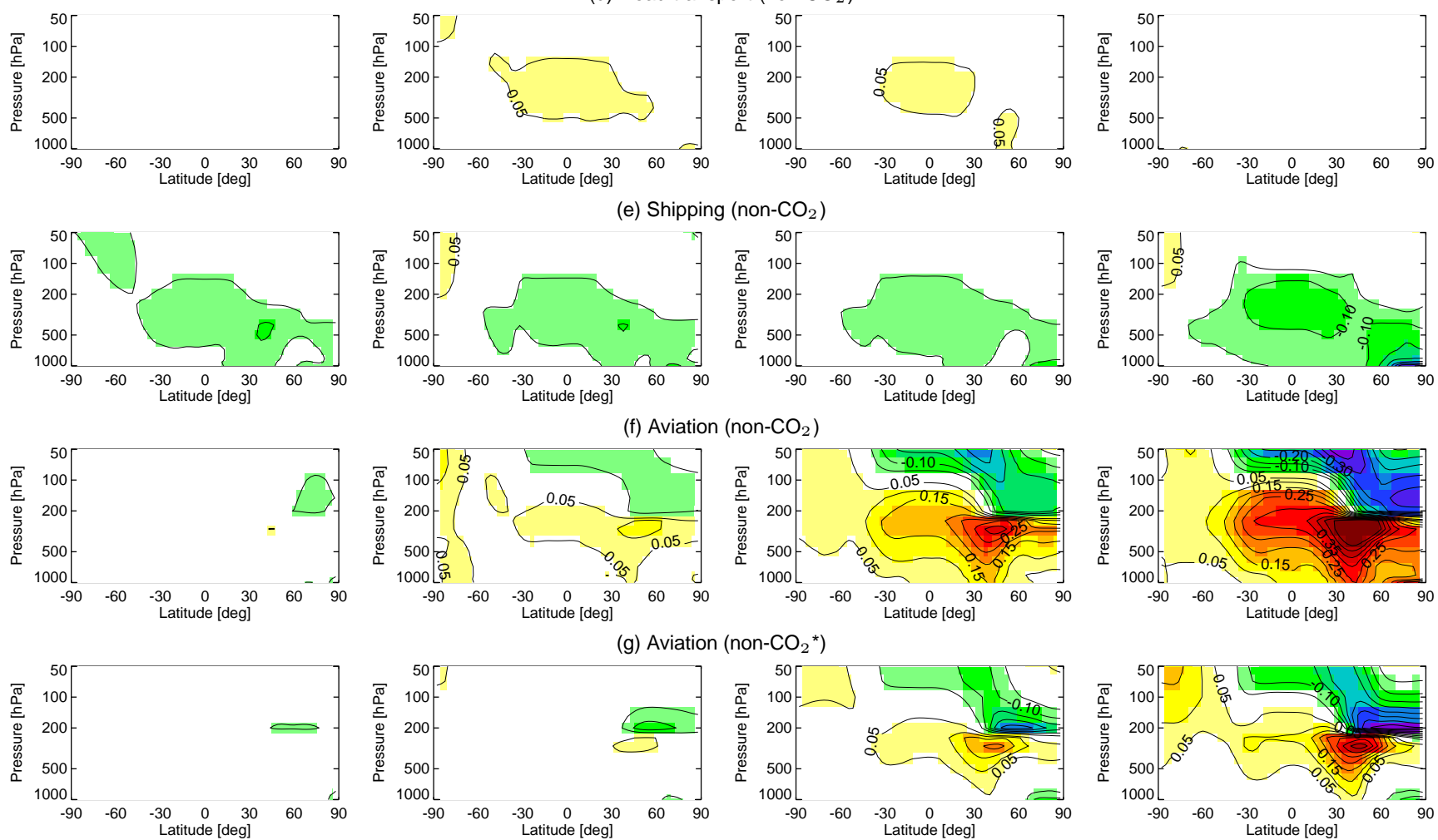

$\begin{array}{llllllllllllllllllll}-0.5 & -0.45 & -0.4 & -0.35 & -0.3 & -0.25 & -0.2 & -0.15 & -0.1 & -0.05 & 0.05 & 0.1 & 0.15 & 0.2 & 0.25 & 0.3 & 0.35 & 0.4 & 0.45 & 0.5\end{array}$

Fig. 15. Impact on annual zonal mean temperature profile in the periods 1980-1999, 2011-2030, 2046-2065 and 2080-2099. The order of the plots is as in Fig. 10. Notice that the contour intervals are 5 times larger for the total anthropogenic perturbation (a). 

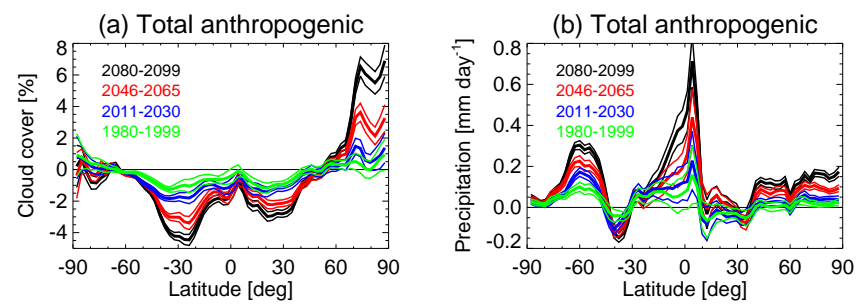

Fig. 16. Zonal annual mean (a) cloud cover and (b) precipitation change in 1980-1999 (green), 2011-2030 (blue), 2046-2065 (red) and 2080-2099 (black) from total anthropogenic forcing. The thick lines indicate the best estimate, the thin lines indicate the $95 \%$ confidence interval.

for cloud cover the evolution is rather noisy. Largest impacts can be observed for $\mathrm{CO}_{2}$ from road transport, showing in 2100 a $0.015 \mathrm{~mm} \mathrm{day}^{-1}$ increase in precipitation and a $0.15 \%$ decrease in cloud cover. All other impacts are below $0.01 \mathrm{~mm} \mathrm{day}^{-1}$ for precipitation and $0.1 \%$ for cloud cover.

To get an idea of the zonal mean distributions, we show the total anthropogenic impact in Fig. 16. The cloud cover remains almost unaffected in the tropics, decreases considerably in the subtropics, and has a strong increase at northern high-latitudes. These characteristics correspond well with those of IPCC (2007, Fig. 10.10). There is generally less confidence in the changes in precipitation but increases in precipitation at high latitudes are very consistent among models, and can also be observed in Fig. 16b. Our model also shows a decrease in subtropical regions.

In Fig. 12b-c, we show the correlation between the patterns of precipitation or cloud cover with the total anthropogenic impact in 2080-2099 (as for the surface air temperature). The results are similar to those for surface air temperature but in general the correlations are weaker, e.g. the non$\mathrm{CO}_{2}$ impact from shipping shows a strong anti-correlation only for the period 2080-2099. The behavior of the non- $\mathrm{CO}_{2}$ impact from aviation is very different: there is no correlation neither for cloud cover nor for precipitation.

\subsection{North Atlantic Oscillation}

Figure 17a shows time series of the North Atlantic Oscillation (NAO) index over the period 1860-2100 taking into account the total anthropogenic impact. NAO anomalies represent the Lisbon $\left(38.7^{\circ} \mathrm{N}, 9.1^{\circ} \mathrm{W}\right)$ minus Reykjavik $\left(65.1^{\circ} \mathrm{N}, 22.7^{\circ} \mathrm{W}\right)$ normalized December-March average sea level pressure anomalies, with 1971-2000 as reference. One can observe a weak positive trend. Figure $17 \mathrm{~b}$ shows the mean impact over the period 2050-2099 from the different transport sectors on the $\mathrm{NAO}$ index. The $\mathrm{CO}_{2}$ impact is positive, road impact being around $20 \%$ of the total anthropogenic one, and shipping or aviation being $5 \%$. For the non- $\mathrm{CO}_{2}$ and non- $\mathrm{CO}_{2} *$ cases, we find small impacts for shipping and road transport, but a relatively strong one for aviation, both for the non- $\mathrm{CO}_{2}$ and non- $\mathrm{CO}_{2} *$ approaches. (a) NAO index

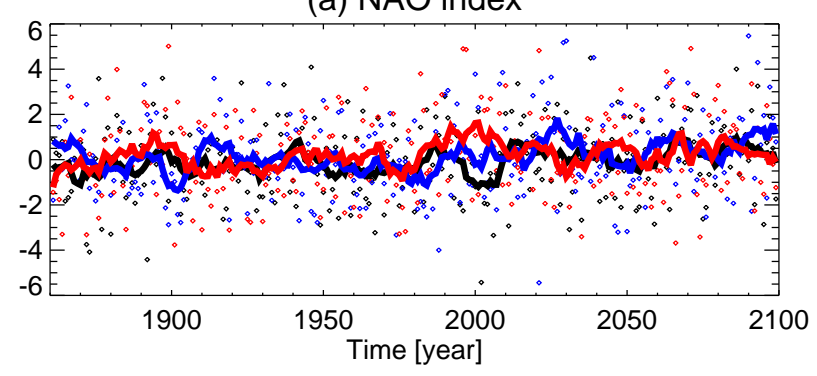

(b) NAO index change

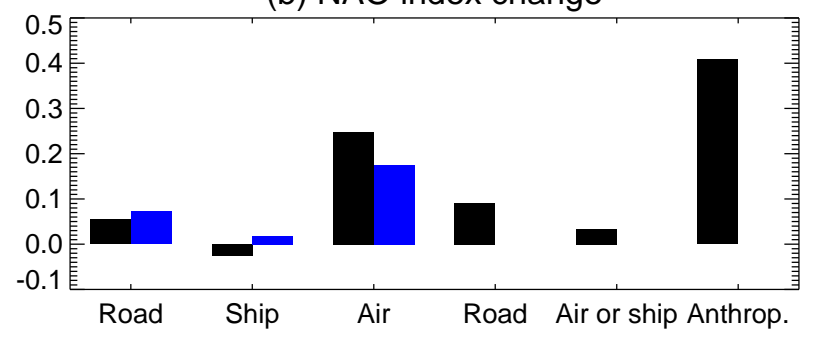

Fig. 17. (a) Mean NAO anomalies calculated from sea level pressures taking into account the total anthropogenic impact (the different colors indicate the 3 simulations of the ensemble). Single dots indicate yearly values, and lines show 11-yr running averages. (b) Impact of the transport sectors on the NAO anomaly averaged over 2050-2099. The first three bars show the non- $\mathrm{CO}_{2}$ (black) and non- $\mathrm{CO}_{2} *$ (blue) impacts, the following two the $\mathrm{CO}_{2}$ impacts, and the last one the total anthropogenic impact.

\section{Ocean}

In this section we describe the impact from the different transport sectors on ocean temperature, sea level, MOC, seaice extent and the Niño 3.4 index.

\subsection{Ocean temperature}

Figure 18 shows zonally averaged impacts on ocean temperature to a depth of $4000 \mathrm{~m}$ for the same periods as for the atmosphere, i.e. 1980-1999, 2011-2030, 2046-2065 and 2080-2099. Figure 18a shows the total anthropogenic impact. For all periods one observes a heating of the southern ocean, and the strongest impact can be seen in the southern mid-latitudes where the heating signal easily penetrates down to $3500-4000 \mathrm{~m}$. At low latitudes, one sees initially (1980-1999 and 2011-2030) a cooling of the waters between 300 and $2000 \mathrm{~m}$, probably caused by reduced mixing in response to more stable temperature profiles. Figure $18 \mathrm{~b}-\mathrm{g}$ shows the impacts from the transport perturbations: the $\mathrm{CO}_{2}$ impact from road transport is the most important, while the non- $\mathrm{CO}_{2}$ emissions from shipping have a cooling impact. The non- $\mathrm{CO}_{2}$ effects of aviation have their greatest impact in the $\mathrm{NH}$.

Figure 19 shows the zonally averaged increase in the heat content in the ocean integrated over the whole depth of 
1980-1999
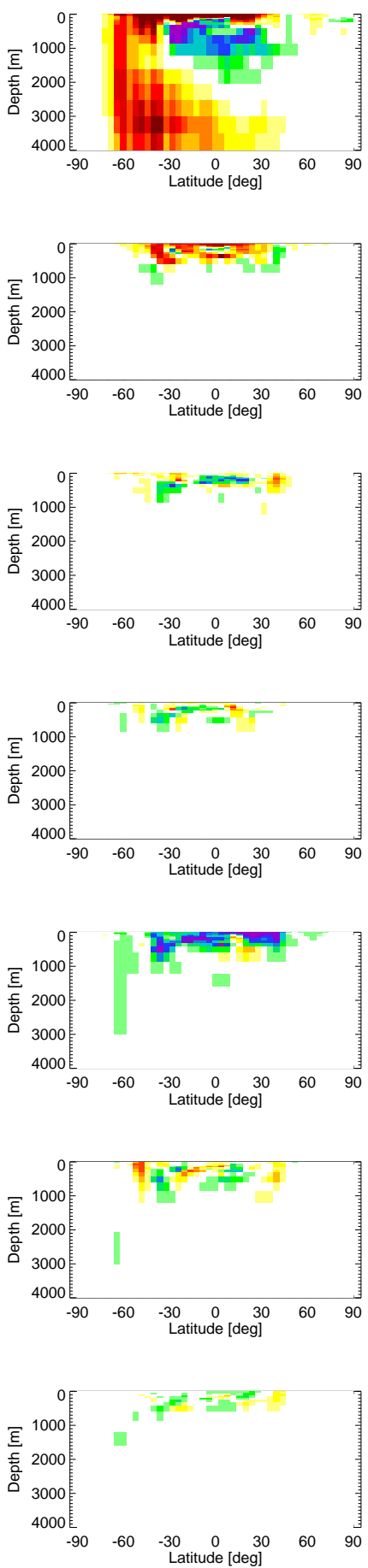

2011-2030
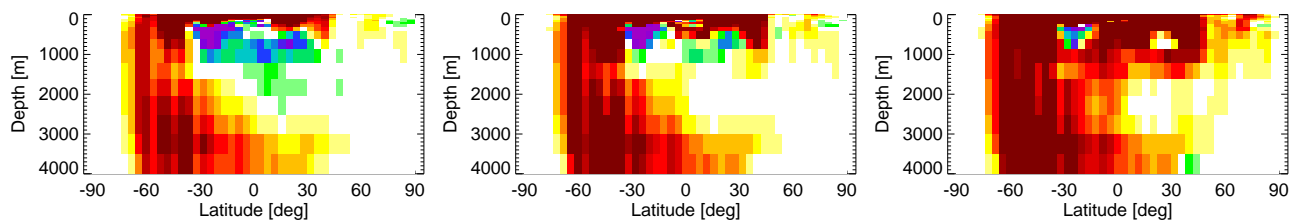

(b) Road transport $\left(\mathrm{CO}_{2}\right)$
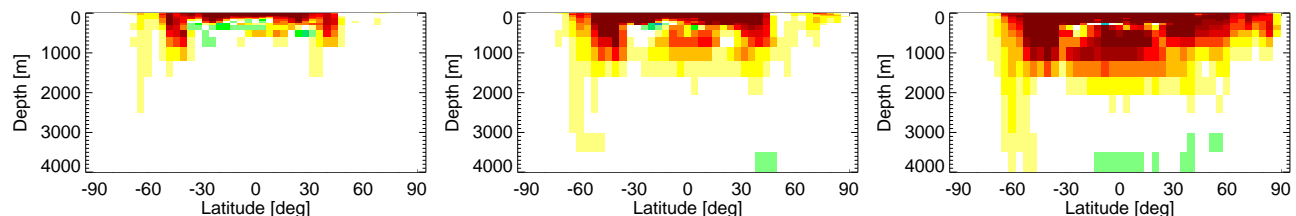

(c) Shipping or aviation $\left(\mathrm{CO}_{2}\right)$
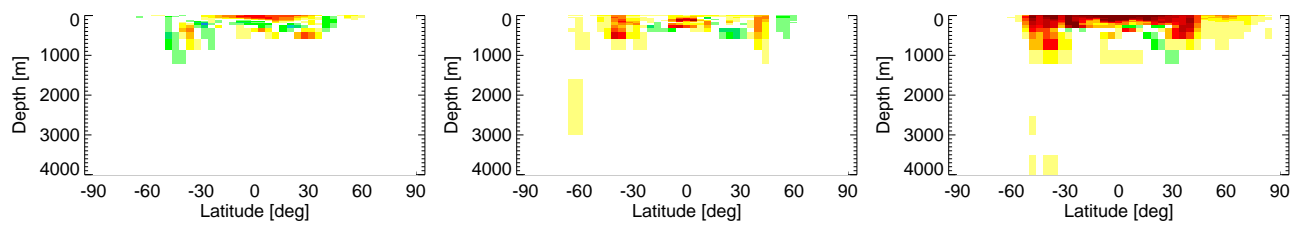

(d) Road transport (non- $\mathrm{CO}_{2}$ )
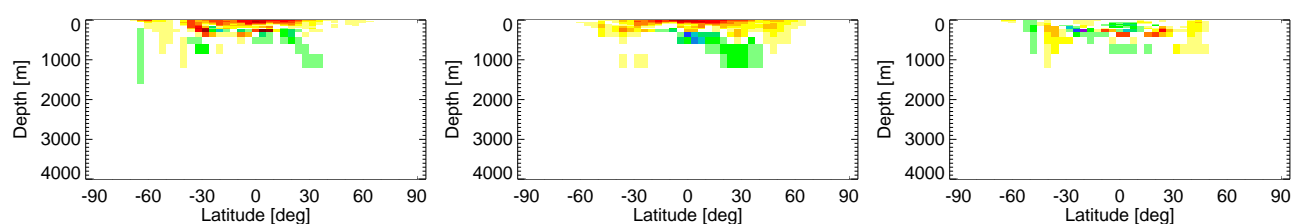

(e) Shipping (non- $\mathrm{CO}_{2}$ )
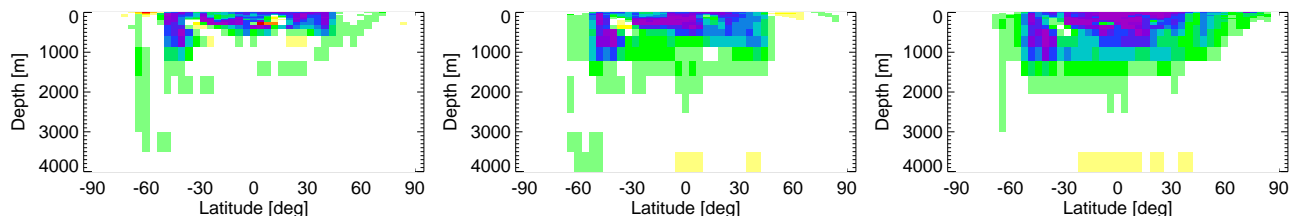

(f) Aviation (non- $\mathrm{CO}_{2}$ )
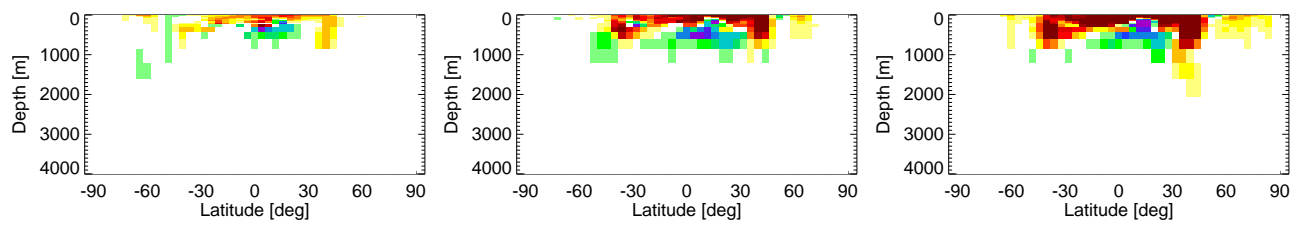

(g) Aviation (non- $\left.\mathrm{CO}_{2}{ }^{*}\right)$
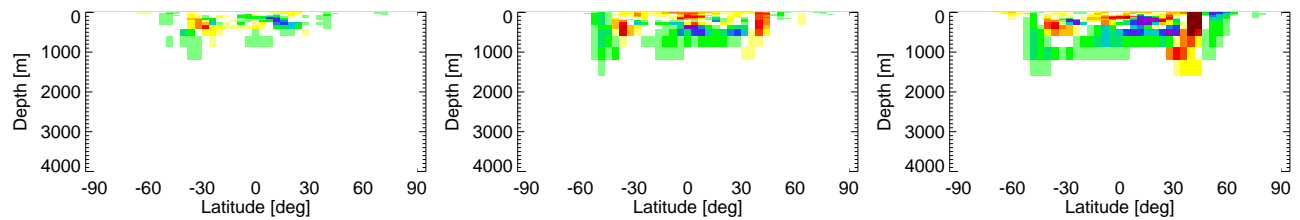

$\begin{array}{llllllllllllllllllllll}-1 & -0.9 & -0.8 & -0.7 & -0.6 & -0.5 & -0.4 & -0.3 & -0.2 & -0.1 & 0.1 & 0.2 & 0.3 & 0.4 & 0.5 & 0.6 & 0.7 & 0.8 & 0.9 & 1 & \mathrm{~K}\end{array}$

Fig. 18. Zonally averaged annual mean impact on the ocean temperature (in $\mathrm{K}$ ) for the four different reference periods. The order of the plots is as in Fig. 10. 


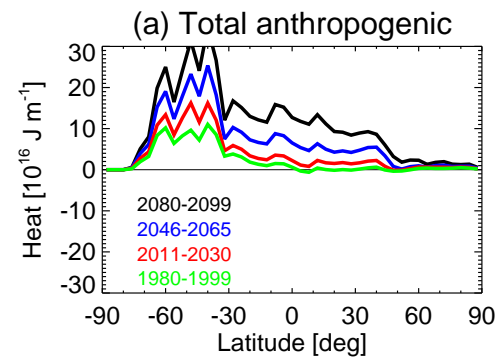

(b) Road $\left(\mathrm{CO}_{2}\right)$

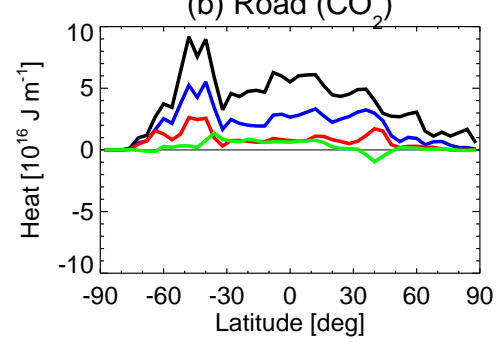

(c) Shipping or aviation $\left(\mathrm{CO}_{2}\right)$

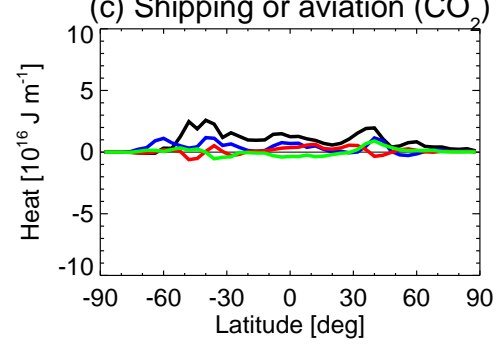

(d) Road (non- $\mathrm{CO}_{2}$ )

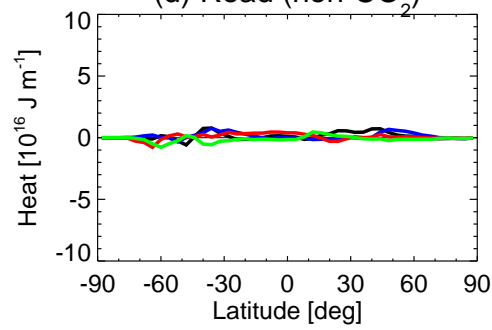

(e) Shipping (non- $\mathrm{CO}_{2}$ )
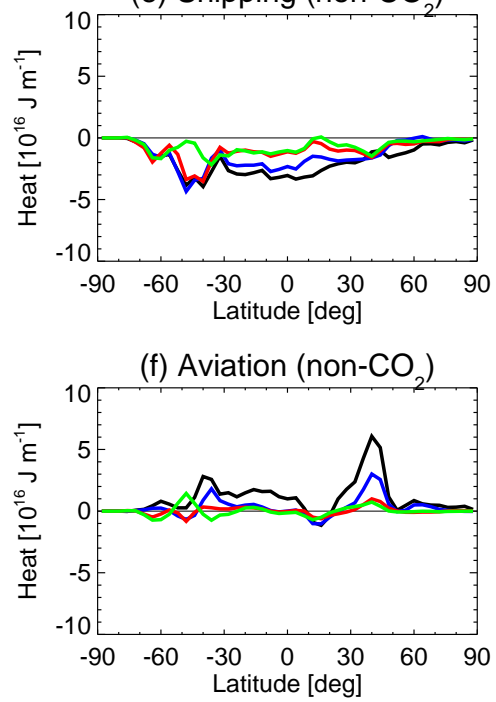

(g) Road (non-CO ${ }^{*}$ )

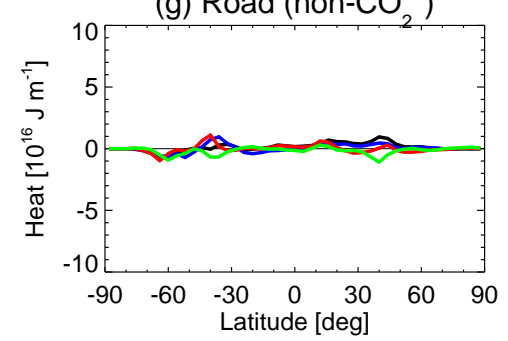

(h) Shipping (non- $\mathrm{CO}_{2}^{*}$ )
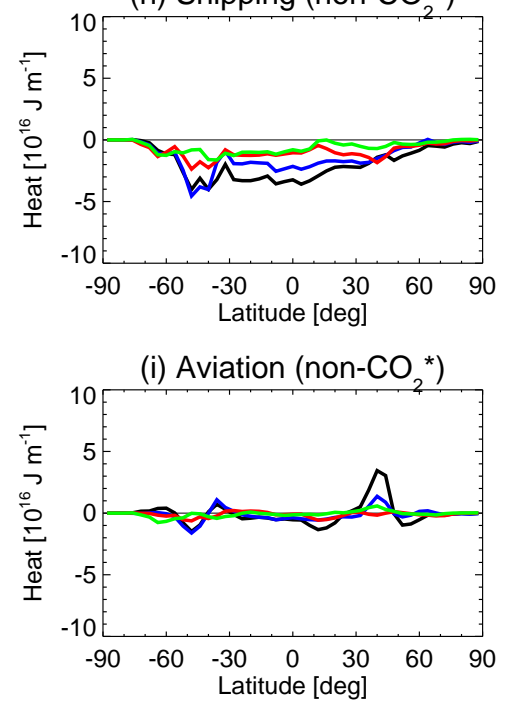

Fig. 19. Zonally integrated heat uptaken by the ocean (in $10^{16} \mathrm{~J} \mathrm{~m}^{-1}$ ) in 1980-1999 (green), 2011-2030 (blue), $2046-2065$ (red) and 2080-2099 (black). The order of the plots is as in Fig. 11.

the ocean (in $10^{16} \mathrm{~J} \mathrm{~m}^{-1}$ ). The total anthropogenic impact (Fig. 19a) shows two characteristic features: most of the heat is stored in the southern ocean, while almost no heat is stored north of $45^{\circ} \mathrm{N}$, and the increase is very regular over the 4 periods. The $\mathrm{CO}_{2}$ impacts from road transport, shipping or aviation present similar features. For the non- $\mathrm{CO}_{2}$ impact, we notice the small values for road transport, the negative impact for shipping, and the large heating between 25 and $50^{\circ} \mathrm{N}$ for aviation in the non- $\mathrm{CO}_{2}$ approach, larger than that of the non$\mathrm{CO}_{2} *$ approach concentrated between 30 and $50^{\circ} \mathrm{N}$.

Time series of the global mean ocean temperature can be seen in Fig. 20a-b. One notices that these time series are rather smooth and show less inter-annual variability than the time series of the surface air temperature (see Fig. 9a-b). The non- $\mathrm{CO}_{2}$ impact from shipping is negative, and prevails over the non- $\mathrm{CO}_{2}$ impact from aviation and the $\mathrm{CO}_{2}$ impact from shipping or aviation - a fact which is not clear for the surface air temperature evolution. Another interesting feature is the significant difference for shipping between the non- $\mathrm{CO}_{2}$ and non- $\mathrm{CO}_{2} *$ approaches in the second half of the 21 st century.

\subsection{Sea level}

Sea level rise in a changing climate results from thermal expansion of the oceans as well as from melting of glaciers, ice caps and the Greenland and Antarctic ice sheets. Figure $20 \mathrm{c}-\mathrm{d}$ shows the sea level rise (in $\mathrm{mm}$ ) that includes only the thermal expansion of the oceans calculated from the standard expression for the density as a function of pressure, temperature and salinity in Millero and Poisson (1981). The total anthropogenic induced rise in sea level is $30 \mathrm{~mm}$ in 2000 and increases to $180 \mathrm{~mm}$ in 2100 . The $\mathrm{CO}_{2}$ impact from road is around $18 \mathrm{~mm}$ in 2100 . The strongest non- $\mathrm{CO}_{2}$ impact results from shipping, causing a $3 \mathrm{~mm}$ decrease in 2000 and almost $8 \mathrm{~mm}$ in 2100 . The $\mathrm{CO}_{2}$ impact from shipping or aviation and the non- $\mathrm{CO}_{2}$ impact from aviation are similar, leading to a rise in sea level of around $4 \mathrm{~mm}$ in 2100 . The non- $\mathrm{CO}_{2} *$ approach for aviation shows almost no impact.

IPCC (2007) report a sea level rise due to thermal expansion of between 130 and $320 \mathrm{~mm}$ (anthropogenic impact in 2090-2099 relative to 1980-1999, scenario A1B), and between 210 and $480 \mathrm{~mm}$ for the total sea level rise. This indicates that thermal expansion contributes to more than $50 \%$ of the total rise in sea level, and shows that our results are at the low end of their range. 
(a) Ocean temperature

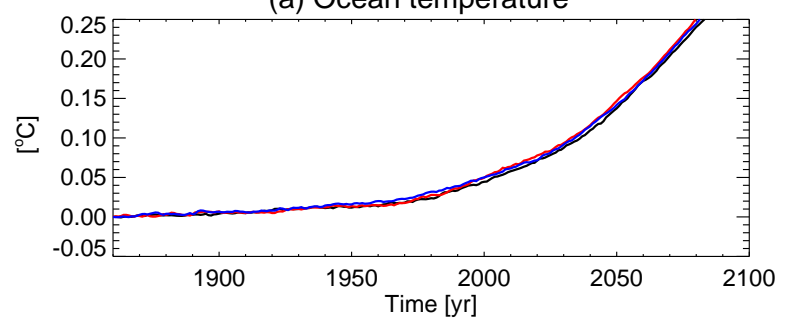

(c) Sea level

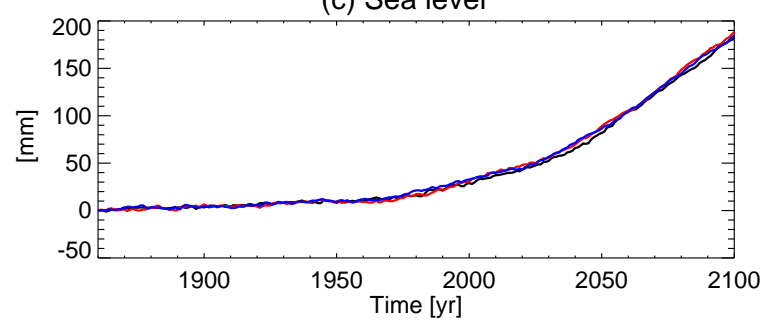

(e) MOC

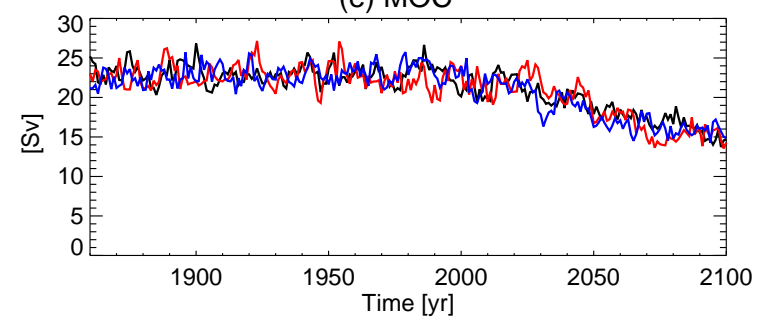

(b) Ocean temperature

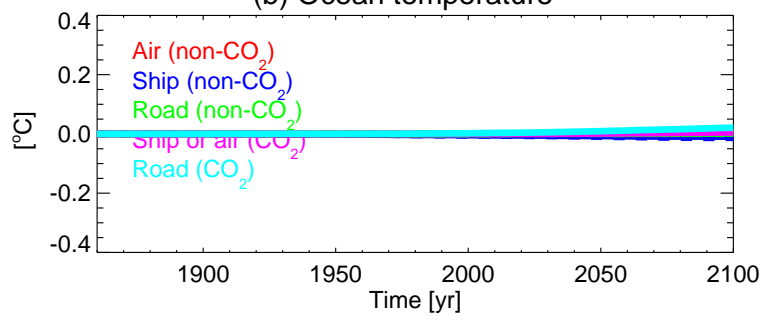

(d) Sea level

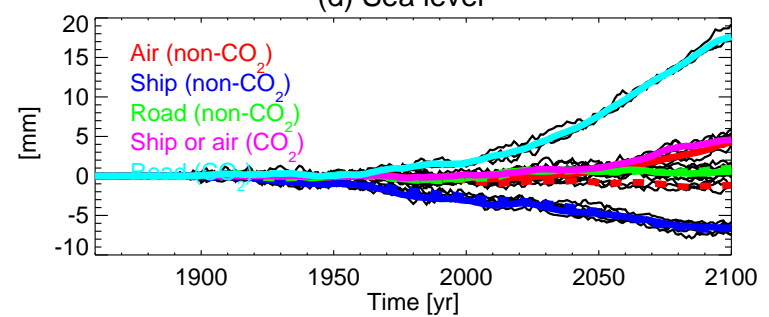

(f) $\mathrm{MOC}$

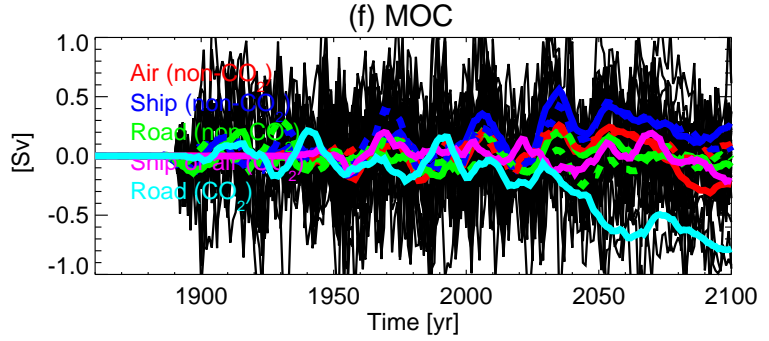

Fig. 20. Left: time series of total anthropogenic impact on (a) the ocean mean temperature, (c) sea level and (e) meridional overturning circulation. The three different lines (black, red and blue) represent the three different members of the ensemble. Right: the impact by road transport, shipping and aviation, separately for their $\mathrm{CO}_{2}$, non- $\mathrm{CO}_{2}$ and non- $\mathrm{CO}_{2} *$ impact (the non- $\mathrm{CO}_{2} *$ impact is indicated by the dashed lines) on (b) the ocean mean temperature, (d) sea level and (f) meridional overturning circulation. The thin black lines indicate the individual impact from each of the three members of the simulation, and the thick lines indicate the 11-yr running average of the ensemble mean.

Sausen and Schumann (2000) estimated the rise in sea level due to emissions from aviation. Their results were obtained using an SCM (see Sect. 3.3), whose calibration was based on an AOGCM that accounted for the rise in sea level due only to thermal expansion. They included the impact from melting ice-sheets by almost doubling the parameter responsible for the rise in sea level in the SCM. They found in 2100 increases in sea level by $6.5,11.2$ and $18.6 \mathrm{~mm}$ for their scenarios Fa1 (that best corresponds with our aviation emission scenario A1B), Eab and Eah, respectively, compared with our values of between 3.5 and $8.5 \mathrm{~mm}$ in 2100 due to thermal expansion only.

\subsection{Meridional overturning circulation}

Figure 20e shows the evolution of the MOC. It is calculated as the maximum of the depth integrated northward mass flux at $30^{\circ} \mathrm{N}$ in the Atlantic Ocean. As our ocean model grid is not regular in the $\mathrm{NH}$, the location of the integration varies slightly between around 33 and $27^{\circ} \mathrm{N}$. Compared with ocean temperature and sea level, there is a much stronger interannual variability. In our model, the MOC of the reference simulation between 1860 and 1970 varies mainly between 21 and 25 Sverdrup (Sv), values slightly higher than late 20th century observations. In 2100 , the model predicts a decrease of the MOC down to $13-15 \mathrm{~Sv}$ for the total anthropogenic impact. Our modeled slowdown of the MOC corresponds well with results obtained in IPCC (2007).

Figure 20f shows the transport impact on the MOC. The $\mathrm{CO}_{2}$ road emissions lead to a decrease of $0.8 \mathrm{~Sv}$ in 2100 , corresponding roughly to $10 \%$ of the total anthropogenic impact. The non- $\mathrm{CO}_{2}$ impact from shipping is positive, while all the other impacts are rather small.

\subsection{Sea-ice}

Figure 21a-d shows the impact on the sea-ice extent in the Arctic (in $10^{12} \mathrm{~m}^{2}$ ) at the end of the winter (March) and at the end of the summer (September) from total anthropogenic influence (left) and from the transport sectors (right). It indicates that the maximum extent of the sea-ice cover in March is not affected very much by the changing climate, with quite good agreement among the different simulations. In September, however, the sea-ice cover decays strongly in the second 
(a) Sea ice coverage $(\mathrm{NH})$

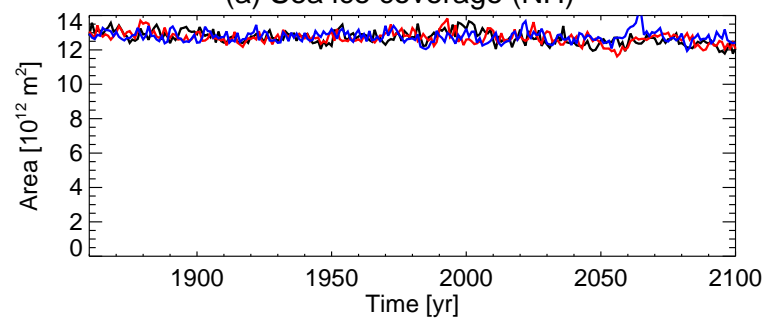

(c) Sea ice coverage $(\mathrm{NH})$

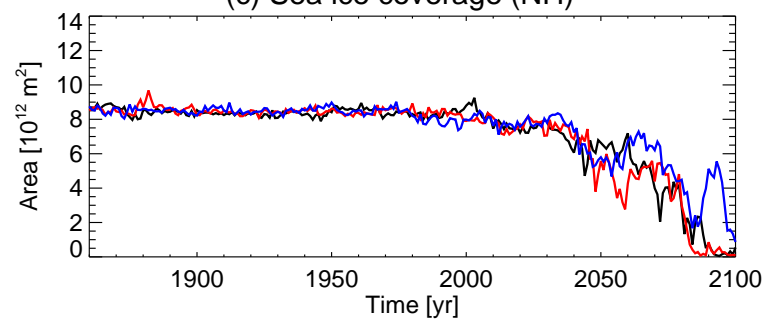

(e) Sea ice volume (NH)

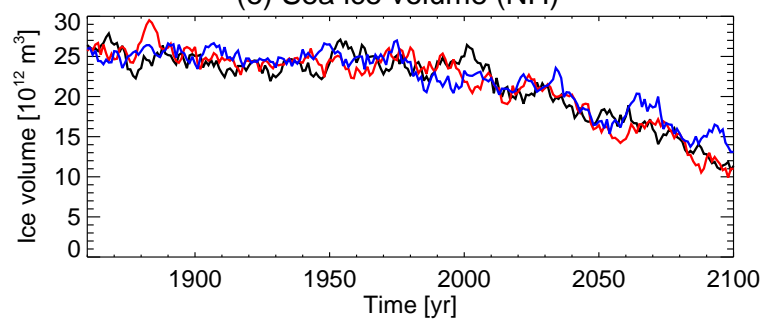

(g) Sea ice volume $(\mathrm{NH})$

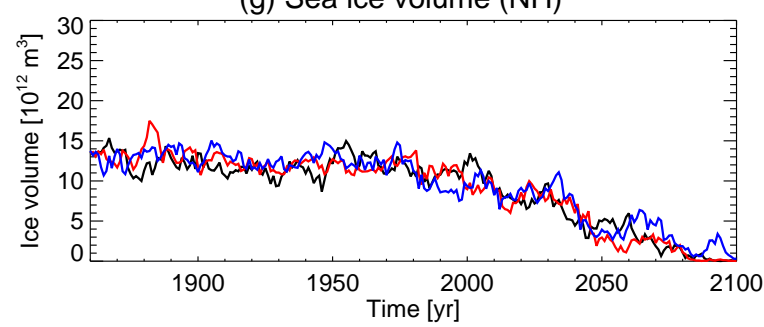

(b) Sea ice coverage $(\mathrm{NH})$

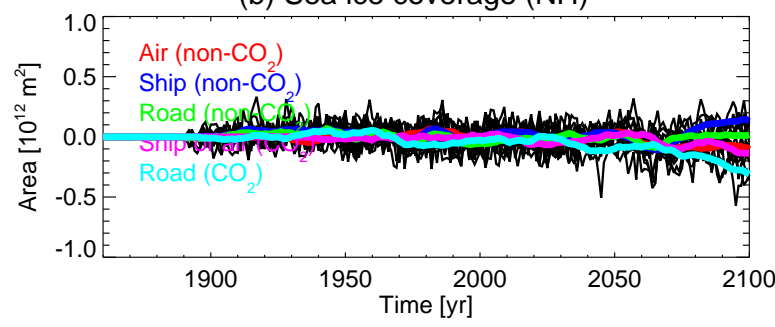

(d) Sea ice coverage $(\mathrm{NH})$

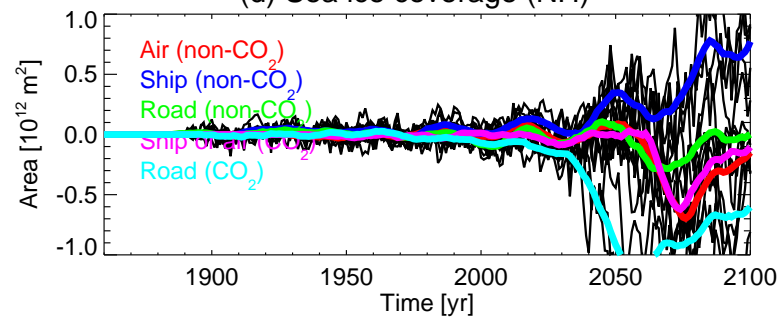

(f) Sea ice volume (NH)

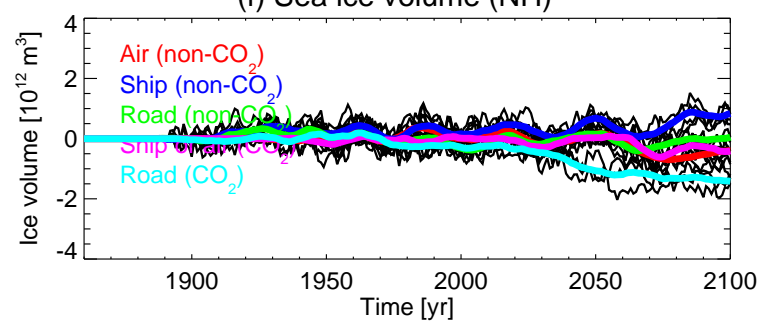

(h) Sea ice volume $(\mathrm{NH})$

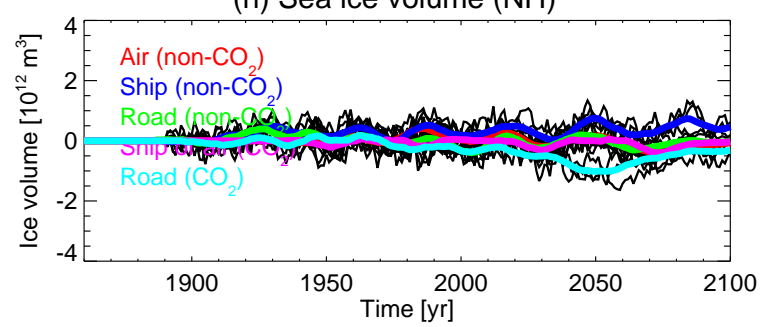

Fig. 21. Left: time series in the reference simulation of (a) NH sea-ice coverage (in $10^{12} \mathrm{~m}^{2}$ ) in March, (c) NH sea-ice coverage in September, (e) $\mathrm{NH}$ sea-ice volume (in $10^{12} \mathrm{~m}^{3}$ ) in March and (g) NH sea-ice volume in September. Right: the impact by road transport, shipping and aviation, separately for their $\mathrm{CO}_{2}$ and non- $\mathrm{CO}_{2}$ impact on (b) $\mathrm{NH}$ sea-ice coverage in March, (d) $\mathrm{NH}$ sea-ice coverage in September, (f) $\mathrm{NH}$ sea-ice volume in March and (h) NH sea-ice volume in September.

half of the 21st century, showing large variability within and among the different simulations. Importantly, two of the simulations have no sea-ice in 2100 in the Arctic in September. The large variability in the Arctic sea-ice cover corresponds with a large variability in the local surface air temperature.

From all transport sectors, we see small impacts in March and large impacts in September. In addition, the $\mathrm{CO}_{2} \mathrm{im}$ pact in September from road transport is very different before 2050 compared with after. This is due to the fact that in the perturbed simulation there is no sea-ice in March from 2050 onwards, and the sensitivity is therefore reduced. The actual impact is therefore expected to be larger than indicated. Similar sudden changes can be seen around 2070 for the $\mathrm{CO}_{2}$ impact from shipping and aviation, and for the non- $\mathrm{CO}_{2} \mathrm{im}-$ pact from aviation. Figure 21e-h shows the evolution of the sea-ice volume (in $10^{12} \mathrm{~m}^{3}$ ) in the Arctic. Due to the total anthropogenic impact, the sea-ice volume decreases considerably in March in the 21st century, which was not the case for the sea-ice extent. Further, all transport sectors show the same reduced sensitivities in September at the end of the 21st century.

\subsection{El Niño}

In Fig. 22a we show the anomaly in the Niño 3.4 index (5month running average sea surface air temperature over the 
(a) Nino3.4 index

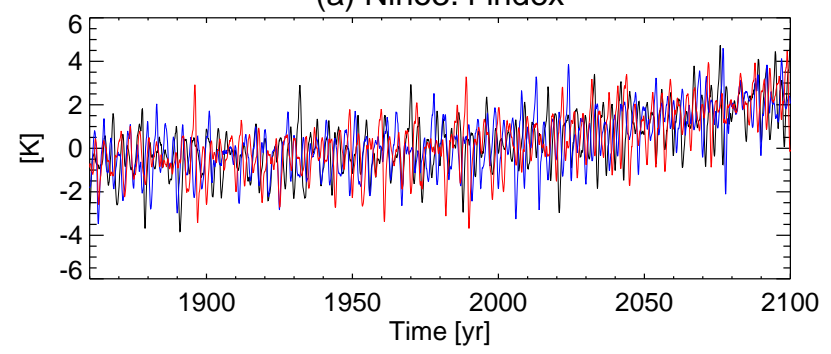

(b) Nino3.4 index change

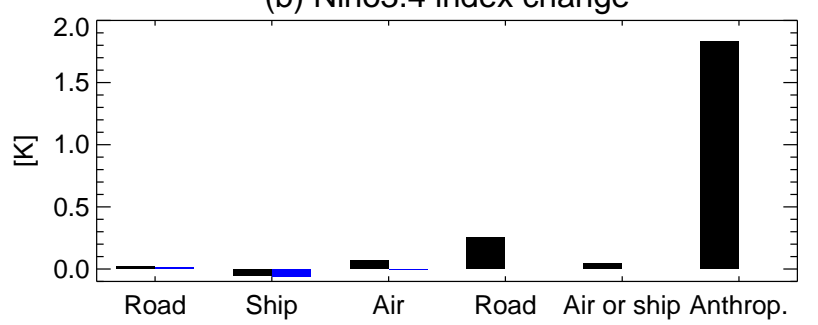

Fig. 22. (a) Evolution of the Niño 3.4 index anomaly over the 1860-2100 period for the 3 simulations forced by the total anthropogenic forcing (reference value calculated as the ensemble mean over 1971-2000). (b) Mean impact on the Niño 3.4 index of the different transport sectors over 2050-2099: the first three bars indicate the non- $\mathrm{CO}_{2}$ impact (black for the dynamic $\mathrm{O}_{3}$ approach, blue for the fixed $\mathrm{O}_{3}$ approach), the following two bars the $\mathrm{CO}_{2}$ impact, and the last bar the total anthropogenic impact.

domain $5^{\circ} \mathrm{S}-5^{\circ} \mathrm{N}, 120-170^{\circ} \mathrm{W}$, Trenberth, 1997) for the reference simulations with the total anthropogenic impact. The reference period is 1971-2000. One sees that the anomaly in Niño 3.4 index increases in the 21st century. Figure 22b shows the impacts from transport on the Niño 3.4 index over the 2050-2099 period, and for reference the total anthropogenic impact is also indicated. The strongest impact is that from $\mathrm{CO}_{2}$ from road transport, which contributes to around $15 \%$ of the total. The non- $\mathrm{CO}_{2}$ impact from shipping is negative, whilst for aviation, the non- $\mathrm{CO}_{2} *$ approach gives a considerably smaller impact than the non- $\mathrm{CO}_{2}$ approach.

\section{Conclusions}

For the period 1860-2100 (SRES scenario A1B for 20002100), we have studied the impact of road transport, maritime shipping and aviation on climate with the atmosphere ocean general circulation model CNRM-CM3.3. This is one of the first studies with an AOGCM where the main forcings of the transport sectors are explicitly taken into account. We performed a reference simulation which represents the total anthropogenic impact and several sensitivity simulations to estimate the impact of the transport sectors. We separately estimated the impact from $\mathrm{CO}_{2}$ and from non- $\mathrm{CO}_{2}$ forcings. As non- $\mathrm{CO}_{2}$ forcings, we included the impact of $\mathrm{O}_{3}, \mathrm{CH}_{4}$, aerosols, contrails, CFC-12 and HFC-134a. Most of the emission inventories we used were the ones generated within the QUANTIFY project (http://www.ip-quantify.eu).

As a principal indicator of climate change we have looked at global mean impacts. In the reference simulation, we found an increase in annual global mean surface air temperature of around $0.8 \mathrm{~K}$ in 2000 , reaching $3.0 \mathrm{~K}$ in 2100 . In 2000 , the $\mathrm{CO}_{2}$ impact from all transport sectors together is of the order of $0.1 \mathrm{~K}$. The emission of $\mathrm{CO}_{2}$ from road transport contributes to a global mean warming of $0.3 \mathrm{~K}$ in 2100 , while shipping and aviation each contribute to $0.1 \mathrm{~K}$ in 2100 . The contribution of $\mathrm{CO}_{2}$ from the transport sectors to the total anthropogenic temperature change increases from $12.5 \%$ in 2000 to $16.7 \%$ in 2100 .

The non- $\mathrm{CO}_{2}$ impact differs strongly among the different sectors. For road, this impact is largest between 2000 and 2050 (order of $0.1 \mathrm{~K}$ ) becoming smaller at the end of the $21 \mathrm{st}$ century. The non- $\mathrm{CO}_{2}$ impact from shipping is clearly negative reaching $-0.1 \mathrm{~K}$ between 2050 and 2100 , while from aviation it is positive but depends strongly on the treatment of the $\mathrm{O}_{3}$ perturbations, reaching possibly $0.15 \mathrm{~K}$ in 2100 . This indicates that during the period 1900-2100, the net impact of road transport on climate is positive and dominated by its $\mathrm{CO}_{2}$ impact, the net impact of maritime shipping is mainly negative only becoming neutral at the end of the $21 \mathrm{st}$ century, while for aviation it is clearly positive and presumably dominated by its non- $\mathrm{CO}_{2}$ emissions, even in 2100 .

The use of an AOGCM also allows us to obtain geographical distributions of impacts. We observe an amplification of the surface air temperature signal at the poles, especially in the Arctic, both in the reference simulation, as well as in the sensitivity simulations. However, while for road and shipping the non- $\mathrm{CO}_{2}$ impact on the surface air temperature is only slightly stronger in northern than in southern midlatitudes, the impact for aviation can be up to a factor of 5 stronger in the northern hemisphere. The geographical pattern of the non- $\mathrm{CO}_{2}$ climate impact for road transport and shipping coincides well with the total anthropogenic impact, while for aviation it is different. We also found a strong impact from the aviation non- $\mathrm{CO}_{2}$ forcing on the NAO index.

Focussing on the ocean, we see that for the total anthropogenic impact and most of the transport impacts, the strongest deep ocean heating is observed in the southern midlatitudes, while for aviation there is a significant response in the northern mid-latitudes. Further we find a rise in sea level due to thermal expansion in 2100 of $17.6 \mathrm{~mm}$ for road transport and $4.6 \mathrm{~mm}$ for maritime shipping and aviation. The rise due to non- $\mathrm{CO}_{2}$ emissions in 2100 is of the order of $1 \mathrm{~mm}$ for road transport, $-6.6 \mathrm{~mm}$ for maritime shipping and probably between -1.2 and $4.3 \mathrm{~mm}$ for aviation. This can be compared with a total anthropogenic impact in 2100 of around $180 \mathrm{~mm}$. An overview of our principal results on surface air temperature and sea level rise can be found in Table 5 .

In order to obtain detectable impacts, we used ensembles of 3 members together with a five-fold amplification of the 
Table 5. Global mean surface air temperature change and sea level rise for selected years. The values are 11-yr means around the year mentioned, and averaged over the different members of the ensemble. The non- $\mathrm{CO}_{2} *$ forcing is as the non- $\mathrm{CO}_{2}$ forcing except for $\mathrm{O}_{3}$ where prescribed $\mathrm{O}_{3}$ perturbation fields are used (see Sects. 2.2.4 and 3.1).

\begin{tabular}{|c|c|c|c|c|c|c|c|c|c|}
\hline & & \multicolumn{7}{|c|}{ Temperature $[\mathrm{K}]$} & \multirow[b]{2}{*}{ Uncertainty } \\
\hline & & 1950 & 1975 & 2000 & 2025 & 2050 & 2075 & 2100 & \\
\hline & Total anthropogenic & 0.260 & 0.420 & 0.837 & 1.113 & 1.777 & 2.347 & 2.830 & \pm 0.060 \\
\hline \multirow[t]{2}{*}{$\mathrm{CO}_{2}$} & Road transport & 0.001 & 0.033 & 0.037 & 0.098 & 0.177 & 0.259 & 0.308 & \pm 0.012 \\
\hline & Shipping or aviation & -0.002 & -0.003 & 0.007 & 0.029 & 0.013 & 0.084 & 0.094 & \pm 0.012 \\
\hline \multirow[t]{3}{*}{ non- $\mathrm{CO}_{2}$} & Road transport & 0.001 & 0.007 & 0.012 & 0.033 & 0.020 & 0.008 & 0.003 & \pm 0.012 \\
\hline & Shipping & -0.024 & -0.036 & -0.053 & -0.035 & -0.053 & -0.060 & -0.076 & \pm 0.012 \\
\hline & Aviation & 0.000 & 0.002 & 0.006 & 0.039 & 0.053 & 0.132 & 0.144 & \pm 0.012 \\
\hline \multirow[t]{6}{*}{ non- $\mathrm{CO}_{2} *$} & Road transport & 0.008 & 0.009 & 0.006 & 0.034 & 0.034 & 0.015 & 0.005 & \pm 0.012 \\
\hline & Shipping & -0.026 & -0.041 & -0.045 & -0.044 & -0.048 & -0.066 & -0.075 & \pm 0.012 \\
\hline & Aviation & -0.011 & -0.002 & 0.003 & 0.007 & -0.004 & 0.020 & 0.021 & \pm 0.012 \\
\hline & & \multicolumn{7}{|c|}{ Sea level rise $[\mathrm{mm}]$} & \\
\hline & & 1950 & 1975 & 2000 & 2025 & 2050 & 2075 & 2100 & Uncertainty \\
\hline & Total anthropogenic & 9.3 & 14.5 & 30.8 & 49.3 & 85.3 & 134.2 & 179.1 & \pm 0.8 \\
\hline \multirow[t]{2}{*}{$\mathrm{CO}_{2}$} & Road transport & 0.0 & 1.0 & 1.6 & 3.9 & 7.6 & 12.8 & 17.6 & \pm 0.2 \\
\hline & Shipping or aviation & -0.1 & -0.2 & 0.1 & 0.7 & 1.0 & 3.2 & 4.6 & \pm 0.2 \\
\hline \multirow[t]{3}{*}{ non- $\mathrm{CO}_{2}$} & Road transport & 0.1 & -0.3 & -0.3 & 0.6 & 0.6 & 0.4 & 0.6 & \pm 0.2 \\
\hline & Shipping & -1.0 & -2.3 & -3.1 & -3.6 & -4.8 & -6.0 & -6.6 & \pm 0.2 \\
\hline & Aviation & -0.1 & -0.1 & -0.2 & -0.1 & 0.6 & 2.2 & 4.3 & \pm 0.2 \\
\hline \multirow[t]{3}{*}{ non- $\mathrm{CO}_{2} *$} & Road transport & -0.1 & -0.5 & -0.4 & 0.8 & 0.6 & 0.5 & 1.0 & \pm 0.2 \\
\hline & Shipping & -1.1 & -1.7 & -2.6 & -3.3 & -4.6 & -6.3 & -6.6 & \pm 0.2 \\
\hline & Aviation & -0.1 & -0.3 & -0.5 & -0.7 & -0.8 & -1.1 & -1.2 & \pm 0.2 \\
\hline
\end{tabular}

transport induced forcings. If the forcings had not been amplified, a larger and computationally more expensive ensemble would have been required. We found that the amplification of the forcing did not excessively disturb variables such as the surface air temperature. However, for quantities like sea-ice extent or sea-ice volume in the NH in September (a period when the sea-ice is very sensitive to variations in a non-linear way), the method has shown some limitations.

Further, we also observed shortcomings in the model. The impact from $\mathrm{BC}$ has probably been underestimated, which affects the results for road transport but has very little effect for the other two sectors. We also observed a significant negative temperature response from aviation at high latitudes, probably caused by sulfate aerosols. It is unclear whether this impact is very realistic. We found values for the $\mathrm{O}_{3}$ radiative forcing which were considerably smaller than those found in other studies for similar perturbations. Although the $\mathrm{O}_{3}$ impact in the lower troposphere was well described using the extended linear ozone scheme, there were important differences in the upper troposphere and lower stratosphere for the impact from aviation.

The results presented here are obtained using only one AOGCM, and therefore the results should be interpreted with care. Impacts on modeled temperature are closely related to the climate sensitivity of the model, and the climate sensitivity is known to vary significantly among models (IPCC, 2007, Table S8.1). However, relative impacts of the transport sectors w.r.t. the total anthropogenic climate impact are probably rather robust. The emissions that are the basis for this study are based on the SRES scenario A1B storyline for GDP development. This scenario is only one out of more GDP scenarios (Nakicenovic et al., 2000). Moreover alternative assumptions for the implementation of fuel efficiency and emission factors for the same A1B storyline have been suggested (Lee et al., 2009; Eyring et al., 2005).

The modeling of impacts from transport would benefit from the description of ice supersaturation in the model, and the possibility to advect tracers which might be beneficial for the contrail parametrization, the extended $\mathrm{O}_{3}$ parametrization, or for the inclusion of small scale chemistry effects (Cariolle et al., 2009). In addition, a more extensive chemistry, an explicit description of aerosol processes, and an integrated carbon cycle would further increase the model's capability to describe impacts from transport. This would allow a more coherent modeling and limit the dependency on results from other models. 
Although 2100 was the time horizon for our simulations based on the SRES scenario A1B, climate change is clearly not stabilized at that time: one can still see strong trends in the $\mathrm{CO}_{2}$ forcings and in the response of the surface air temperature and ocean temperature. It is clear that in 2100 the $\mathrm{CO}_{2}$ impacts (total anthropogenic impact and individual transport sectors) are still increasing considerably, suggesting further important changes in the 22 nd century.

Acknowledgements. This work was supported by the European Union FP6 Integrated Project QUANTIFY (http://www.ip-quantify.eu/) under contract no. 003893 (GOCE). We would like to thank Marianne Lund for providing $\mathrm{CO}_{2}$ mixing ratio time series, Gaby Rädel for providing time series for CFC-12 and HFC-134a emission estimates, Pascal Laveau for his work on the extended linear $\mathrm{O}_{3}$ scheme, and Keith Shine for useful discussions and his comments on the manuscript. We gratefully acknowledge the work of Activity 1 in the QUANTIFY project for creating emission estimates for the transport sector.

Edited by: M. Schulz

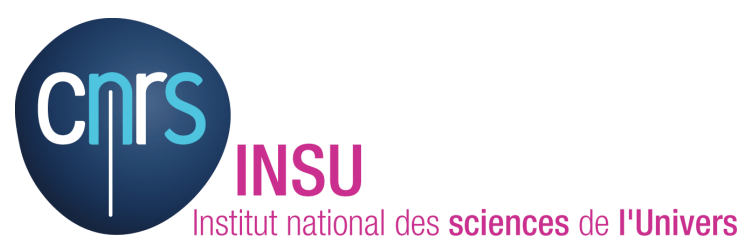

The publication of this article is financed by CNRS-INSU.

\section{References}

Bakan, S., Betancor, M., Gayler, V., and Gral, H.: Contrail frequency over Europe from NOAA-satellite images, Ann. Geophys., 12, 962-968, doi:10.1007/s00585-994-0962-y, 1994.

Balkanski, Y., Myhre, G., Gauss, M., Rädel, G., Highwood, E. J., and Shine, K. P.: Direct radiative effect of aerosols emitted by transport: from road, shipping and aviation, Atmos. Chem. Phys., 10, 4477-4489, doi:10.5194/acp-10-4477-2010, 2010.

Berntsen, T. and Fuglestvedt, J.: Global temperature responses to current emissions from the transport sectors, P. Natl. Acad. Sci. USA, 105, 19154-19159, 2008.

Borken, J., Steller, H., Merétei, T., and Vanhove, F.: Global and country inventory of road passenger and freight transportation: fuel consumption and emissions of air pollutants in year 2000, Journal of the Transportation Research Board, 2011, 127-136, doi:10.3141/2011-14, 2007.

Boucher, O. and Lohmann, U.: The sulfate-CNN-cloud albedo effect: a sensitivity study with two general circulation models, Tellus, 47B, 281-300, 1995.

Boucher, O. and Reddy, M. S.: Climate trade-off between black carbon and carbon dioxide emissions, Energ. Policy, 36, 193200, doi:10.1016/j.enpol.2007.08.039, 2008.

Boucher, O. and Rodhe, H.: The sulfate-CNN-cloud alebedo effect: a sensitivity study, Tech. Rep. 83, Department of Meteorology, Stockholm University, Sweden, 1994.
Bougeault, P.: A simple parameterization of the large-scale effects of cumulus, Mon. Weather Rev., 113, 2108-2121, 1985.

Brasseur, G. P., Müller, J.-F., and Granier, C.: Atmospheric impact of NOx emissions by subsonic aircraft: A three-dimensional model study, J. Geophys. Res., 101, 1423-1428, 1996.

Brasseur, G. P., Cox, R. A., Hauglustaine, D., Isaksen, I., Lelieveld, J., Lister, D. H., Sausen, R., Schumann, U., Wahner, A., and Wiesen, P.: European scientific assessment of the atmospheric effects of aircraft emissions, Atmos. Environ., 32, 2329-2418, 1998.

Brasseur, G. P., Schultz, M., Granier, C., Saunois, M., Diehl, T., Botzet, M., Roeckner, E., and Walters, S.: Impact of climate change on the future chemical composition of the global troposphere, J. Climate, 19, 3932-3951, 2006.

Brohan, P., Kennedy, J. J., Haris, I., Tett, S. F. B., and Jones, P. D.: Uncertainty estimates in regional and global observed temperature changes: a new dataset from 1850, J. Geophys. Res., 111, D12106, doi:10.1029/2005JD006548, 2006.

Burkhardt, U. and Kärcher, B.: Process-based simulation of contrail cirrus in a global climate model, J. Geophys. Res., 114, D16201, doi:10.1029/2008JD011491, 2009.

Burkhardt, U. and Kärcher, B.: Global radiative forcing from contrail cirrus, Nature Climate Change, 1, 54-58, doi:10.1038/NCLIMATE1086, 2011.

Cariolle, D. and Déqué, M.: Southern hemisphere medium-scale waves and total ozone disturbances in a spectral general circulation model, J. Geophys. Res., 91, 10825-10846, 1986.

Cariolle, D. and Teyssèdre, H.: A revised linear ozone photochemistry parameterization for use in transport and general circulation models: multi-annual simulations, Atmos. Chem. Phys., 7, 2183-2196, doi:10.5194/acp-7-2183-2007, 2007.

Cariolle, D., Lasserre-Bigory, A., and Royer, J. F.: A general circulation model simulation of the springtime Antarctic ozone decrease and its impact on mid-latitudes, J. Geophys. Res., 95, 1883-1898, 1990.

Cariolle, D., Caro, D., Paoli, R., Hauglustaine, D. A., Cuénot, B., Cozic, A., and Paugam, R.: Parameterization of plume chemistry into large-scale atmospheric models: Application to aircraft $\mathrm{NO}_{\mathrm{x}}$ emissions, J. Geophys. Res., 114, D19302, doi:10.1029/2009JD011873, 2009.

Champeaux, J. L., Masson, V., and Chauvin, F.: ECOCLIMAP: a global database of land surface parameters at $1 \mathrm{~km}$ resolution, Meteorol. Appl., 12, 29-32, doi:10.1017/S1350482705001519, 2005.

Clodic, D., Baker, J., Chen, J., Hirata, T., Hwang, R., Köhler, J., Petitjean, C., and Suwono, A.: IPCC/TEAP Special Report. Safeguarding the ozone layer and the global climate system: issues related to hydrofluorocarbons and perfluorocarbons, Cambridge University Press, Cambridge, United Kingdom and New York, NY, USA, 478 pp., 2005.

Collins, W. J., Sitch, S., and Boucher, O.: How vegetation impacts affect climate metrics for ozone precursors, J. Geophys. Res., 115, D23308, doi:10.1029/2010JD014187, 2010.

Dahlmann, K., Grewe, V., Ponater, M., and Matthes, S.: Quantifying the contributions of individual $\mathrm{NO}_{\mathrm{x}}$ sources to the trend in ozone radiative forcing, Atmos. Environ., 45, 2860-2868, doi:10.1016/j.atmosenv.2011.02.071, 2011.

Eide, M. S., Endresen, Ø., Mjelde, A., Mangset, L. E., and Gravir, G.: Ship emissions of the future, Tech. Rep. 2007-1325, Det 
Norske Veritas, Høvik, Norway, 2007.

Endresen, O., Sorgard, E., Sundet, J. K., Dalsoren, S., Isaksen, I. S. A., Berglen, T., and Gravir, G.: Emission from international sea transportation and environmental impact, J. Geophys. Res., 108, 4560, doi:10.1029/2002JD002898, 2003.

Eyring, V., Köhler, H. W., Lauer, A., and Lemper, B.: Emissions from international shipping: 2. Impact of future technologies on scenarios until 2050, J. Geophys. Res., 110, D17306, doi:10.1029/2004JD005620, 2005.

Eyring, V., Stevenson, D. S., Lauer, A., Dentener, F. J., Butler, T., Collins, W. J., Ellingsen, K., Gauss, M., Hauglustaine, D. A., Isaksen, I. S. A., Lawrence, M. G., Richter, A., Rodriguez, J. M., Sanderson, M., Strahan, S. E., Sudo, K., Szopa, S., van Noije, T. P. C., and Wild, O.: Multi-model simulations of the impact of international shipping on Atmospheric Chemistry and Climate in 2000 and 2030, Atmos. Chem. Phys., 7, 757-780, doi:10.5194/acp-7-757-2007, 2007.

Eyring, V., Isaksen, I. S. A., Berntsen, T., Collins, W. J., Corbett, J. J., Endresen, O., Grainger, R. G., Moldanova, J., Schlager, H., and Stevenson, D. S.: Transport impacts on atmosphere and climate: Shipping, Atmos. Environ., 44, 4735-4771, doi:10.1016/j.atmosenv.2009.04.059, 2010.

Fuglestvedt, J., Berntsen, T., Isaksen, I., Mao, H., Liang, X.-Z., and Wang, W.-C.: Climatic forcing of nitrogen oxides through changes in tropospheric ozone and methane; global 3D model studies, Atmos. Environ., 33, 961-977, 1999.

Fuglestvedt, J., Berntsen, T., Myhre, G., Rypdal, K., and Skeie, R. B.: Climate forcing from the transport sectors, P. Natl. Acad. Sci. USA, 105, 454-458, 2008.

Fuglestvedt, J. S., Shine, K. P., Berntsen, T., Cook, J., Lee, D. S., Stenke, A., Skeie, R. B., Velders, G. J. M., and Waitz, I. A.: Transport impacts on atmosphere and climate: Metrics, Atmos. Environ., 44, 4648-4677, doi:10.1016/j.atmosenv.2009.04.044, 2010.

Gauss, M., Isaksen, I. S. A., Lee, D. S., and Søvde, O. A.: Impact of aircraft $\mathrm{NO}_{\mathrm{x}}$ emissions on the atmosphere - tradeoffs to reduce the impact, Atmos. Chem. Phys., 6, 1529-1548, doi:10.5194/acp-6-1529-2006, 2006.

Granier, C. and Brasseur, G. P.: The impact of road traffic on global tropospheric ozone, Geophys. Res. Lett., 30, 1086, doi:10.1029/2002GL015972, 2003.

Granier, C., Niemeier, U., Jungclaus, J. H., Emmons, L., Hess, P., Lamarque, J.-F., Walters, S., and Brasseur, G. P.: Ozone pollution from future ship traffic in the Arctic northern passages, Geophys. Res. Lett., 33, L13807, doi:10.1029/2006GL026180, 2006.

Gregory, J. M., Ingram, W. J., Palmer, M. A., Jones, G. S., Stott, P. A., Thorpe, R. B., Lowe, J. A., Johns, T. C., and Williams, K. D.: A new method for diagnosing radiative forcing and climate sensitivity, Geophys. Res. Lett., 31, L03205, doi:10.1029/2003GL018747, 2004.

Guémas, V. and Salas-Mélia, D.: Simulation of the Atlantic meridional overturning circulation in an atmosphere-ocean global coupled model. Part I: a mechanism governing the variability of ocean convection in a preindustrial experiment, Clim. Dynam., 31, 29-48, doi:10.1007/s00382-007-0336-8, 2008.

Harvey, D., Gregory, J., Hoffert, M., Jain, A., Lal, M., Leemans, R., Raper, S., Wigley, T., and de Wolde, J.: An introduction to simple climate models used in the IPCC second assessment report, 1997.
Hasselmann, K., Sausen, R., Maier-Reimer, E., and Voss, R.: On the cold start problem in transient simulations with coupled atmosphere-ocean models, Clim. Dynam., 9, 53-61, 1993.

Hedegaard, G. B., Brandt, J., Christensen, J. H., Frohn, L. M., Geels, C., Hansen, K. M., and Stendel, M.: Impacts of climate change on air pollution levels in the Northern Hemisphere with special focus on Europe and the Arctic, Atmos. Chem. Phys., 8, 3337-3367, doi:10.5194/acp-8-3337-2008, 2008.

Hodnebrog, Ø., Berntsen, T. K., Dessens, O., Gauss, M., Grewe, V., Isaksen, I. S. A., Koffi, B., Myhre, G., Olivié, D., Prather, M. J., Pyle, J. A., Stordal, F., Szopa, S., Tang, Q., van Velthoven, P., Williams, J. E., and Ødemark, K.: Future impact of non-land based traffic emissions on atmospheric ozone and $\mathrm{OH}-$ an optimistic scenario and a possible mitigation strategy, Atmos. Chem. Phys., 11, 11293-11317, doi:10.5194/acp-11-11293-2011, 2011.

Hoor, P., Borken-Kleefeld, J., Caro, D., Dessens, O., Endresen, O., Gauss, M., Grewe, V., Hauglustaine, D., Isaksen, I. S. A., Jöckel, P., Lelieveld, J., Myhre, G., Meijer, E., Olivie, D., Prather, M., Schnadt Poberaj, C., Shine, K. P., Staehelin, J., Tang, Q., van Aardenne, J., van Velthoven, P., and Sausen, R.: The impact of traffic emissions on atmospheric ozone and $\mathrm{OH}$ : results from QUANTIFY, Atmos. Chem. Phys., 9, 3113-3136, doi:10.5194/acp-9-3113-2009, 2009.

IPCC: Climate change 1995: the science of climate change. Contribution of working group I to the second assessment report of the intergovernmental panel on climate change, Cambridge University Press, Cambridge, United Kingdom and New York, NY, USA, 572 pp., 1996.

IPCC: Climate change 2001: the scientific basis. Contribution of working group I to the third assessment report of the intergovernmental panel on climate change, Cambridge University Press, Cambridge, United Kingdom and New York, NY, USA, 881 pp., 2001.

IPCC: Climate change 2007: the physical science basis. Contribution of working group I to the fourth assessment report of the intergovernmental panel on climate change, Cambridge University Press, Cambridge, United Kingdom and New York, NY, USA, 996 pp., 2007.

Jiang, K., Masui, T., Morita, T., and Matsuoka, Y.: Long-term GHG emission scenarios for Asia-Pacific and the world, Technol. Forecast. Soc., 63, 207-229, doi:10.1016/S0040-1625(99)00110-9, 2000.

Johns, T. C., Royer, J.-F., Höschel, I., Huebener, H., Roeckner, E., Manzini, E., May, W., Dufresne, J.-L., Otterå, O. H., van Vuuren, D. P., Salas y Melia, D., Giorgetta, M. A., Denvil, S., Yang, S., Fogli, P. G., Körper, J., Tjiputra, J. F., Stehfest, E., and Hewitt, C. D.: Climate change under aggressive mitigation: The ENSEMBLES multi-model experiment, Clim. Dynam., 37, 1975-2003, doi:10.1007/s00382-011-1005-5, 2011.

Joshi, M., Shine, K., Ponater, M., Stuber, N., Sausen, R., and Li, L.: A comparison of climate response to different radiative forcings in three general circulation models: towards an improved metric of climate change, Clim. Dynam., 20, 843-854, 2003.

Kärcher, B., Burkhardt, U., Ponater, M., and Frömming, C.: Importance of representing optical depth variability for estimates of global line-shaped contrail radiative forcing, P. Natl. Acad. Sci. USA, 107, 19181-19184, 2010.

Kentarchos, A. S. and Roelofs, G. J.: Impact of aircraft $\mathrm{NO}_{\mathrm{x}}$ emissions on tropospheric ozone calculated with a chemistry-general 
circulation model: Sensitivity to higher hydrocarbon chemistry, J. Geophys. Res., 107, 4175, doi:10.1029/2001JD000828, 2002.

Koffi, B., Szopa, S., Cozic, A., Hauglustaine, D., and van Velthoven, P.: Present and future impact of aircraft, road traffic and shipping emissions on global tropospheric ozone, Atmos. Chem. Phys., 10, 11681-11705, doi:10.5194/acp-1011681-2010, 2010.

Lee, D. S., Fahey, D. W., Forster, P. M., Newton, P. J., Wit, R. C. N., Lim, L. L., Owen, B., and Sausen, R.: Aviation and global climate change in the 21st century, Atmos. Environ., 43, 3520$3537,2009$.

Lee, D. S., Pitari, G., Grewe, V., Gierens, K., Penner, J. E., Petzold, A., Prather, M. J., Schumann, U., Bais, A., Berntsen, T., Iachetti, D., Lim, L., and Sausen, R.: Transport impacts on atmosphere and climate: Aviation, Atmos. Environ., 44, 4678-4734, doi:10.1016/j.atmosenv.2009.06.005, 2010.

Lim, L., Lee, D. S., Sausen, R., and Ponater, M.: Quantifying the effects of aviation on radiative forcing and temperature with a climate response model, in: Proceedings of an international conference on transport, atmosphere and climate (TAC), edited by: Sausen, R., Blum, A., Lee, D. S., and Brüning, C., 202-207, http://www.pa.op.dlr.de/tac/proceedings.html, 2007.

Liu, X., Penner, J. E., and Wang, M.: Influence of anthropogenic sulfate and black carbon on upper tropospheric clouds in the NCAR CAM3 model coupled to the IMPACT global aerosol model, J. Geophys. Res., 113, D03204, doi:10.1029/2008JD010492, 2009.

Mannstein, H., Meyer, R., and Wendling, P.: Operational detection of contrails from NOAA-AVHRR-data, Int. J. Remote Sen., 20, 1641-1660, 1998.

Marquart, S., Ponater, M., Mager, F., and Sausen, R.: Future development of contrail cover, optical depth, and radiative forcing: impacts of increasing air traffic and climate change, J. Climate, 16, 2890-2904, 2003.

Matthes, S., Grewe, V., Sausen, R., and Roelofs, G.-J.: Global impact of road traffic emissions on tropospheric ozone, Atmos. Chem. Phys., 7, 1707-1718, doi:10.5194/acp-7-1707-2007, 2007.

Meinshausen, M., Raper, S., and Wigley, T.: Emulating coupled atmosphere-ocean and carbon cycle models with a simpler model, MAGICC6 - Part 1: Model description and calibration, Atmos. Chem. Phys., 11, 1417-1456, doi:10.5194/acp-11-14172011, 2011a.

Meinshausen, M., Wigley, T., and Raper, S.: Emulating atmosphere-ocean and carbon cycle models with a simpler model, MAGICC6 - Part 2: Applications, Atmos. Chem. Phys., 11, 1457-1471, doi:10.5194/acp-11-1417-2011, $2011 \mathrm{~b}$.

Millero, F. J. and Poisson, A.: International one-atmosphere equation of state of seawater, Deep-Sea Res., 28A, 625-629, 1981.

Minnis, P., Ayers, J. K., Palikonda, R., and Phan, D.: Contrails, cirrus trends, and climate, J. Climate, 17, 1671-1685, 2004

Morcrette, J.-J.: Impact of changes to the radiation transfer parameterizations plus cloud optical properties in the ECMWF model, Mon. Weather Rev., 118, 847-873, 1990.

Morcrette, J.-J.: Radiation and cloud radiative properties in the European Centre for Medium Range Weather Forecasts forecasting system, J. Geophys. Res., 96, 9121-9132, doi:10.1029/89JD01597, 1991.

Myhre, G., Kvalevåg, M., Rädel, G., Cook, J., Shine, K. P., Clark,
H., Karcher, F., Markowicz, K., Kardas, A., Wolkenberg, P., Balkanski, Y., Ponater, M., Forster, P., Rap, A., and de Leon, R. R.: Intercomparison of radiative forcing calculations of stratospheric water vapour and contrails, Meteorol. Zeitschrift, 18, 585-596, 2009.

Myhre, G., Shine, K., Rädel, G., Gauss, M., Isaksen, I., Tang, Q., Prather, M., Williams, J., van Velthoven, P., Dessens, O., Koffi, B., Szopa, S., Hoor, P., Grewe, V., Borken-Kleefeld, J., Berntsen, T., and Fuglestvedt, J.: Radiative forcing due to changes in ozone and methane caused by the transport sector, Atmos. Environ., 45 , 387-394, doi:10.1016/j.atmosenv.2010.10.001, 2011.

Nakicenovic, N., Alcamo, J., Davis, G., de Vries, B., Fenhann, J., Gaffin, S., Gregory, K., Grübler, A., Jung, T. Y., Kram, T., Rovere, E. L. L., Michaelis, L., Mori, S., Morita, T., Pepper, W., Pitcher, H., Price, L., Riahi, K., Roehrl, A., Rogner, H.-H., Sankovski, A., Schlesinger, M., Shukla, P., Smith, S., Swart, R., van Rooijen, S., Victor, N., and Dadi, Z.: Emissions scenarios, Cambridge University Press, Cambridge, United Kingdom and New York, NY, USA, 2000.

Niemeier, U., Granier, C., Kornblueh, L., Walters, S., and Brasseur, G. P.: Global impact of road traffic on atmospheric chemical composition and on ozone climate forcing, J. Geophys. Res., 111, D09301, doi:10.1029/2005JD006407, 2006.

Oki, T. and Sud, Y. C.: Design of Total Runoff Integrating Pathways (TRIP) - A global river channel network, Earth Interact., 2, 1-36, 1998.

Oki, T., Wishimyra, T., and Dirmeyer, P.: Assessment of annual runoff from land surface models using Total Runoff Integrating Pathways (TRIP), J. Meteor. Soc. Japan, 77, 235-255, 1999.

Olivié, D. and Stuber, N.: Emulating AOGCM results using simple climate models, Clim. Dynam., 35, 1257-1287, doi:10.1007/s00382-009-0725-2, 2010.

Owen, B., Lee, D. S., and Lim, L.: Flying into the future: aviation emissions scenarios to 2050, Environ. Sci. Technol., 44, 22552260, doi:10.1126/science.1196285, 2010.

Paugam, R., Paoli, R., and Cariolle, D.: Influence of vortex dynamics and atmospheric turbulence on the early evolution of a contrail, Atmos. Chem. Phys., 10, 3933-3952, doi:10.5194/acp10-3933-2010, 2010

Penner, J. E., Lister, D. H., Griggs, D. J., Dokken, D. J., and McFarland, M. (Eds.): Aviation and the global atmosphere, Cambridge University Press, Cambridge, United Kingdom and New York, NY, USA, 1999.

Penner, J. E., Chen, Y., Wang, M., and Liu, X.: Possible influence of anthropogenic aerosols on cirrus clouds and anthropogenic forcing, Atmos. Chem. Phys., 9, 879-896, doi:10.5194/acp-9-8792009, 2009.

Ponater, M., Marquart, S., Sausen, R., and Schumann, U.: On contrail climate sensitivity, Geophys. Res. Lett., 32, L10706, doi:10.1029/2005GL022580, 2005.

Ponater, M., Pechtl, S., Sausen, R., Schumann, U., and Hüttig, G.: A state-of-the-art assessment of the potential of the cryoplane technology to reduce aircraft climate impact, Atmos. Environ., 40, 6928-6944, 2006.

Prather, M. J.: Lifetimes and eigenstates in atmospheric chemistry, Geophys. Res. Lett., 21, 801-804, 1994.

Quaas, J. and Boucher, O.: Constraining the first aerosol in direct radiative forcing in the LMDZ GCM using POLDER and MODIS satellite data, Geophys. Res. Lett., 32, L17814, 
doi:10.1029/2005GL023850, 2005.

Rädel, G. and Shine, K. P.: Radiative forcing by persistent contrails and its dependence on cruise altitudes, J. Geophys. Res., 113, D07105, doi:10.1029/2007JD009117, 2008.

Rap, A., Forster, P. M., Jones, A., Boucher, O., Bellouin, J. M. H. N., and Leon, R. R. D.: Parameterization of contrails in the UK Met Office Climate Model, J. Geophys. Res., 115, D10205, doi:10.1029/2009JD012443, 2010.

Ricard, J.-L. and Royer, J.-F.: A statistical cloud scheme for use in an AGCM, Ann. Geophysicae, 11, 1095-1115, 1993.

Salas-Mélia, D.: A global coupled sea ice-ocean model, Ocean Modelling, 4, 137-172, 2002.

Salas-Mélia, D., Chauvin, F., Déqué, M., Douville, H., Guérémy, J. F., Marquet, P., Planton, S., Royer, J., and Tyteca, S.: Description and validation of the CNRM-CM3 global coupled model, Tech. Rep. 103, CNRM, 2005.

Sausen, R. and Schumann, U.: Estimates of the climate response to aircraft $\mathrm{CO}_{2}$ and $\mathrm{NO}_{\mathrm{x}}$ emissions scenarios, Climate Change, 44, 27-58, 2000.

Sausen, R., Isaksen, I., Grewe, V., Hauglustaine, D., Lee, D. S., Myhre, G., Köhler, M. O., Pitari, G., Schumann, U., Stordal, F., and Zerefos, C.: Aviation radiative forcing in 2000: an update on IPCC (1999), Meteorol. Zeitschrift, 14, 555-561, 2005.

Schumann, U.: On conditions for contrail formation from aircraft exhausts, Meteorol. Zeitschrift, 5, 4-23, 1996.

Sitch, S., Cox, P. M., Collins, W. J., and Huntingford, C.: Indirect radiative forcing of climate change through ozone effects on the land-carbon sink, Nature, 448, 791-794, doi:10.1038/nature06059, 2007.

Skeie, R. B., Fuglestvedt, J., Berntsen, T., Lund, M. T., Myhre, G., and Rypdal, K.: Global temperature change from the transport sectors: Historical development and future scenarios, Atmos. Environ., 43, 6260-6270, 2009.

Stevenson, D. S., Doherty, R. M., Sanderson, M. G., Collins, W. J., Johnson, C. E., and Derwent, R. G.: Radiative forcing from aircraft $\mathrm{NO}_{\mathrm{x}}$ emissions: Mechanisms and seasonal dependence, J. Geophys. Res., 109, D17307, doi:10.1029/2004JD004759, 2004.
Stordal, F., Myhre, G., Stordal, E. J. G., Rossow, W. B., Lee, D. S., Arlander, D. W., and Svendby, T.: Is there a trend in cirrus cloud cover due to aircraft traffic?, Atmos. Chem. Phys., 5, 2155-2162, doi:10.5194/acp-5-2155-2005, 2005.

Stuber, N., Sausen, R., and Ponater, M.: Stratosphere adjusted radiative forcing calculations in a comprehensive climate model, Theor. Appl. Climatol., 68, 125-135, 2001.

Stuber, N., Ponater, M., and Sausen, R.: Why radiative forcing might fail as a predictor of climate change, Clim. Dynam., 24, 497-510, 2005.

Teyssèdre, H., Michou, M., Clark, H. L., Josse, B., Karcher, F., Olivié, D., Peuch, V.-H., Saint-Martin, D., Cariolle, D., Attié, J.-L., Nédélec, P., Ricaud, P., Thouret, V., van der A, R. J., VolzThomas, A., and Chéroux, F.: A new tropospheric and stratospheric Chemistry and Transport Model MOCAGE-Climat for multi-year studies: evaluation of the present-day climatology and sensitivity to surface processes, Atmos. Chem. Phys., 7, 58155860, doi:10.5194/acp-7-5815-2007, 2007.

Trenberth, K. E.: The definition of El Niño, B. Am. Meteorol. Soc., 78, 2771-2777, 1997.

Uherek, E., Halenka, T., Borken-Kleefeld, J., Balkanski, Y., Berntsen, T., Borrego, C., Gauss, M., Hoor, P., Juda-Rezler, K., Lelieveld, J., Melas, D., Rypdal, K., and Schmid, S.: Transport impacts on atmosphere and climate: land transport, Atmos. Environ., 44, 4772-4816, doi:10.1016/j.atmosenv.2010.01.002, 2010.

Watterson, I. G.: Non-dimensional measures of climate performance, Int. J. Climatol., 16, 379-391, 1996.

WMO: Scientific assessment of ozone depletion: 2010, no. 52 in Global ozone research and monitoring project report, Geneva, 2010.

Wu, S., Mickley, L. J., Jacob, D. J., Rind, D., and Streets, D. G.: Effects of 2000-2050 changes in climate and emissions on global tropospheric ozone and the policy-relevant background surface ozone in the United States, J. Geophys. Res., 113, D18312, doi:10.1029/2007JD009639, 2008. 